\title{
Fouilles à Vat Phu (province de Champassak,
} Sud-Laos)

Recherches archéologiques sur le site de Vat Sang'O 5 (2014-2020)

\section{Christine Hawixbrock}

\section{CpenEdition}

\section{Journals}

Édition électronique

URL : https://journals.openedition.org/baefe/4697

DOI : $10.4000 /$ baefe.4697

ISSN : 2732-687X

Éditeur

ResEFE

Référence électronique

Christine Hawixbrock, «Fouilles à Vat Phu (province de Champassak, Sud-Laos) » [notice archéologique], Bulletin archéologique des Écoles françaises à l'étranger [En ligne], Asie du Sud-Est continentale, mis en ligne le 02 mars 2022, consulté le 05 mars 2022. URL : http:// journals.openedition.org/baefe/4697 ; DOI : https://doi.org/10.4000/baefe.4697

Ce document a été généré automatiquement le 5 mars 2022.

\section{cc) $(1) \odot$}

Le Bulletin archéologique des Écoles françaises à l'étranger est mise à disposition selon les termes de la Licence Creative Commons Attribution - Pas d'Utilisation Commerciale - Pas de Modification 4.0 International. 


\section{Fouilles à Vat Phu (province de Champassak, Sud-Laos)}

Recherches archéologiques sur le site de Vat Sang'O 5 (2014-2020)

Christine Hawixbrock

\section{NOTE DE L'AUTEUR}

Les travaux présentés dans cette contribution ont bénéficié d'un appui financier de la Commission consultative des recherches archéologiques françaises à l'étranger du MEAE dans le cadre de deux quadriennaux de recherche (2015 - 2018 et 2019 - 2022). Ces travaux prennent place depuis 2020 au sein d'un projet plus global que l'École française d'Extrême-Orient conduit sur financements de l'Agence française de Développement (AFD) pour la mise en valeur du patrimoine du Sud-Laos (Projet CHAMPA, -2020-2024).

Le projet CHAMPA est axé sur la préservation, la mise en valeur du patrimoine et le développement de l'attractivité territoriale de Champassak et Savannakhet. Une partie du projet est opérée par l'EFEO, l'autre étant déléguée aux autorités provinciales de Champassak et Savannakhet, notamment le Bureau du Patrimoine Mondial de Vat PhuChampassak (WHSO) et le Département de l'Information, de la Culture et du Tourisme (DICT) de la province de Savannakhet.

Date précise de l'opération : 24 février-10 avril $2014 ; 1^{\mathrm{er}}$ mars-12 avril 2017 ;

6 février-18 avril $2018 ; 20$ juillet-2 août 2020

Autorité nationale présente : Viengkeo Souksavatdy, Direction des Patrimoines, ministère de l'Information, de la culture et du tourisme (MICT) de la République démocratique Lao.

Composition de l'équipe de terrain : Viengkèo Souksavatdy, MICT, Directeur général adjoint du Patrimoine, archéologue ; Souliya Bounxaythip, MICT, archéologue ; Jade Vanessa Thau, doctorante EPHE, archéologue ; Jean-Pierre Message, indépendant, dessinateur-restaurateur; Nopphalak Vongsouthi, SAGV, topographe; Chanphenh Pommavandy, SAGV, archéologue ; Thongbang Phengsawat, SAGV, archéologue. 
Partenariats institutionnels : Direction des Patrimoines, ministère de l'Information, de la culture et du tourisme (MICT) de la République démocratique Lao ; Service d'Aménagement et de gestion du Vat Phu-Champassak (SAGV/WHSO)

Établissement éditeur : EFEO

Établissements porteurs de l'opération : EFEO

\section{La mission archéologique française au Sud-Laos}

1 La Mission archéologique française au Sud-Laos (MAFSL) a vu le jour en 2010. Elle fait suite au Projet de Recherche en Archéologie Lao (PRAL) qui a débuté en 1991 pour s'achever en $1999^{1}$. Le PRAL a bénéficié d'un financement du ministère de l'Europe et des Affaires étrangères français (MEAE) jusqu'en 1999. Il en est de même de la MAFSL depuis 2010. La MAFSL (ainsi que le PRAL auparavant) est conduite en coopération avec la Direction des Patrimoines, ministère de l'Information, de la Culture et du Tourisme (MICT) de la République démocratique populaire $\mathrm{Lao}^{2}$.

2 Au niveau administratif local, les travaux de la MAFSL s'intègrent à la convention cadre de partenariat entre l'EFEO et la direction des Patrimoines (MICT) qui inclut les autorisations de fouilles. Le programme de recherche général de l'EFEO au Laos, intitulé Patrimoines archéologiques et ethnographiques en RDP Lao, comporte le volet Archéologie du Moyen Mékong et du Sud-Laos: des chefferies à l'empire, l'évolution du monde khmer dans le sud du Laos, sous la responsabilité de C. Hawixbrock. Ce volet couvre l'étude du site de Vat Phu et de sa région (province de Champassak) entendu dans sa globalité (temple et établissements urbains) durant les périodes préangkorienne et angkorienne ${ }^{3}$, indépendamment des limites du périmètre du site classé en 2001 au Patrimoine Mondial de l'UNESCO (voir infra).

Le champ de recherche de la MAFSL comprend également le site de Nong Hua Thong et son trésor, dans la province de Savannakhet. 
Fig. 1. Localisation des sites fouillés par la MAFSL.

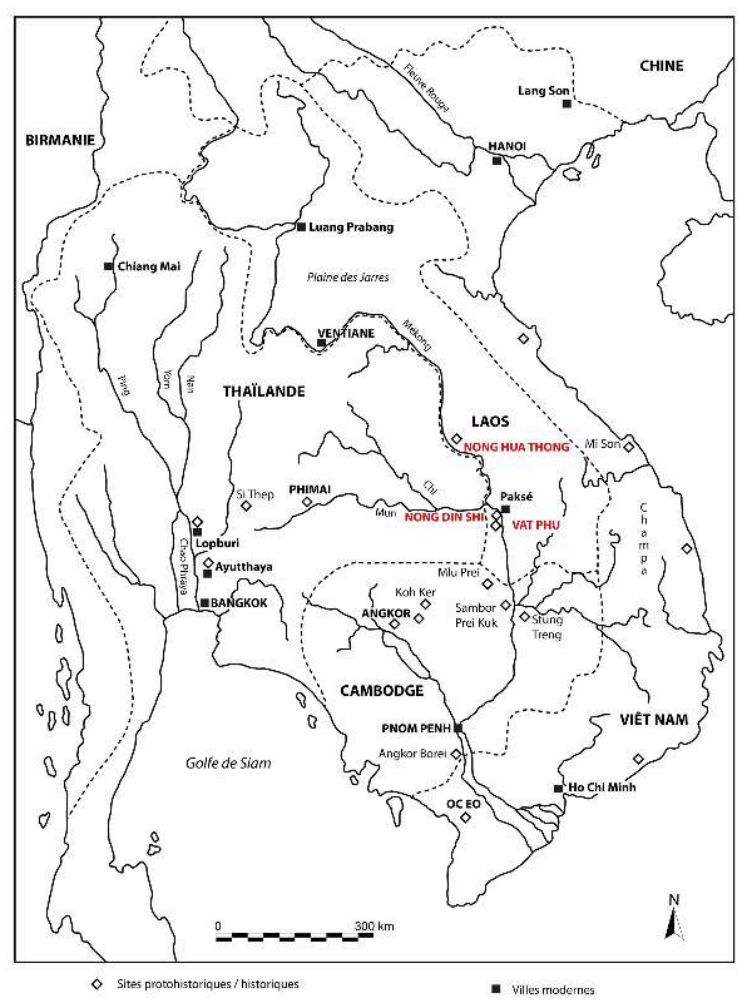

MAFSL.

\section{Présentation du site et des fouilles menées depuis 1991}

4 Le site de Vat Phu est dominé par une montagne culminant à $1416 \mathrm{~m}$, couronnée par une éminence rocheuse cylindrique naturelle de $18 \mathrm{~m}$ de haut pour $30 \mathrm{~m}$ de circonférence, qui rappelle la forme du linga, représentation phallique et manifestation symbolique du dieu Śiva ${ }^{4}$. Unique dans le monde khmer ancien, elle est identifiée, dès le $\mathrm{V}^{\mathrm{e}}$ siècle au moins, comme le Lingaparvata, la montagne du dieu Śiva (photo 1). 
Photos 1 et 2. Le Lingaparvata (photo 1) et le temple de Vat Phu.

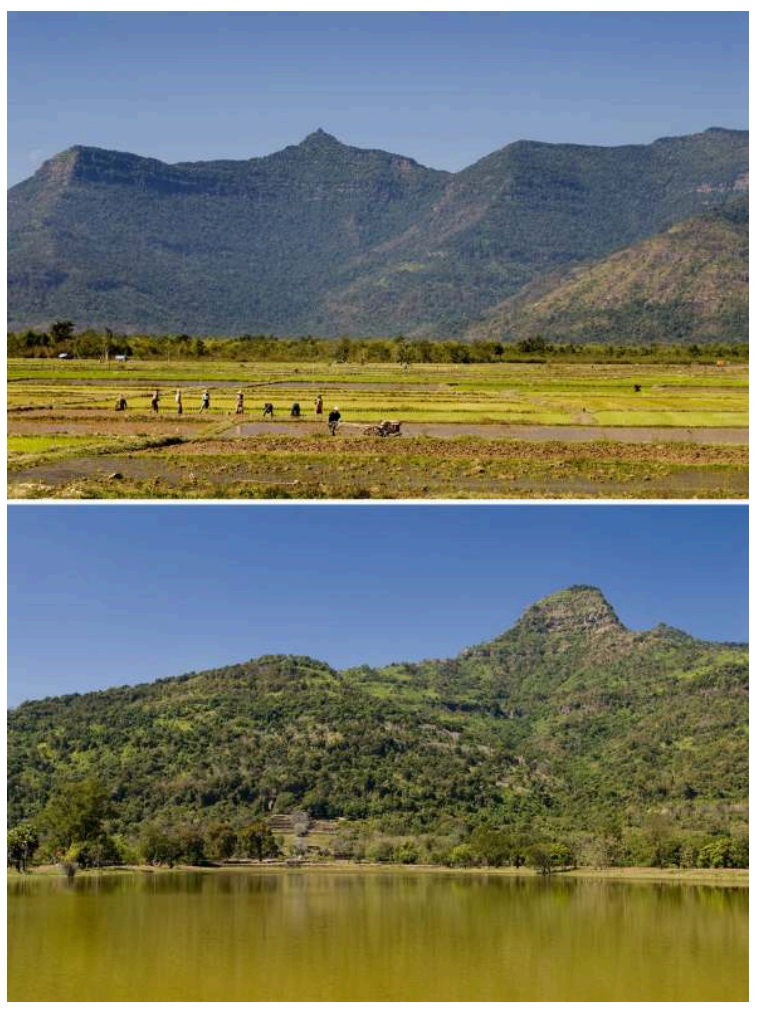

Il est à noter que le Lingaparvata n'est pas visible du temple car il est masqué par la première éminence de la montagne (PHOTO 2). 2008.

Stéphane Fradelizi. 
Fig. 2. Vue cavalière des sites archéologiques de Vat Phu. 2016.

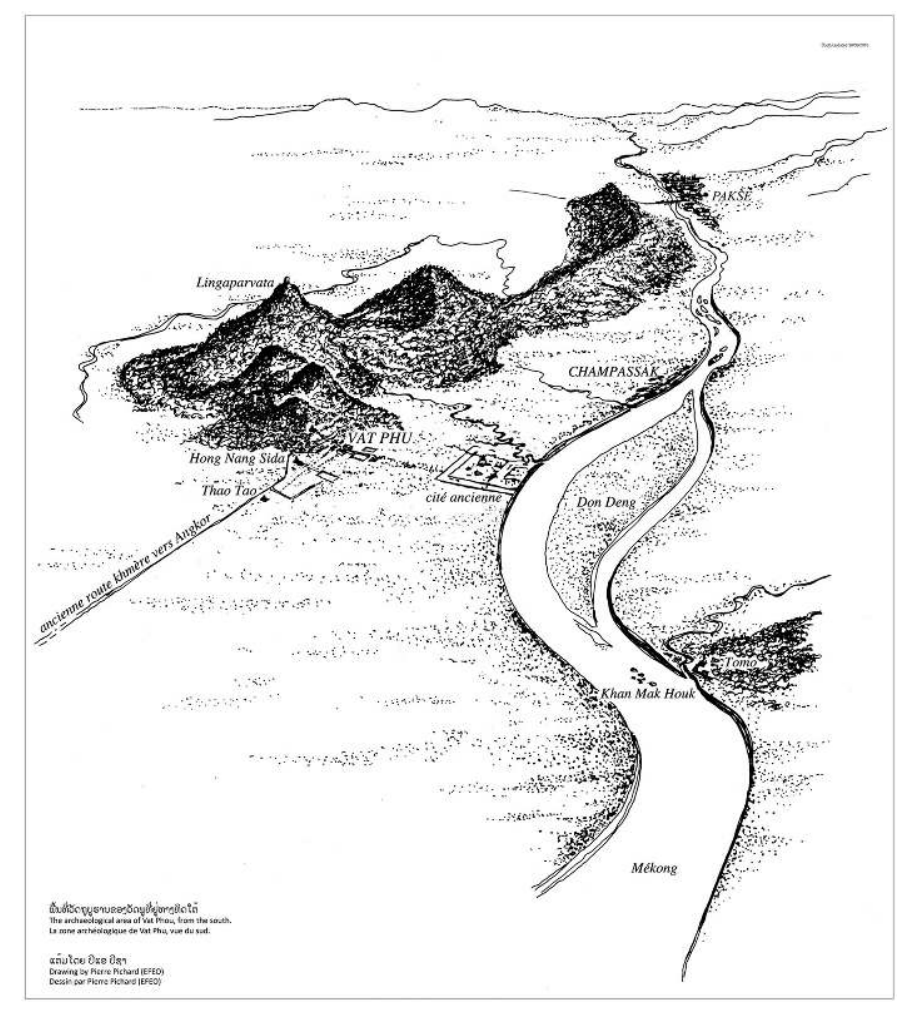

Pierre Pichard.

5 En effet, la stèle de fondation de la Ville Ancienne $\left(\mathrm{K}^{5} .365^{6}\right)$, datée paléographiquement du milieu du ve siècle EC, précise que le Lingaparvata est « connu depuis l'antiquité » $^{7}$ et qu'un temple était dédié à Śiva dès cette époque ${ }^{8}$. L'inscription K. 367, datée du règne de Jayavarman I (VIII siècle EC), confère au temple de Vat Phu le statut particulier de « lieu d'asile » et donne la liste des immunités pour tous les êtres qui s'y réfugient".

C'est également cette dimension "paysagère » remarquable du site qui est à l'origine de son classement au Patrimoine mondial de l'UNESCO en $2001^{10}$. Le temple de Vat Phu est bâti sur le premier contrefort de la montagne (photo 2). Les bâtiments encore visibles datent des $\mathrm{XI}^{\mathrm{e}}$-XIII ${ }^{\mathrm{e}}$ siècles ${ }^{11}$. Ils ont remplacé des états antérieurs dont les plus anciens appartiennent à la période préangkorienne ${ }^{12}$. Dès le $\mathrm{v}^{\mathrm{e}}$ siècle, une ville est installée à quatre kilomètres du temple, en bordure du Mékong. Cette cité, «la Ville Ancienne » $(2,4 \mathrm{~km} \times 2,2 \mathrm{~km})$, enclose de doubles murs en terre, est subdivisée en quartiers. Près de 30 tertres de monuments, souvent associés à un bassin du côté est (trapeang), ont été recensés par le PRAL dès 1991. Son nom, Kurukśetra ${ }^{13}$, donné par sa stèle de fondation K. 365, est repris dans d'autres inscriptions découvertes lors de nos prospections ${ }^{14}$, ainsi celles du sanctuaire de Houay Kadienne, en sanskrit et en vieux khmer, datées très précisément du 18 mai $654 \mathrm{EC}$ (K. 1201) ${ }^{15}$. Ces inscriptions en réemploi, trouvées dans un temple situé à plus de 60 kilomètres au sud de la Ville Ancienne en direction du Cambodge actuel, témoignent de l'aire d'influence de cette dernière au vII ${ }^{\mathrm{e}}$ siècle.

7 Cette ville associée au temple de Vat Phu, est le seul établissement urbain qui puisse fournir des informations sur la période de transition entre la fin du « Funan », royaume " pré-khmer » situé dans le delta du Mékong, et la prise de pouvoir du «Chenla », situé 
dans l'intérieur des terres, y compris dans la région de Vat Phu (fin du ve-début du $\mathrm{VI}^{\mathrm{e}}$ siècle) ${ }^{16}$. Son occupation présente un ensemble assez homogène sur deux ou trois siècles, très peu remanié par les occupations postérieures, à la différence de la cité d'Oc-Eo (delta du Mékong, Vietnam), en grande partie détruite ( ( ${ }^{\mathrm{er}}-\mathrm{VII}{ }^{\mathrm{e}}$ siècles).

\section{L'évolution de la problématique de recherche}

8 Les travaux se sont concentrés tout d'abord sur la terrasse supérieure du temple de Vat Phu, autour d'un abri sous roche sous lequel une source provenant de la montagne sacrée s'écoule perpétuellement. Les fouilles (1991-1995) ont permis de mettre au jour des aménagements cultuels uniques dans le monde khmer (système d'acheminement des eaux sacrées captées depuis la source grâce à des conduites aériennes en grès jusqu'à la cella principale du temple pour l'ondoiement permanent de Śiva, installé dans le sanctuaire sous la forme d'un linga $\left[\mathrm{XI}^{\mathrm{e}}\right.$-XIII ${ }^{\mathrm{e}}$ siècles]). Ces aménagements sont fondés sur des éléments en réemploi parfois décorés, appartenant au tout début de la période préangkorienne ${ }^{17}$.

9 Les recherches ont ensuite privilégié l'étude des vestiges préangkoriens du Sud-Laos, plus particulièrement dans la région de Vat $\mathrm{Phu}$, point de départ à la fin $\mathrm{du}_{\mathrm{VI}} \mathrm{e}^{\mathrm{e}}$ siècle des premières expansions khmères vers le nord et l'est (Laos et Thaïlande actuels) et vers le sud (Cambodge) ${ }^{18}$.

10 Le monde khmer ancien situé à l'intérieur des frontières actuelles du Laos a été très peu étudié jusqu'ici, à la différence d'Angkor, malgré des inventaires monumentaux partiels initiés au tout début du $\mathrm{Xx}^{\mathrm{e}}$ siècle ${ }^{19}$ et le déchiffrement d'inscriptions sur stèles en grès dès 1902 par les épigraphistes de l'École française d'Extrême-Orient (A. Barth, G. Cœdès, L. Finot $)^{20}$ puis, plus récemment, par C. Jacques. L'étude de cette période de transition entre les communautés agricoles évoluées et les premières cités-États, puis les premiers royaumes, est primordiale pour la compréhension de l'évolution culturelle de l'Asie du Sud-Est continentale.

11 Cette problématique est toujours d'actualité 30 ans après le début des recherches archéologiques du PRAL puis de la MAFSL, les autres pays qui interviennent sur le site (Inde, Corée du Sud) se consacrant en priorité aux restaurations architecturales.

12 Cette région étant au cœur de réseaux d'échanges, comme l'attestent les vestiges fouillés, les recherches se sont rapidement étendues à la compréhension du territoire régi par ce premier royaume khmer. Comme l'ont mis en évidence les travaux du PRAL et de la MAFSL, la Ville Ancienne de Vat Phu est le lieu d'émergence du premier pouvoir central unifié khmer. Ce fait a été confirmé durant nos fouilles par la mise au jour d'inscriptions (K. 1173 et K. 1174) sur le site de Houay Sa Houa 2 en 1993-1994.

13 Nos prospections vers le sud jusqu'à la frontière cambodgienne (1998-1999) ont mis en évidence que ces cités-États étaient situées au cœur de réseaux d'échanges fluviaux et terrestres, avec une occupation urbaine et suburbaine préangkorienne dense en bordure du Mékong et dans l'intérieur des terres. À la période angkorienne, ce sont au contraire les voies terrestres qui seront privilégiées. L'étude stylistique des templesétapes qui jalonnent la route khmère reliant Vat Phu à Angkor ${ }^{21}$ a permis de situer leur date de construction au début du $\mathrm{x}^{\mathrm{e}}$ siècle $^{22}$.

14 Jusqu'à la fin de l'empire khmer (fin XIII ${ }^{\mathrm{e}}$-début XIV $\mathrm{s}$.), chaque monarque, pour légitimer en quelque sorte son droit au trône, honorera Vat Phu en souvenir des 
origines de sa «filiation"-supposée et recherchée - à cette première dynastie historique par des donations et fondations diverses. L'inscription K. 1320, mise au jour en 2013 dans le quadrangle nord de Vat Phu par les équipes de l'Archaeological Survey of India, en est un témoignage supplémentaire ${ }^{23}$. Elle donne la liste exhaustive des dons que le roi d'Angkor, İsānavarman II, fit au début du $x^{\mathrm{e}}$ siècle à la divinité tutélaire de Vat Phu, Śiva Badreśvara ${ }^{24}$. L'analyse du grès de cette stèle, effectuée grâce à un spectromètre à fluorescence $\mathrm{X}$ et un spectromètre à réflectance, indique d'autre part qu'elle provient d'Angkor, nouvelle preuve des étroits contacts commerciaux et des liens religieux qui unissaient Vat Phu à la capitale de l'empire khmer dès le début de la période angkorienne ${ }^{25}$.

L'importance des résultats obtenus et le potentiel archéologique au niveau régional nous ont incité à étendre la zone de recherche de la MAFSL jusqu'à la limite nord, archéologiquement identifiée, de l'occupation khmère ancienne dans le Sud-Laos actuel. Cet élargissement s'est traduit par l'étude du site de Nong Hua Thong (province de Savannakhet), où la découverte fortuite en 2008 d'un trésor d'orfèvrerie mon/ khmer, " unique dans les annales ", a conduit la Direction Générale des Patrimoines du Laos à demander l'aide de l'EFEO et de la MAFSL pour une première évaluation effectuée par C. Hawixbrock en 2009. Cette dernière s'est également vu confier l'inventaire du «trésor » composé de plus de 200 objets en or et en argent dont trois pièces (deux plateaux et un bol en argent) sont gravées de dédicaces en sanskrit et en vieux khmer honorant des divinités brahmaniques (ca. viII siècle EC) ${ }^{26}$.

En ce qui concerne la Ville Ancienne, des sondages et des prospections systématiques ont été menés entre 1991 et 1996 pour en établir le plan. Trois monuments ont été fouillés, révélant non seulement de nouvelles sources épigraphiques précieuses pour la compréhension de la formation de l'État khmer mais aussi des formes architecturales et artistiques originales, antérieures à celles connues pour le monde préangkorien. L'un des plus anciens sanctuaires bouddhiques khmer, un stūpa double, fut ainsi mis au jour (site de Nong Vienne). Les éléments sculptés associés à ces structures révèlent des influences de deux grandes cultures voisines, le Campa $\bar{a}^{27}$ à l'ouest, le monde mon (Dvāravatîi ${ }^{28}$ à l'est. Certains témoignent d'une empreinte indienne plus directe, tel le linteau en grès de Vat Sang'O 2, site appartenant au complexe de Vat Sang'O29.

La configuration du site et son étendue permettent d'avancer l'hypothèse d'une installation urbaine peut-être antérieure à la Ville Ancienne fondée au milieu du $V^{e}$ siècle EC.

\section{Le complexe de Vat Sang'0}

\section{Présentation du site}

Comme indiqué précédemment, la MAFSL a pour objectifs de préciser la période de fondation de ces premières cités-États indianisées, ainsi que l'étendue des territoires qu'elles administraient, en particulier à travers nos recherches conduites sur le complexe urbain de Vat Sang'O depuis 2014 (photo 3). Séparé de la Ville Ancienne par la rivière Houay Sa Houa au nord, Vat Sang'O a fait l'objet de prospections pédestres systématiques dès 1994 et son relevé topographique a débuté en 2013 (fig. 3). 
Fig. 3. Topographie générale du complexe de Vat Sang'O par Nopphalak Vongsouthi (WHSO), 2013.

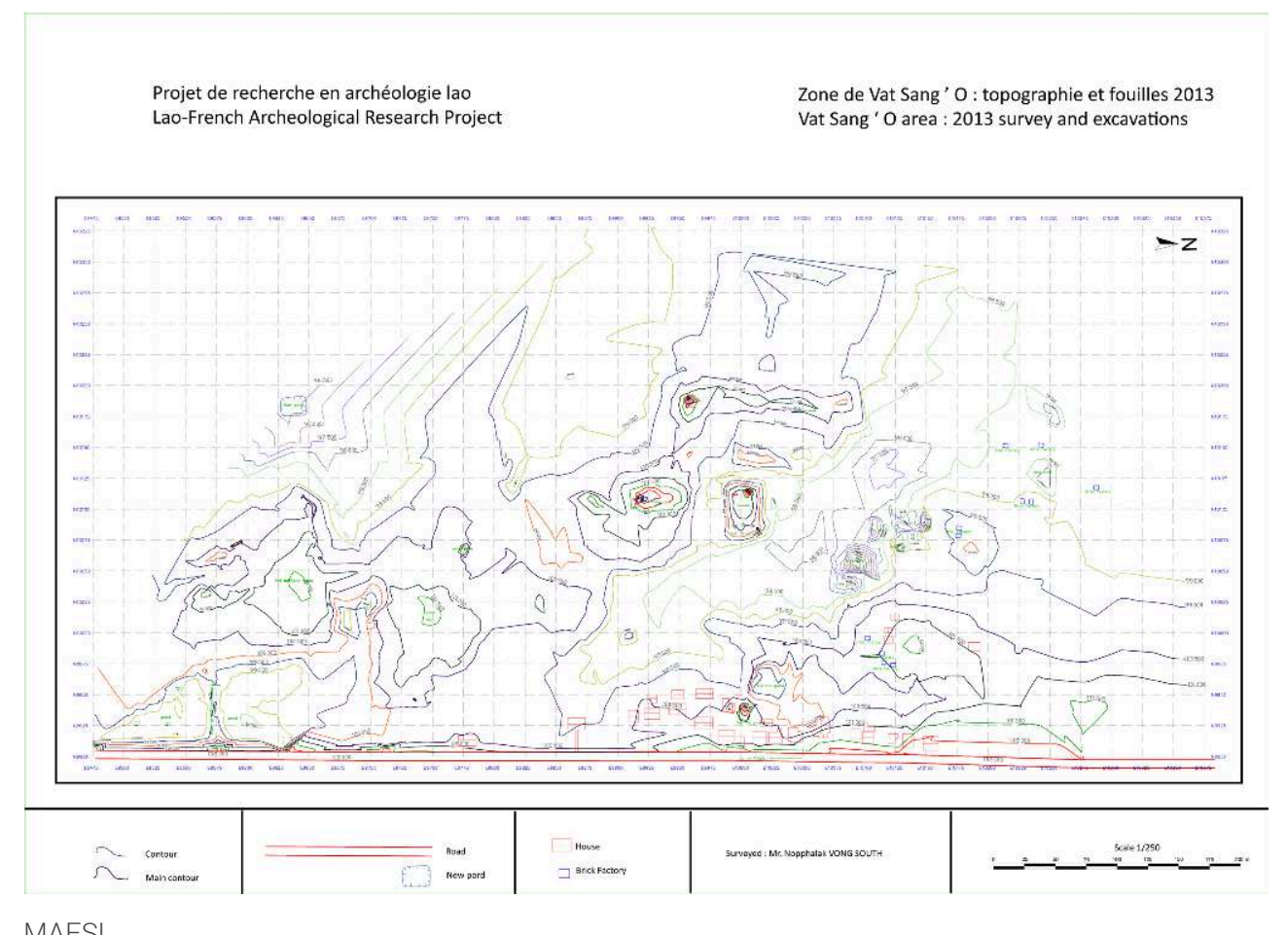

Ce complexe présente une forme carrée d'environ un kilomètre de côté. La présence d'au moins cinq tertres (soit cinq sites) de grandes dimensions, situés à proximité les uns des autres, nous a conduit à nommer cet ensemble le " complexe de Vat Sang'O ». Deux tertres ont été fouillés: Vat Sang'O 2 (2013) et Vat Sang'O 5 (2014, 2017, 2018 et 2020). L'édifice en briques mis au jour à Vat Sang'O 2 était ceinturé d'une allée pourtournante, dégagée du bâtiment central rectangulaire ( $13 \mathrm{~m} \times 9 \mathrm{~m}$ environ). Il s'agit d'un dispositif inédit qui pourrait indiquer un site bouddhique. Le système de fondation de cette structure est très différent de ceux rencontrés habituellement à la période préangkorienne, en particulier dans la région de Vat Phu. La taille exceptionnelle des briques ( $54 \mathrm{~cm}$ de longueur), des éléments architecturaux, dont le linteau retrouvé en surface, de forme totalement originale et directement inspiré de modèles indiens, ainsi que la céramique mise au jour, permettent de dater provisoirement ce bâtiment des périodes préangkoriennes les plus anciennes, c'est-à-dire aux environs du v $v^{e}$ siècle EC.

Le site de Vat Sang'O 5, à l'ouest du précédent, consiste en une levée de terre, haute, en l'état actuel, d'environ cinq mètres ${ }^{30}$, longue de $150 \mathrm{~m}$ et large de $30 \mathrm{~m}$. Les fouilles (2014, 2017, et en partie 2018) se sont concentrées sur la zone située à son extrémité nord où affleuraient de petites structures de latérite ${ }^{31}$ victimes de pillages, structures repérées dès nos prospections des années 1990. D'autres structures du même type, intactes celles-là, ont été mises au jour en 2014. Leur disposition suggérait l'existence d'un plan d'ensemble, mis en évidence durant la campagne 2017. Les sondages de 2018 et 2020 ont été consacrés au dégagement de la partie centrale de la levée de terre dans le but de rejoindre son extrémité sud, qui pourrait avoir une fonction religieuse au vu des vestiges visibles. 
Photo 3. Carte de situation de la Ville Ancienne de Vat Phu et du complexe de Vat Sang'O situé au nord de cette dernière, 2014.

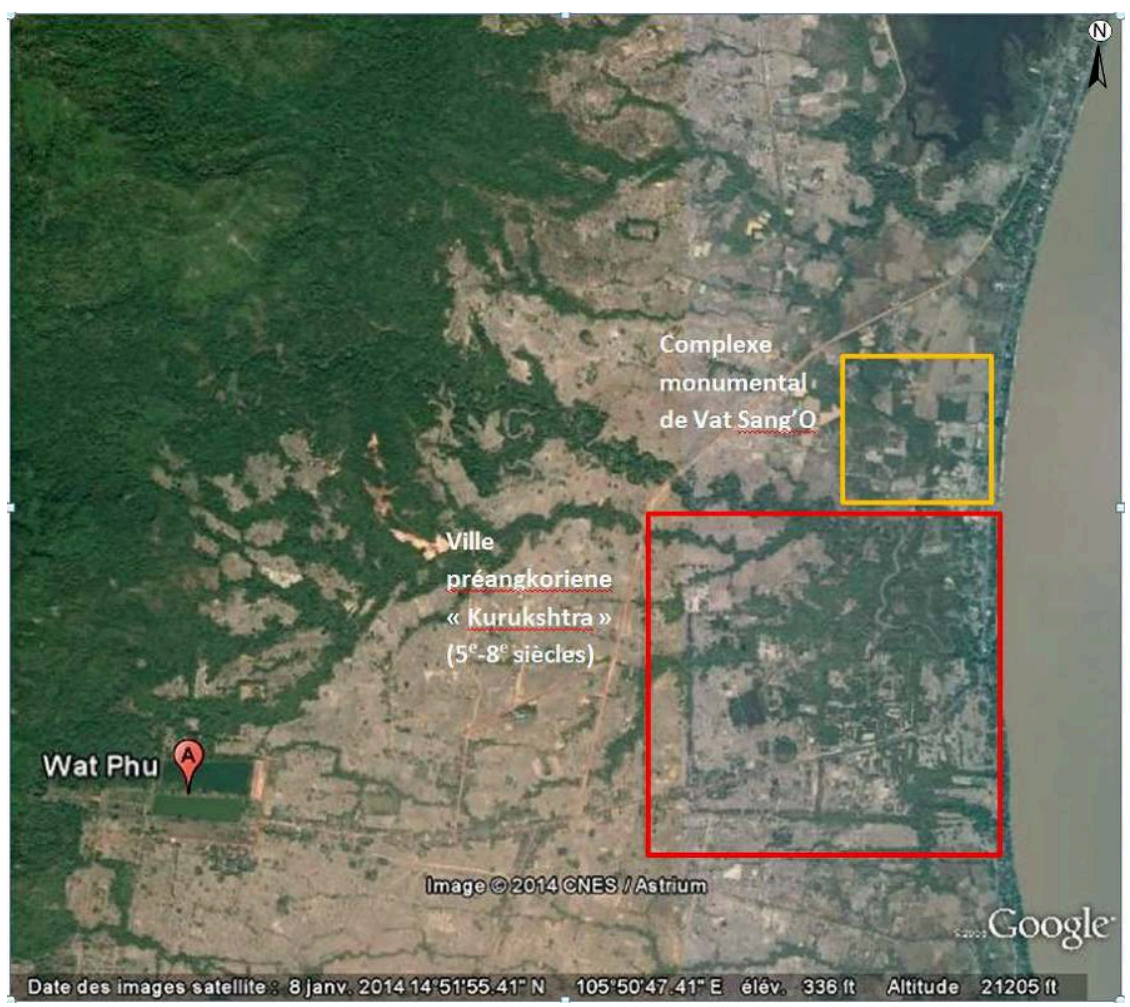

Photo 4. Complexe de Vat Sang'O (VSO) avec tertres identifiés, 2017.

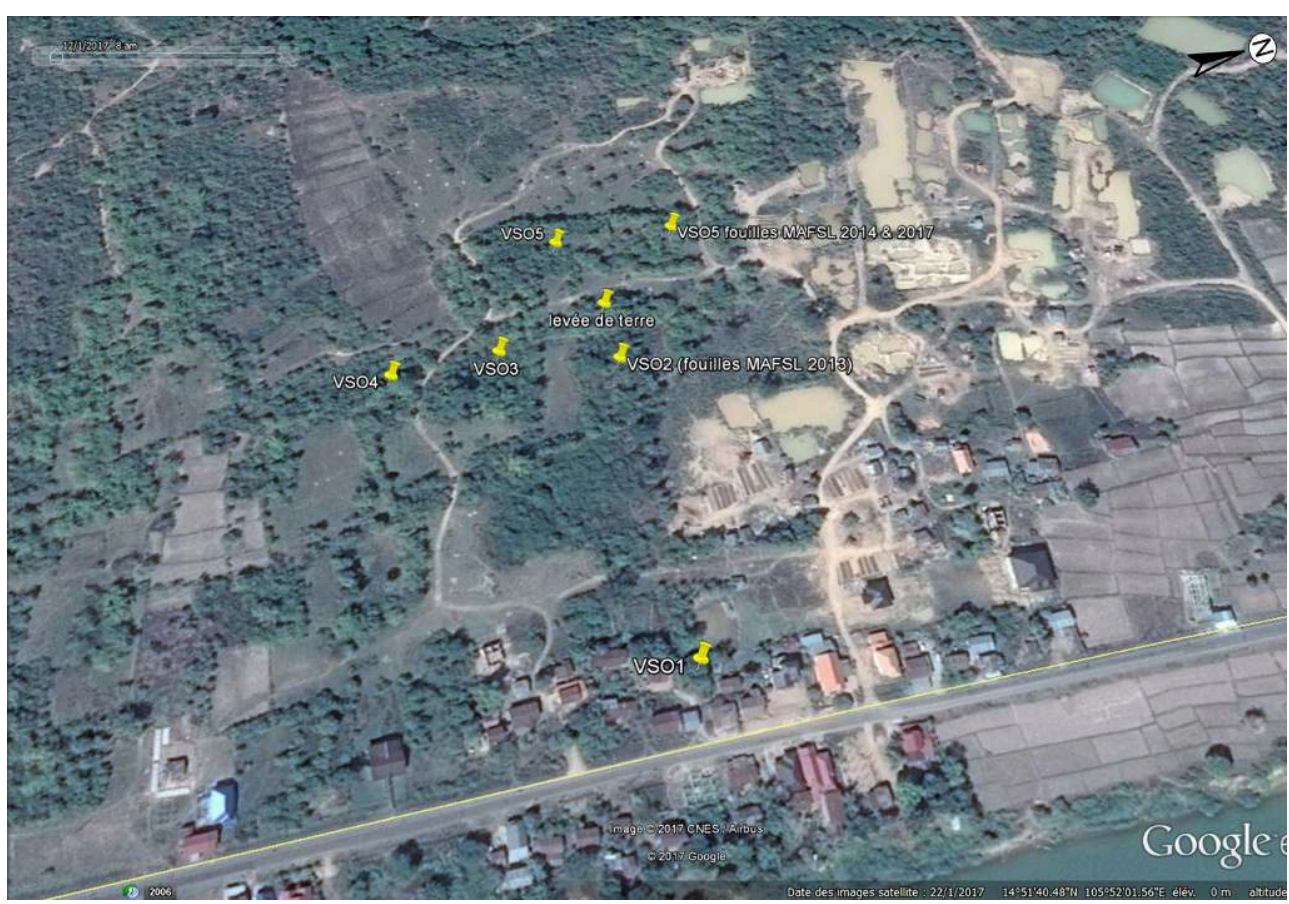




\section{État actuel du site}

Si ce complexe de Vat Sang'O semble limité à l'ouest par la levée de terre de Vat Sang'O 5, il se développe vers l'est jusqu'au Mékong. La route moderne qui relie la ville actuelle de Champassak au temple de Vat Phu le traverse à l'est, parallèle au fleuve. Elle a été surélevée et élargie il y a quelques années, entraînant la destruction de vestiges préangkoriens dont les briques dispersées, parfois taillées et témoins d'architectures moulurées, sont visibles en surface sur les bas-côtés de la route.

Vat Sang'O est menacé depuis quelques années par des briqueteries modernes en pleine activité, installées à 15 mètres au nord des vestiges, et dont l'empiétement ne fait que s'accroître. D'une unique briqueterie en 2014, il en existe aujourd'hui une vingtaine (photo 5) bien qu'elles soient installées à l'intérieur du périmètre protégé par l'UNESCO dans la zone dite "d'études archéologiques ». Aucune disposition juridique n'a été prise pour stopper leur développement, mettant ainsi les vestiges préangkoriens en grand danger. Le plan de protection préparé lors de l'élaboration du dossier de classement pour l'UNESCO en 1998-1999 classe la seule Ville Ancienne intramuros en périmètre de protection maximale (ce qui n'empêche pas les destructions), tandis que toute la zone située au nord-est a été classée en « risques moindres » et « zones de briques » bien que les tertres archéologiques étaient déjà identifiés à l'époque. Le secteur de Vat Sang'O est de ce fait encore moins "respecté " que celui de la Ville Ancienne. Ainsi, Vat Sang'O 2 a été planté de tecks il y a quelques années.

En 2014, les vestiges de monuments en brique préangkoriens étaient encore visibles, cernés par les zones de travail et les fours. Ils ont aujourd'hui en partie disparu sans avoir eu le temps nécessaire pour vérifier leur appartenance à cette série cohérente de monuments qui composent le complexe de Vat Sang'O (photo 5).

Photo 5. Périmètre du complexe de Vat Sang'O en 2017 et empiétement des briqueteries modernes.

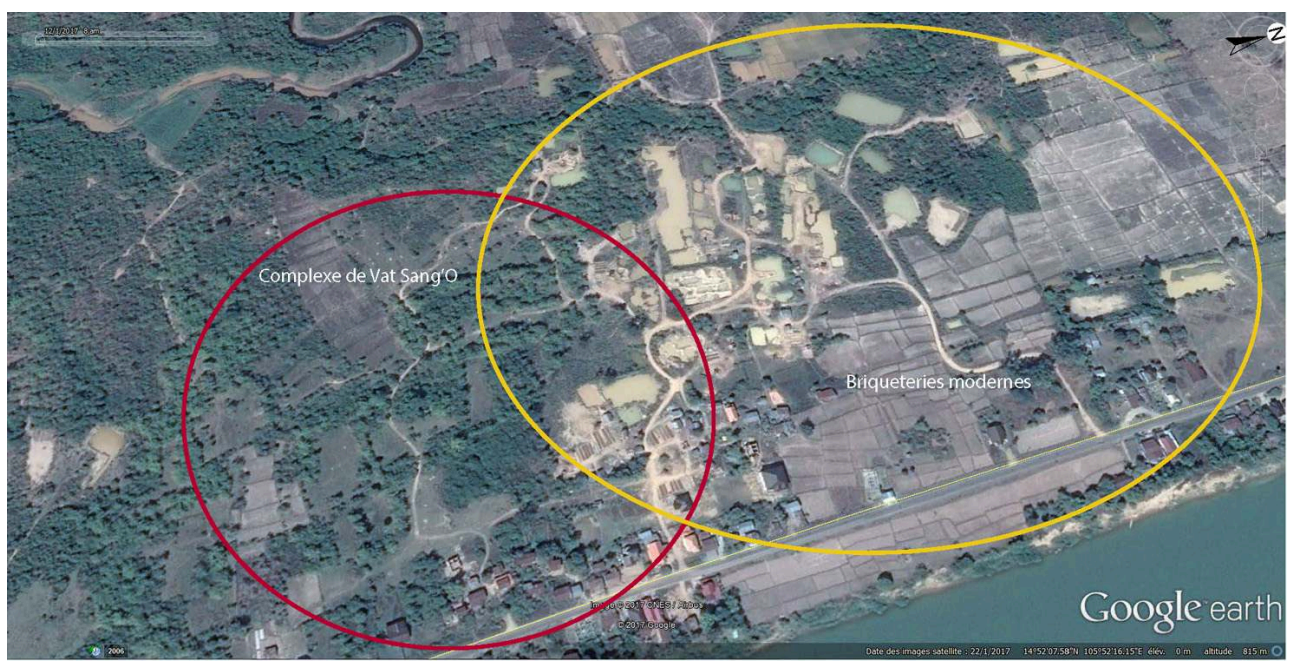

\section{Vat Sang'0 5}

La levée de terre de Vat Sang'O 5, à l'ouest des tertres de Vat Sang'O 2 et Vat Sang'O 3, est orientée nord-nord-ouest/sud-sud-est (long., $150 \mathrm{~m}$; larg., $30 \mathrm{~m}$ ). Elle semble constituer la limite ouest du complexe de Vat Sang'O, qui se développe vers l'est et le 
Mékong. Au-delà, la plaine rizicole s'étend à l'ouest. La partie supérieure de la levée forme une vaste plateforme, pratiquement plane (photo 6).

Photo 6. Vue satellite de Vat Sang'0 5, 2017.

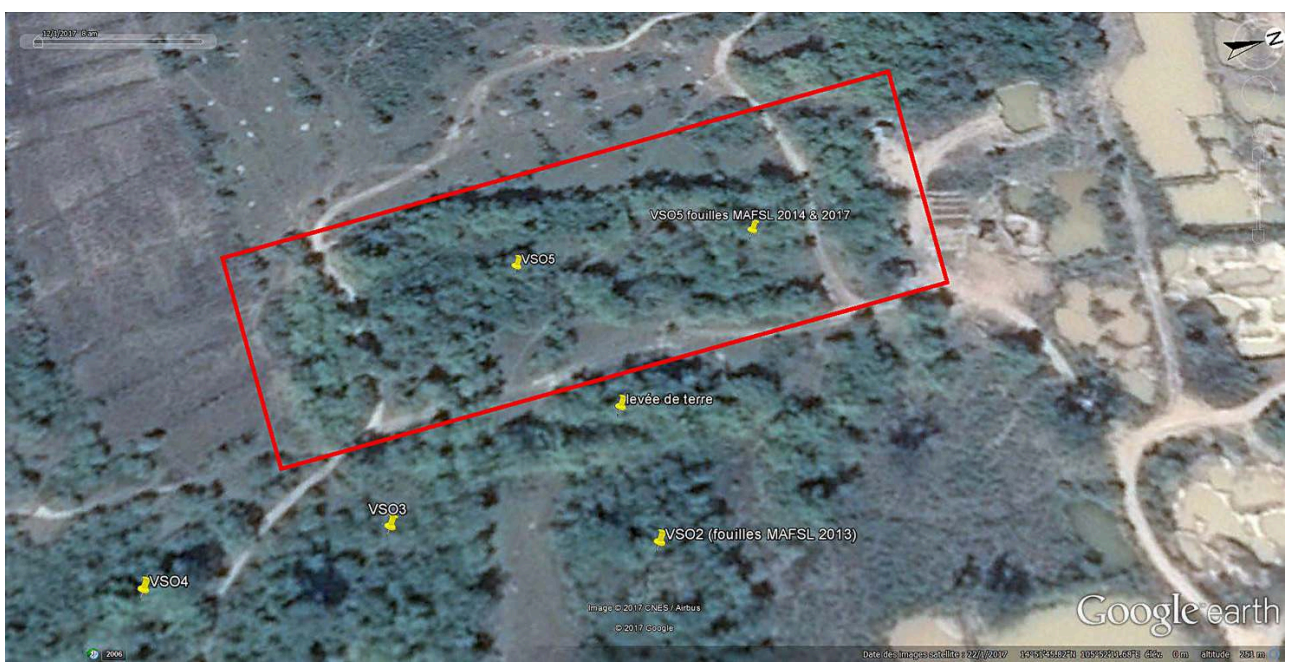

En 2014, les fouilles ont débuté par l'étude de l'extrémité nord de cette levée où affleuraient les petites structures de latérite déjà pillées mentionnées plus haut. Cinq structures d'un même type (totalement inédit) ont été mises au jour durant cette campagne, dont trois intactes (photo 7). Il restait à tenter de mettre en évidence le plan d'ensemble par des fouilles complémentaires extensives, qui ont pu être réalisées en 2017.

Photo 7. Vue générale vers le nord de la fouille de Vat Sang'0 5. 2014.

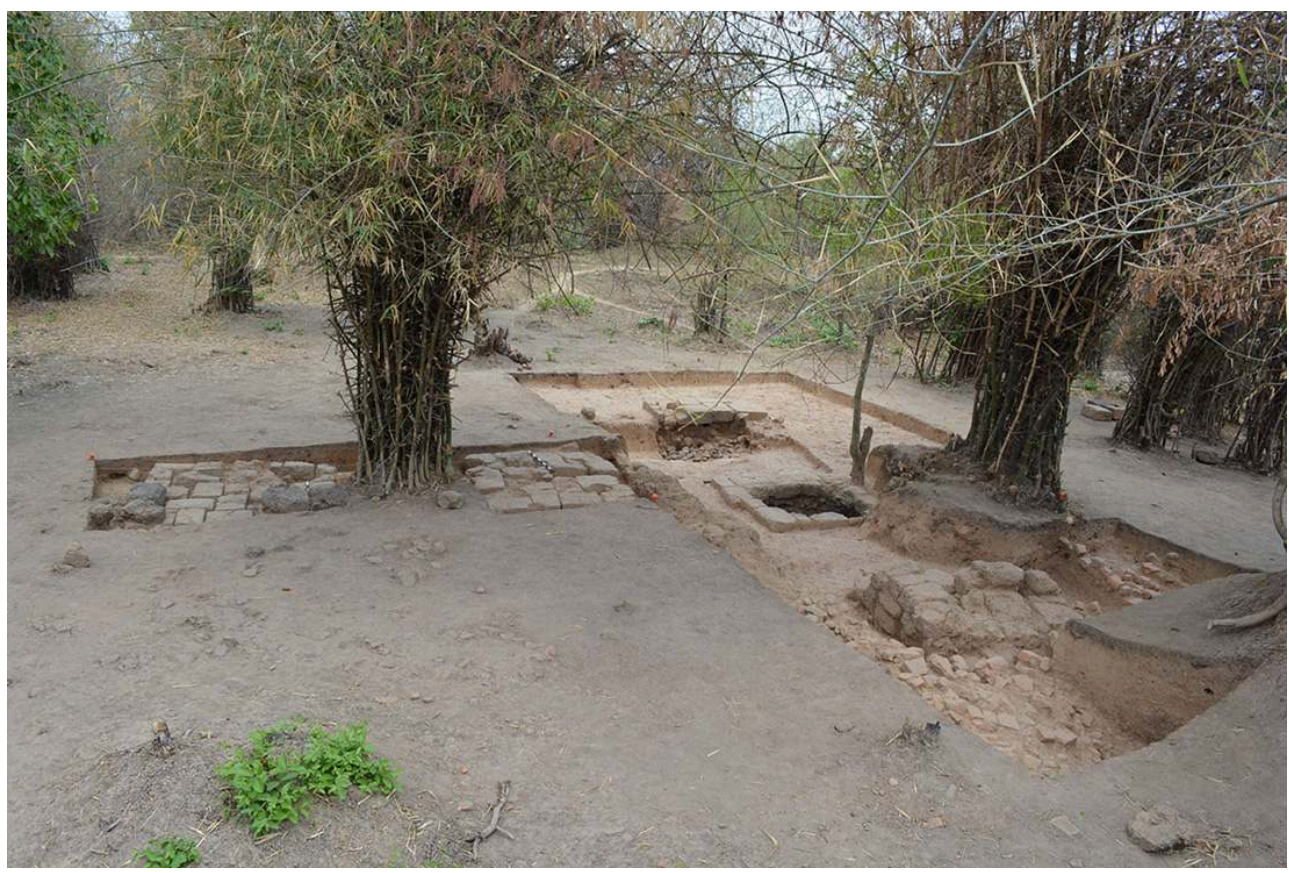

C. Hawixbrock.

Les fours de la briqueterie moderne la plus proche sont maintenant installés contre l'extrémité nord de la levée de Vat Sang'O 5 et les abris des travailleurs ont été 
construits sur la levée elle-même. Bien qu'il s'agisse de cabanes en bois sur pilotis, peu perturbantes en elles-mêmes, leur existence empêche l'implantation de tranchées de vérification à l'extrémité nord de la levée pour déterminer le périmètre exact de l'espace ayant fonctionné avec ces structures.

Le reste de la levée est traversé de chemins mais vide de toute réoccupation moderne. Considéré par les villageois comme habité par des esprits, l'ensemble est par ailleurs bien préservé. Ceci explique la faible épaisseur des dépôts anthropiques. En effet, soit les structures apparaissent au niveau actuel de la surface, soit elles sont enfouies sous à peine une dizaine de centimètres de sédiment (photos 8 et 9 ).

Photos 8 et 9 . Vues vers le sud de la levée de Vat Sang'0 5 avant fouilles en 2017 avec, à droite, les fouilles de 2014 en partie laissées au jour. 2017.
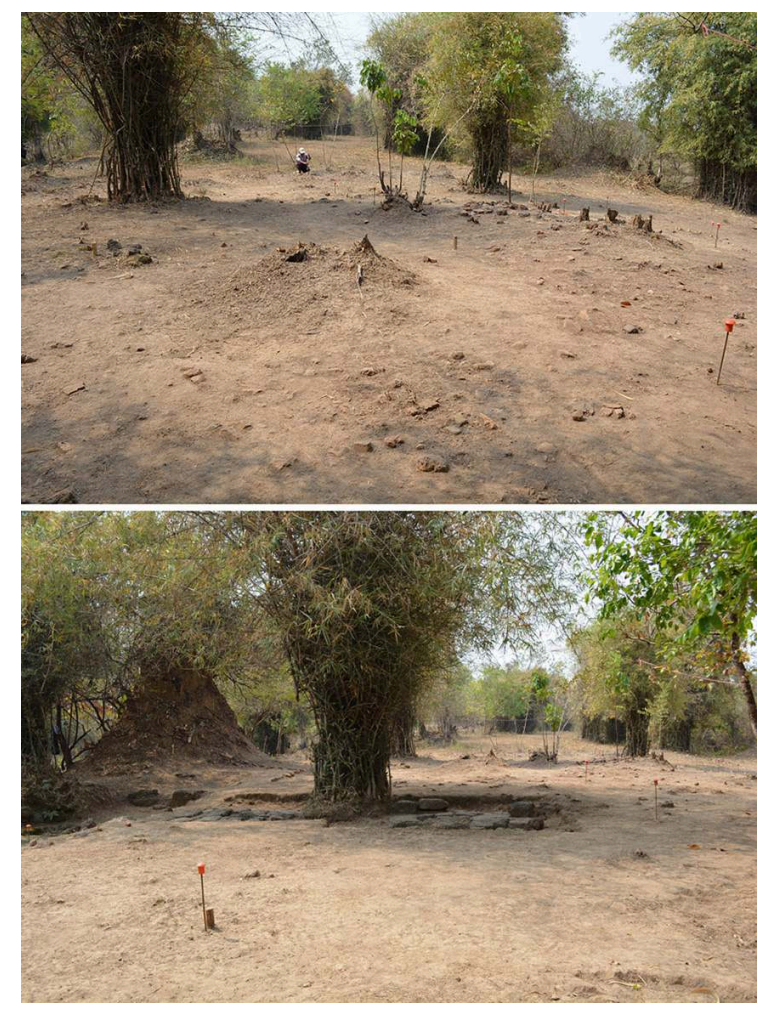

C. Hawixbrock.

\section{Quelques généralités au sujet des structures}

Les structures mises au jour sont de petite taille (de $1,80 \times 1,90 \mathrm{~m}$ à $2 \times 2 \mathrm{~m}$ ), approximativement carrées ou légèrement trapézoïdales en plan. Elles sont implantées à intervalles réguliers (1,50 m environ) et fondées sur des galets. Certains éléments tels que les fondations en galets et la manière dont les blocs de latérite sont disposés pour former des motifs « en roue » juxtaposés les uns aux autres avec, le plus souvent, un élément carré marquant le centre du dispositif (photos 10 et 11) - indiquent leur appartenance aux périodes préangkoriennes les plus anciennes ( $\mathrm{vi}^{\mathrm{e}}$ siècle au plus tard). Ce motif, que l'on retrouve sur d'autres monuments (en briques cette fois, fouilles MAFSL) parmi les plus anciens de la région, constitue un critère de datation. C'est le cas 
de Houay Sa Houa $2\left(\right.$ fin $\mathrm{VI}^{\mathrm{e}} \mathrm{s}$.), du stūpa de Nong Vienne (fin $\mathrm{VI}^{\mathrm{e}} \mathrm{s}$.), alors qu'il est rare à Nong Din Shi (fin VII ${ }^{\mathrm{e}}$.).

Photos 10 et 11 . Exemples de blocs de latérite formant le motif de la « roue » sur les structures mises au jour à Vat Sang'O 5, 2017.

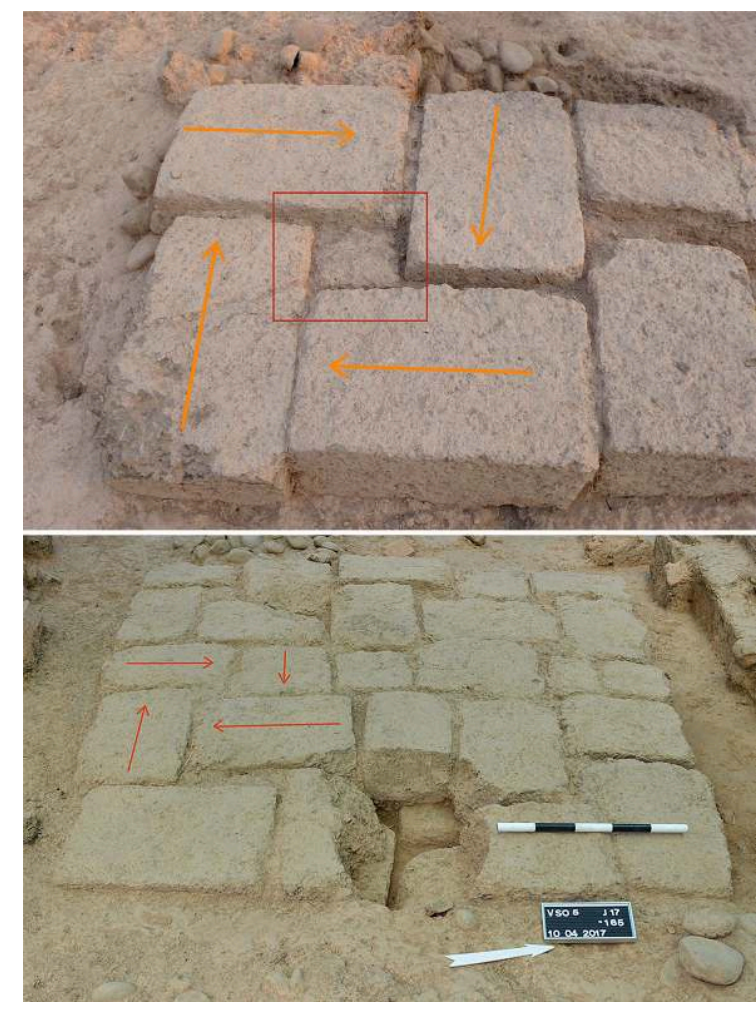

C. Hawixbrock.

Des trous de poteaux, de circonférences et de profondeurs diverses, entament ces structures. Ils correspondent vraisemblablement aux derniers vestiges de bâtiments de grande taille en matériaux périssables disparus depuis longtemps. Ces constructions à usage probablement domestique ont pu fonctionner en association avec les temples situés en avant vers l'est (Vat Sang'O 2 au moins). La quantité importante de céramiques $^{32}$ mises au jour dans cette zone vient étayer cette hypothèse. 
Fig. 4. Plan des fouilles de Vat Sang'O 5, 2014 et 2017, 2017.

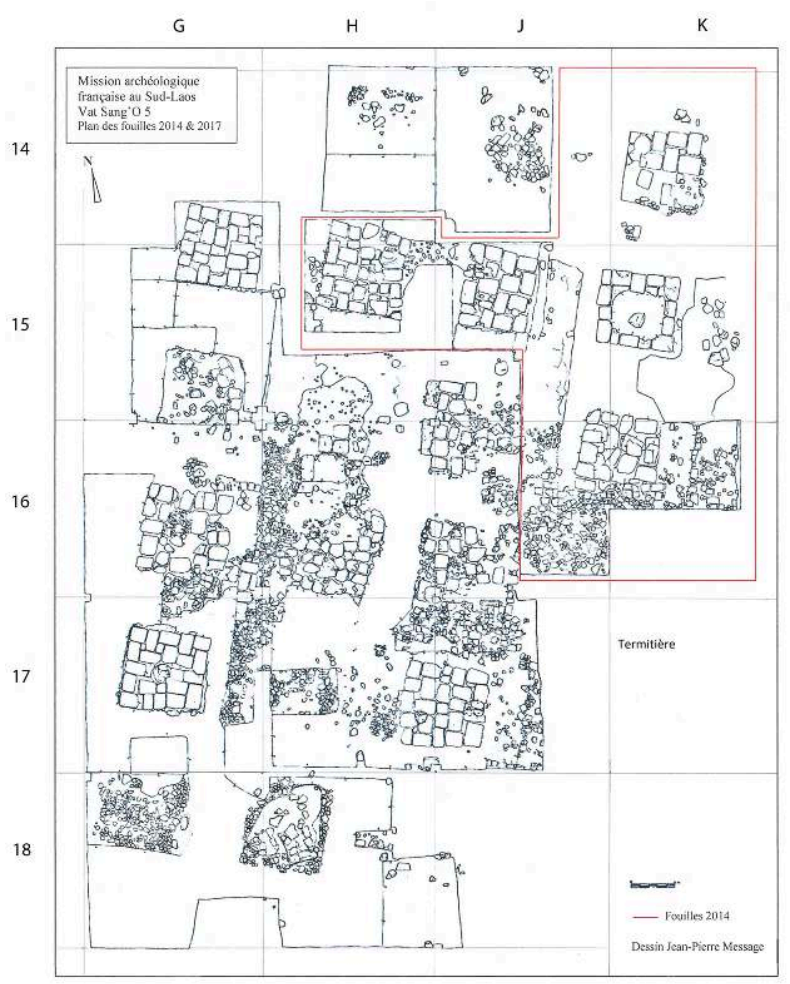

MAFSL. levée, du côté nord. Elle s'étend sur $300 \mathrm{~m}^{2}$. Un carroyage de 4 mètres de côté a été implanté sur la totalité de la largeur de la levée pour s'étendre sur sa longueur.

31 Douze structures du même type ont été mises au jour en 2017, portant ainsi leur nombre total à 17. Dans le carré $\mathrm{H} 16$, quelques blocs en place pourraient être les vestiges perturbés d'une structure supplémentaire.

Parmi les structures mises au jour, seules deux ont été largement pillées (K 14 et 15 -

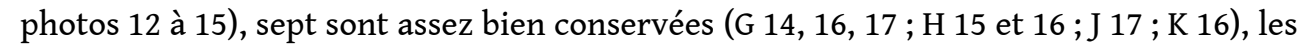
huit autres étant, soit détruites (H 14 et J 14), soit endommagées ( $G$ 15, H/J 15-16, H 16, $\mathrm{J} 16, \mathrm{G} 18$ et H 18). En H 14 et J 14, c'est essentiellement la position de deux amas de blocs de latérite brisés qui suggèrent l'existence de deux structures à ces emplacements-là compte tenu du plan général du bâtiment. Ces amas sont proches des structures pillées et on ne voit pas bien d'où proviendraient ces blocs brisés qui forment (surtout en J14) des monticules assez conséquents mêlés à du sable peu dense. 
Photo 12 (en haut). Les structures supposées H 14 et K 14 ; Photo 13 (en bas). Structure G 16.

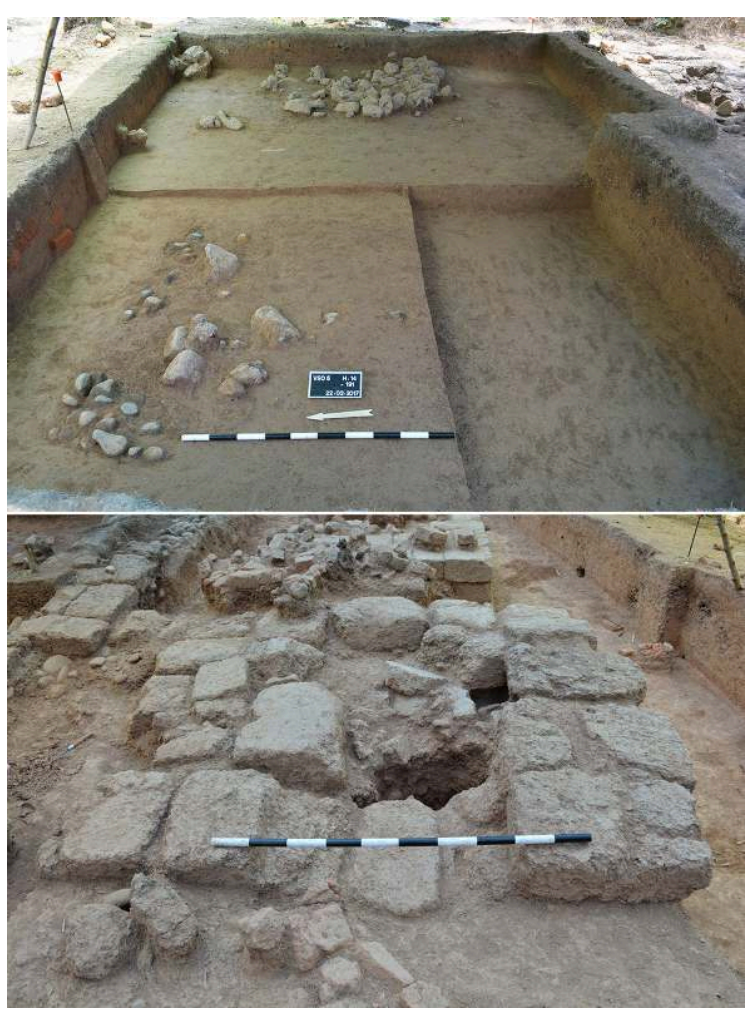

C. Hawixbrock.

Photo 14. Vue des structures construites avec soin ( $\mathrm{J} 17$ et $\mathrm{G} 17$, au second plan), de celles moins soignées ( $\mathrm{J} 16, \mathrm{H} 16$ au premier plan).

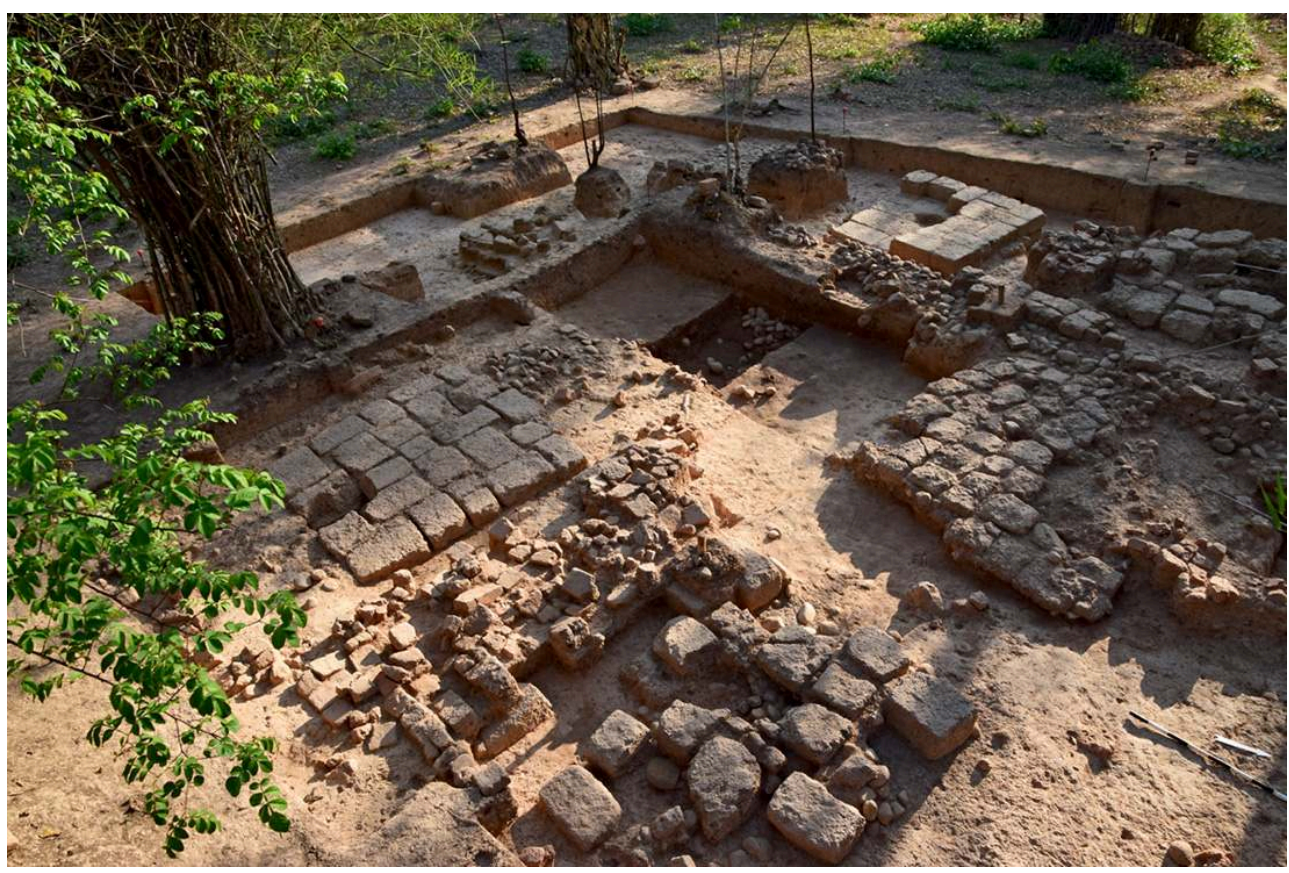

C. Hawixbrock. 
Photo 15. Structure en J 17, à lit unique de latérite, 2017.

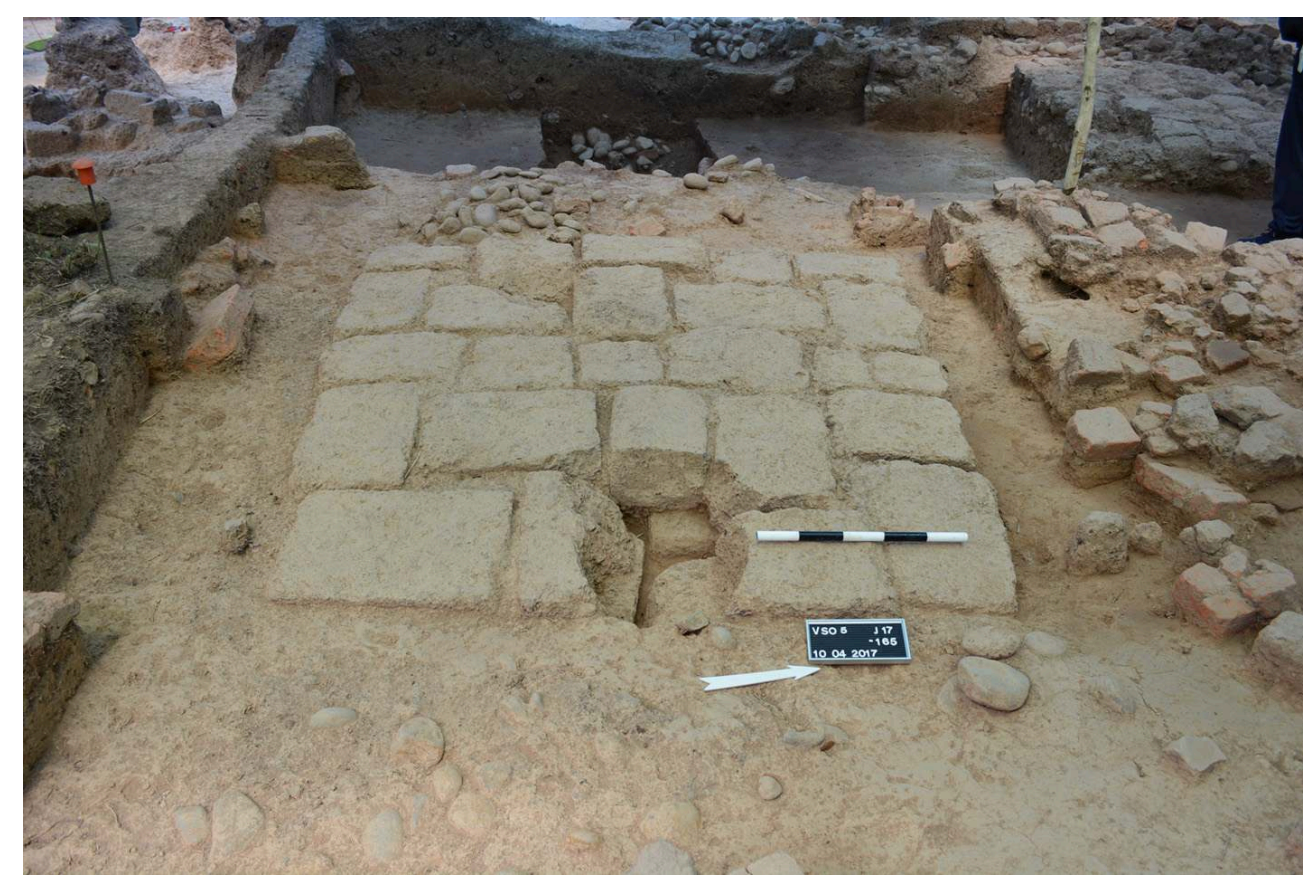

C. Hawixbrock.

\section{Les fondations des structures}

À l'exception de celles qui n'existaient plus qu'à l'état de traces, les structures détruites restent bien visibles grâce à leurs fondations. Les parois des fosses de fondation sont verticales et s'adaptent parfaitement à la dimension des structures qu'elles reçoivent. Elles sont remplies de galets de rivière maintenus en place par un sable concrétionné dense et bien damé. Un liant y a peut-être été ajouté puisque le substrat résiste aux intempéries (à court terme), et elles ont perduré malgré la destruction des structures elles-mêmes. Tel est le cas des structures situées en G 15, G 18 et H 18, mais pas de celles en $\mathrm{K} 14$ et 15, qui ont été pillées. 
Photos 16 et 17 . Vues des structures $\mathrm{G} 18$ et $\mathrm{H} 18$. Le sable concrétionné est bien visible sur la H 18 (sous la couche de latérite « fondue » des blocs brisés), 2017.
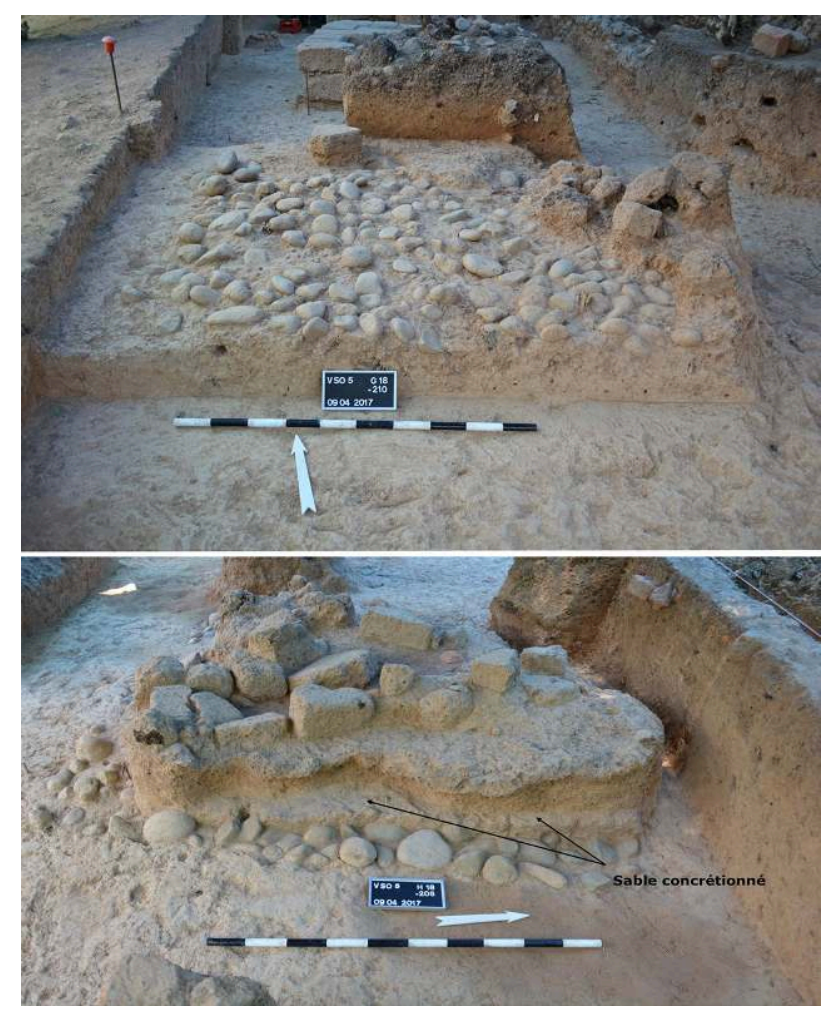

C. Hawixbrock.

En 2014, la structure pillée K 14 (photo 18) a pu être observée jusqu'à la base de sa fondation, révélant une épaisseur de $1,16 \mathrm{~m}$ de galets. Un seul sondage en profondeur a été pratiqué en 2017, de façon à ne pas fragiliser ces structures. Il avait pour but de comprendre les relations entre les fondations des autres éléments bâtis à proximité et de mettre en évidence les niveaux sur lesquels ils reposent. Ce sondage, conduit en $G 15$, a permis de mettre au jour les fondations des structures $G 14$ et $G 15$. Leur profondeur est d'un mètre, qu'il s'agisse de la structure $G 14$, parfaitement conservée (photo 20), ou de la structure G 15, qui a été détruite (photo 19). Toutes les autres structures reposent sur des fondations de type similaire, exceptée la structure H 16, dont la profondeur de fondation est bien moindre (environ $30 \mathrm{~cm}$ ), et dont la base en galets forme un arrondi assez marqué. Cette structure semble correspondre à un ajout postérieur : les blocs de latérite sont de moindre qualité, ils sont moins bien taillés et de dimensions inférieures à celles des autres structures. 
Photos 18 à 21 (de haut en bas et de gauche à droite). Vues des fondations des structures K 14 (2014), G 15, G 14 et de celles, différentes, de la structure H 16, 2014 et 2017.

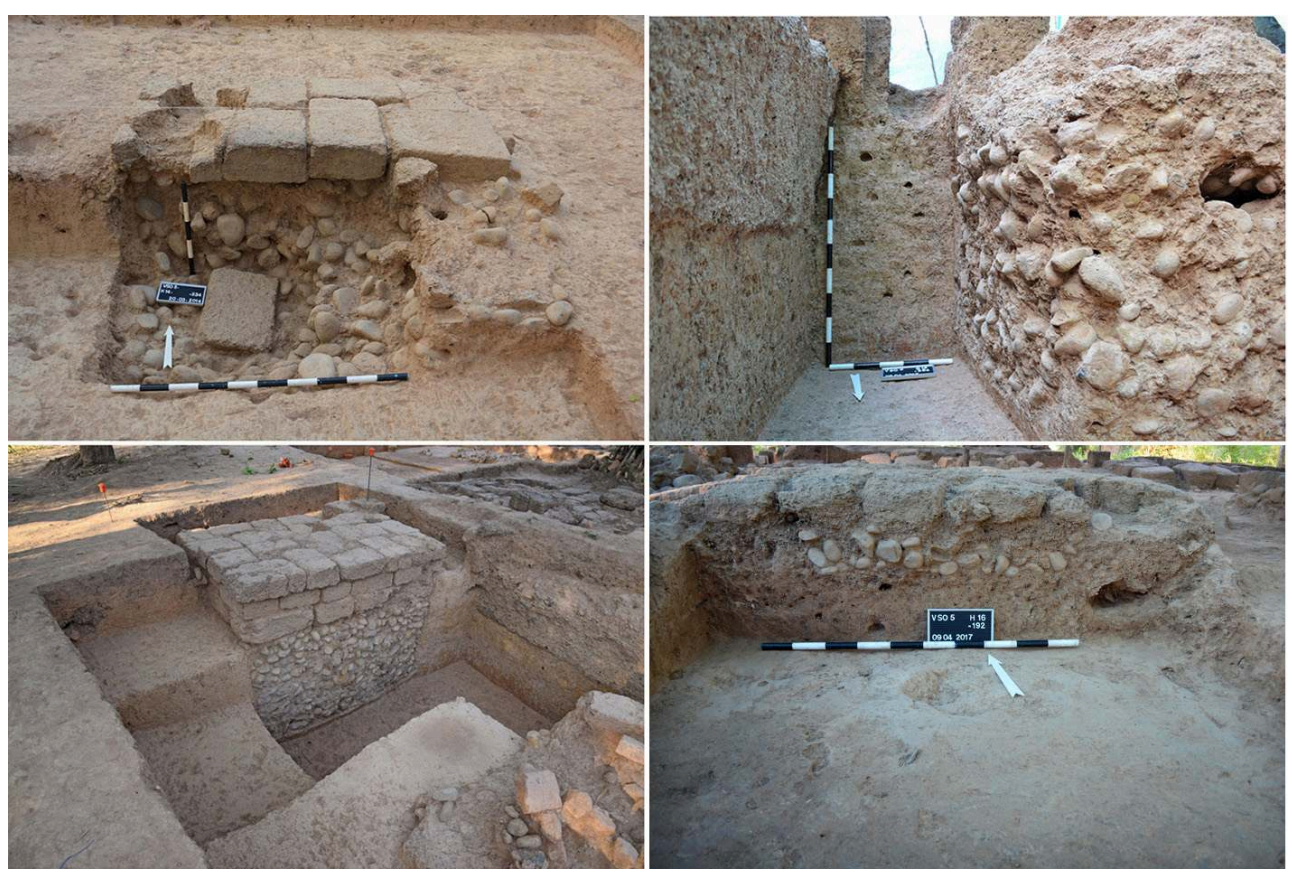

C. Hawixbrock.

Fig. 5. Élévation sud de la structure G 14 et de ses fondations en galets. Dessin J.-P. Message. 2017.

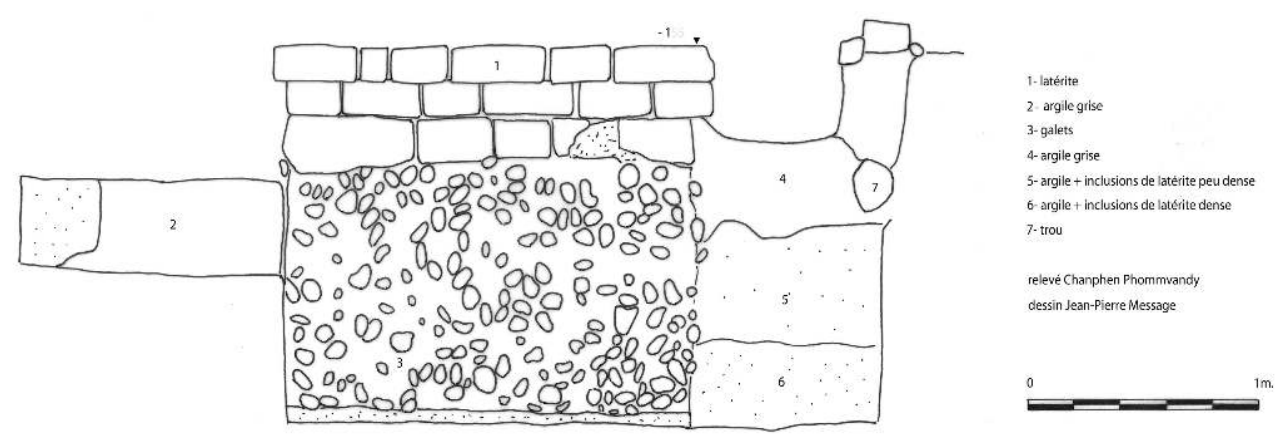

MAFSL.

\section{L'élévation des structures}

Une seule structure (H 15) est formée de quatre lits de blocs de latérite superposés, les autres en ont conservé de un à trois. Les blocs sont de dimensions variables, en moyenne $50 \mathrm{~cm}$ de longueur pour une largeur de $35 \mathrm{~cm}$, et une épaisseur de $15-20 \mathrm{~cm}$, sauf pour les blocs carrés qui marquent le centre des motifs «en roue» du dispositif d'assemblage. La hauteur des structures varie par conséquent entre quelque 20 et $70 \mathrm{~cm}$. Certaines des structures bien conservées (K 16, G 14, G 16 et G 17) ont subi des démontages partiels de leur lit supérieur à une date indéterminée. 
Photos 22 à 24 (de haut en bas et de gauche à droite). Vues des structures G 16, G 17, G 14 (au premier plan, en bas sur le cliché) avec lit supérieur de latérite partiellement démonté. 2017.
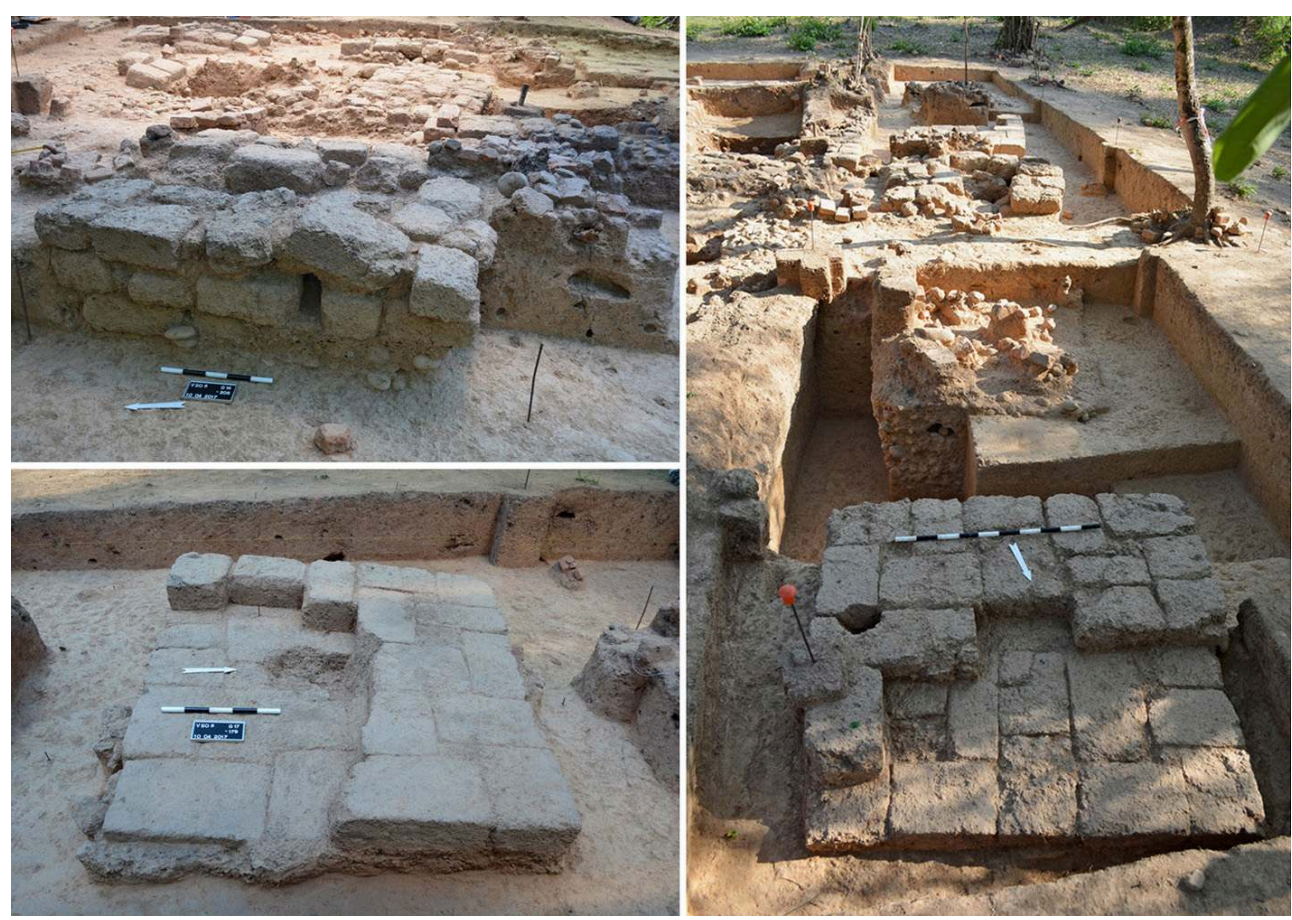

C. Hawixbrock.

Curieusement, ces démontages affectent systématiquement une moitié de structure, une initiative qui reste inexpliquée. Seule la structure J 15 est bien conservée mais elle n'est formée que d'un seul lit de latérite. Ces perturbations sont peut-être le fait de chercheurs de trésors. Ces mêmes pilleurs en ont détruit certaines entièrement puisqu'une partie au moins des blocs qui composaient ces dernières ont été retrouvés à proximité immédiate de ces structures, affleurant la surface actuelle ou même en surface ( $\mathrm{G} 16$ à G 18, H 18). S'il est difficile de dater ces pillages, certains ont eu lieu récemment puisqu'une chaîne en métal doré de fabrication récente a été retrouvée à $35 \mathrm{~cm}$ de profondeur par rapport à la surface actuelle lors du sondage en $\mathrm{G} 15$.

Les blocs de latérite qui composent ces structures ne sont pas tous de la même qualité : ceux des structures G 14, G 16, G 17, H 15, J 15, J 17, K 14 et K 15 sont taillés avec soin et parfaitement jointoyés, alors que les autres montrent des blocs plus grossiers, avec des angles arrondis au lieu d'angles droits parfaits, et s'épaufrent facilement. La qualité du matériau en est en partie responsable mais on peut remarquer que le soin apporté à leur aménagement est moindre.

38 Ces différences posent la question de la reprise possible, à une date plus récente, du plan général initial de la composition par un ajout de structures. Nous avons souligné plus haut que le même soin n'avait pas toujours été apporté à l'aménagement des fondations (les structures $\mathrm{H} 16$ et J 16 en particulier et dans une moindre mesure la structure J 15/16 - à cheval sur les deux carrés).

Il n'est pas certain qu'il manque des lits aux structures bien conservées: la comparaison des niveaux relatifs des faces supérieures des structures indique une variation de $23 \mathrm{~cm}$ au plus (c'est entre les structures J 15/16 et $\mathrm{G} 16$ que l'écart est le plus élevé). Ailleurs, les niveaux sont identiques ou varient tout au plus de 9 à $10 \mathrm{~cm}$. 
Compte tenu qu'elles ont toutes "bougé » sur le plan horizontal en raison de perturbations naturelles (pluies de mousson, racines d'arbres, termitières) et que la surface des blocs n'est pas rigoureusement plane, nous pensons qu'il ne manque nulle part de lit complet de blocs de latérite. La variation du nombre de lits pour chaque structure serait donc volontaire.

\section{Quelques hypothèses sur la destination des structures} ne sont pas nécessaires pour supporter entre un et quatre lits de blocs de latérite de taille réduite. Beaucoup de soin a donc été apporté à la construction de ces piles. Les fondations en galets apparaissent d'ordinaire dans des bâtiments à usage religieux en matériaux permanents, tels les tours sanctuaires, nécessitant des fondations solides et profondes. Si ces piles ne sont pas les vestiges de bâtiments en briques, elles pourraient avoir porté un (ou des) bâtiments en bois d'une taille imposante et d'un poids conséquent. Par ailleurs, la latérite est rarement utilisée par les Khmers de l'époque préangkorienne pour bâtir leurs sanctuaires. Peut-on alors en conclure que ce choix est lié à une destination différente des bâtiments, à usage laïc plutôt que religieux ? Doit-on supposer, pour ce site aussi une influence mon (Dvāravatī), voire cam dans l'adoption de ce matériau? La question reste ouverte pour le moment.

\section{Les trous de poteaux}

La quasi-totalité des structures mises au jour sont percées de trous de poteaux, de diamètres et profondeurs très variables. Dix-sept trous de poteaux ont été identifiés 
avec certitude, alors que cinq sont supposés (voir les tentatives de restitution, fig. $\mathbf{6}$ et 7).

D'une circonférence importante, certains s'ancrent profondément dans les structures, traversant les lits successifs de latérite (H 15, G 16 et 17) en s'enfonçant parfois dans les fondations en galets ( $\mathrm{G} 16)$. D'autres sont moins profonds ou forment un simple creux dans le lit supérieur de latérite, et sont souvent installés à cheval sur plusieurs blocs (K 14, J 17). D'autres encore sont de petite taille (H 15, J 17). Un seul, de dimension réduite, possède des angles droits (J 15). Probablement de forme carrée, il s'appuie pour moitié sur la bordure sud de la structure J 15.

Certaines structures présentent plusieurs trous de poteaux (cf. H 15, J 17, J 15, K 14). Les structures G 14, G 15, G 17, G 18 (?), J 15/16, K 15, K 16 n'en montrent qu'un mais elles sont incomplètes. Une pierre en quart de cercle sur la structure (détruite) G 18 indique qu'elle était probablement percée d'un trou de poteau au moins, sans qu'on puisse le positionner.

Des reprises sont visibles : l'angle nord-ouest de la structure K 14 comporte trois trous de poteaux qui se chevauchent, indiquant soit le remplacement d'un poteau défectueux soit une hésitation quant au choix de l'emplacement exact. Indépendamment de leurs dimensions, les trous de poteaux assez profonds ont une forme en cône inversé. Certains blocs portent encore les traces du ciseau de sculpteur sur leur pourtour. Deux blocs en quart de rond, retrouvés isolés et à distance de leur emplacement d'origine sur les structures $G 16$ et $G 18$, soulèvent la question d'un aménagement prévu pour recevoir des poteaux dès le début de la construction.

Photos 25 à 30 . Quelques exemples de trous de poteaux (de haut en bas et de gauche à droite : J 17, H 15, K 15, G 15, K 14, J 17), 2017.

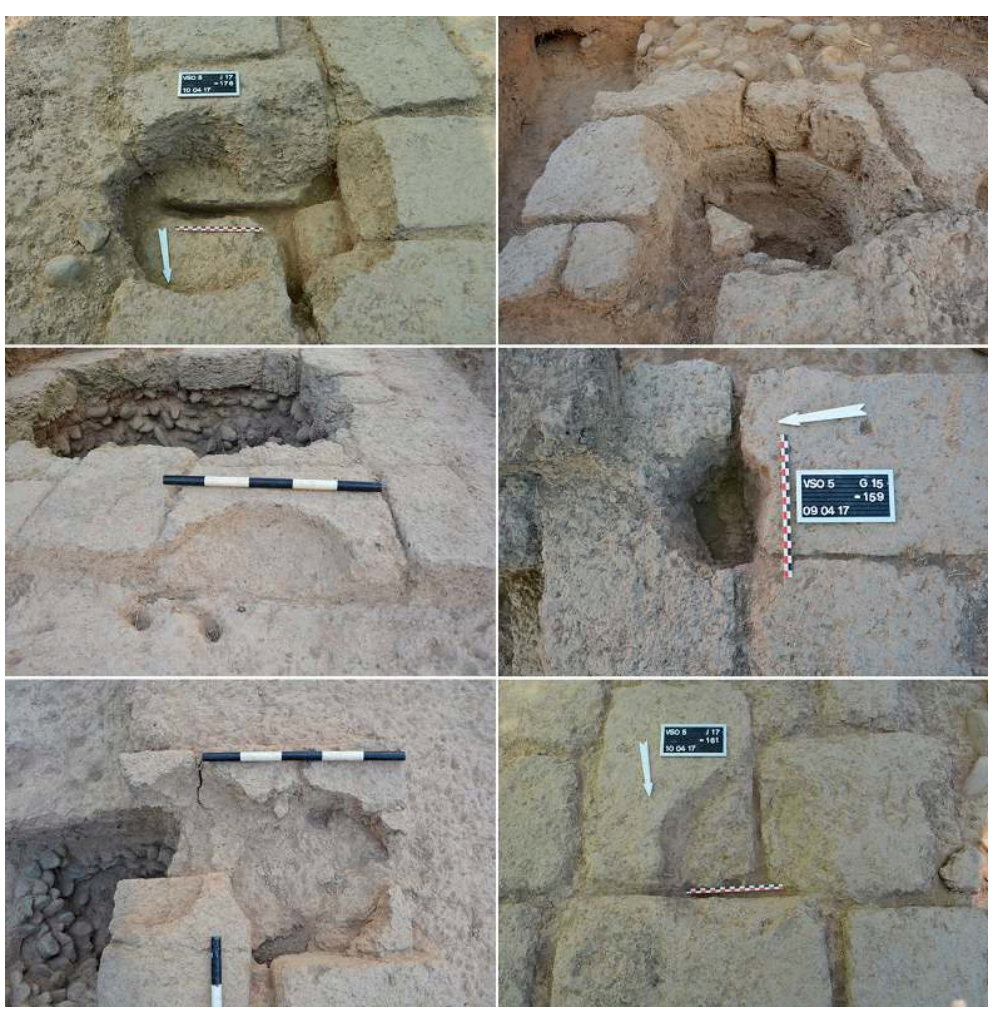

C. Hawixbrock 
Sauf pour la structure G 17, aucun des trous de poteaux n'est centré sur les structures. Ils sont disposés sur les bords des piles et l'un d'eux (K 15) ne repose que pour une faible partie sur la latérite.

51 L'impression laissée suggère la superposition de deux projets de construction qui n'auraient pas été conçus tout à fait en même temps, tels deux calques qui auraient glissé l'un sur l'autre et n'auraient pas été réalignés parfaitement. Il semble en effet que les structures en latérite ont été construites dans un premier temps, peut-être pas la totalité d'entre elles comme nous l'avions supposé de prime abord. Dans un deuxième temps, les trous de poteaux auraient été creusés dans les blocs. Creuser un bloc de latérite qui a parfaitement séché n'est pas aisé. Dans la majorité des cas, lorsqu'il a atteint sa dureté maximale, il se brise imparfaitement en suivant les grains ferreux qui entrent dans sa composition. Nous suggérons par conséquent, au moins pour ceux qui portent des traces de coups de ciseaux, que le percement des trous de poteaux a été réalisé peu après l'élévation des structures.

Replacés sur le plan général, la disposition de ces poteaux est hésitante, bien que des alignements se dessinent. Toutefois, la forme du ou des bâtiments n'apparaît pas clairement. Aucun élément de bois n'a été conservé en place mais il est possible que les édifices aient été démontés au lieu de s'effondrer sur eux-mêmes lors de leur abandon. Par ailleurs, aucune trace d'incendie majeur n'a été repérée. Des petits fragments de charbons ont été retrouvés dans plusieurs sondages à plusieurs niveaux, sans qu'on puisse conclure qu'il s'agit de restes de foyers (analyses en cours).

Fig. 6 et 7 . Vues cavalières du bâtiment et des pilotis identifiés avec certitude (en haut) et de l'ensemble des poteaux, avérés et supposés (en bas), 2017.
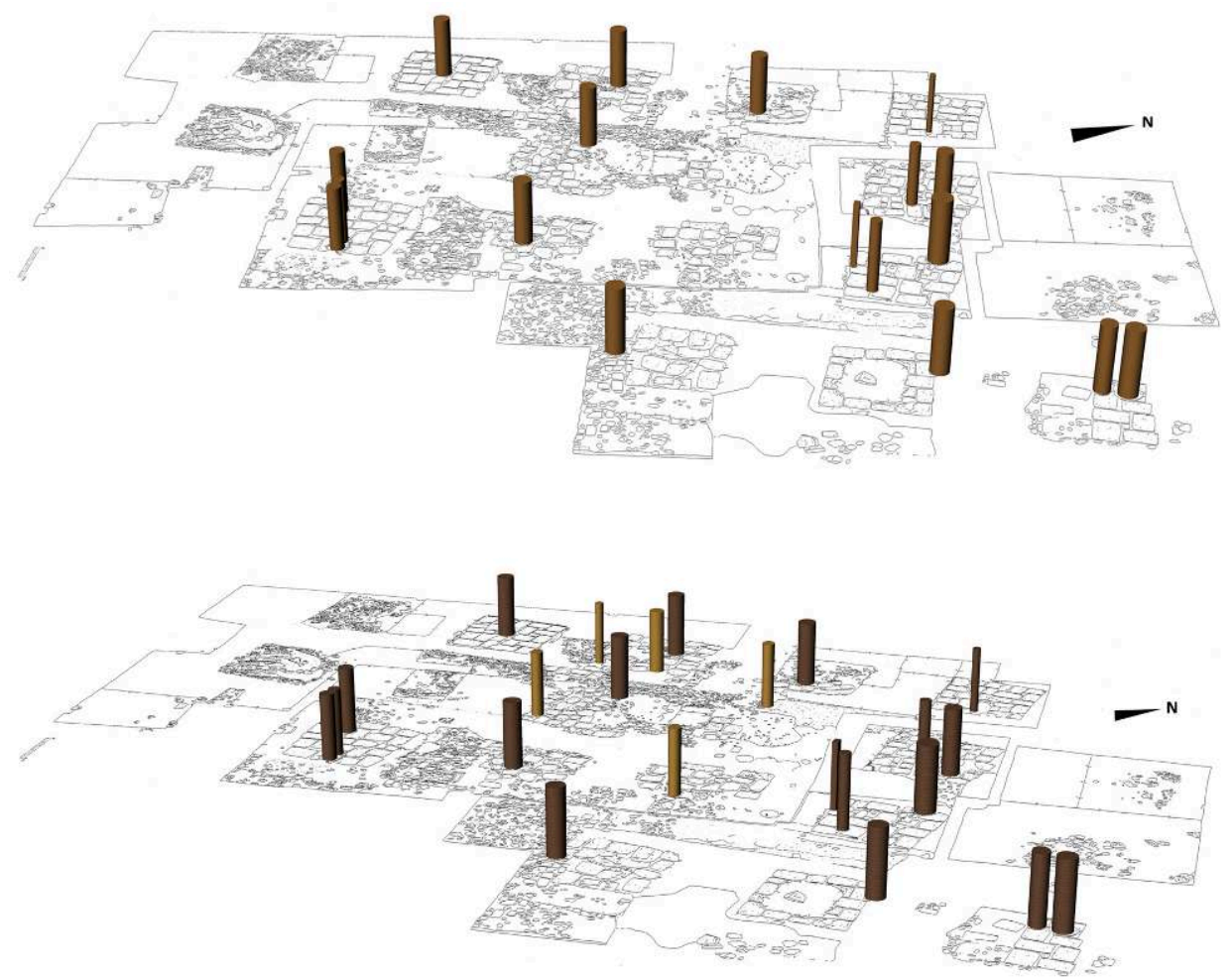

Dessin : David Bazin ; MAFSL. 


\section{Le plan d'ensemble}

53 Il est en tout cas manifeste que le plan d'origine a subi plusieurs modifications qui restent difficiles à dater précisément à ce stade des recherches. On peut tout au plus affirmer que ces transformations se sont déroulées durant la période préangkorienne, puisque la céramique mise au jour appartient quasi exclusivement à cette époque.

Par ailleurs, le site a connu une occupation suffisamment longue pour que, dans un dernier état, un pavement discontinu fait de morceaux de grosses briques préangkoriennes vienne recouvrir une partie des structures et des trous de poteaux. Ces aménagements se situent donc à un moment où une section du bâti n'était plus en service.

L'étude de l'espace central (situé dans les lignes des carrés H et J) renforce l'impression d'une possible modification du projet initial. Deux banquettes de graviers de latérite compactés et de galets, parallèles et orientées nord/sud, séparent les structures des carrés situés en $\mathrm{H}$ et $\mathrm{J}$ de ceux situés en $\mathrm{G}$ et $\mathrm{K}$. La banquette ouest a été dégagée sur près de 11 mètres, la banquette est l'avait été sur un peu plus de 4 mètres lors des fouilles de 2014. Cette dernière disparaît sous le pavement de briques postérieur. Leur composition est semblable dans leur tronçon nord: graviers de latérite rapportés, progressivement remplacés par des galets.

Photos 31 et 32. Vues de la partie nord de la banquette de latérite ouest et du niveau sur lequel elle repose, 2017.

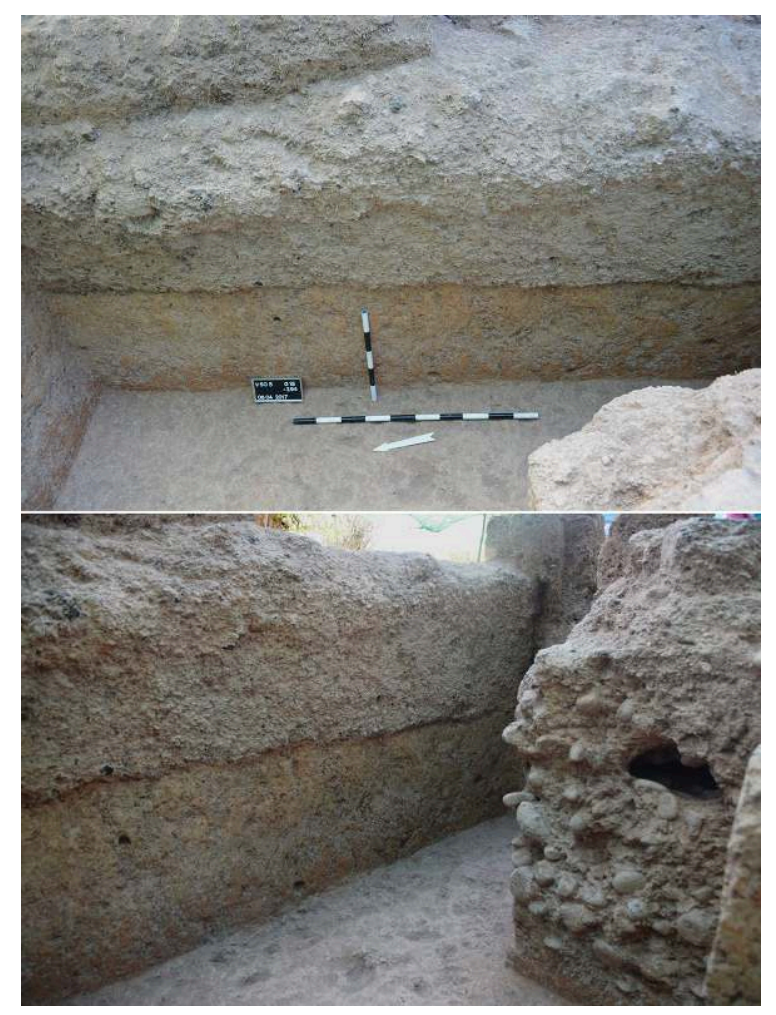

C. Hawixbrock. 
Photos 33 et 34 . Vues de la partie sud de la banquette de latérite ouest et des galets qui la recouvre, 2017.

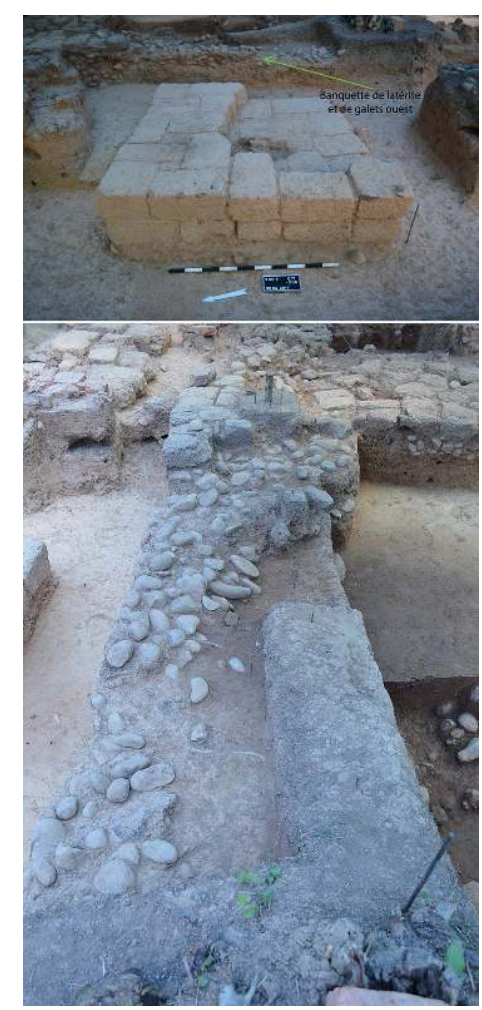

C. Hawixbrock.

Fig. 8. G 27, élévation ouest, partie sud de la banquette de latérite, 2017.

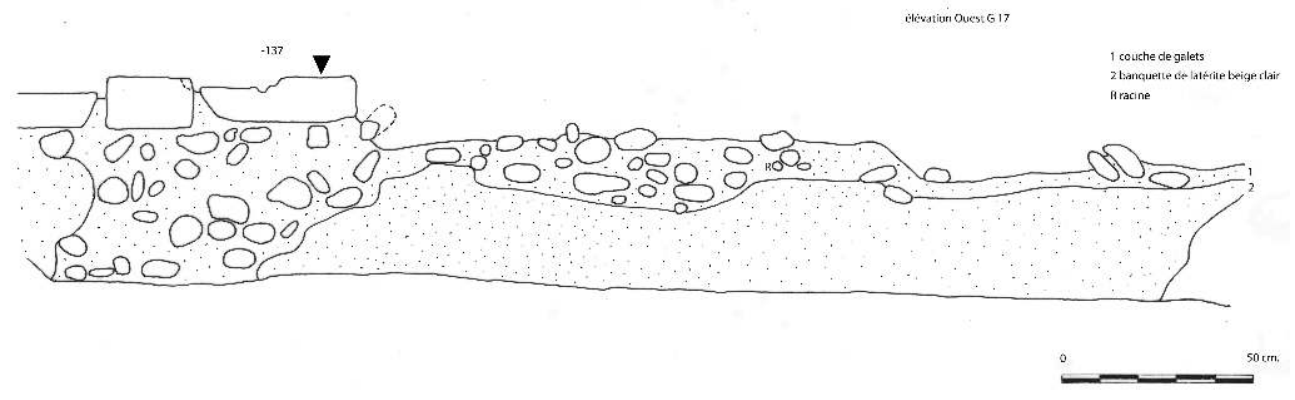

Dessin J.-P. Message ; MAFSL. 
Fig. 9. Plan général avec mise en évidence des trous de poteaux et des banquettes de latérite, 2017.

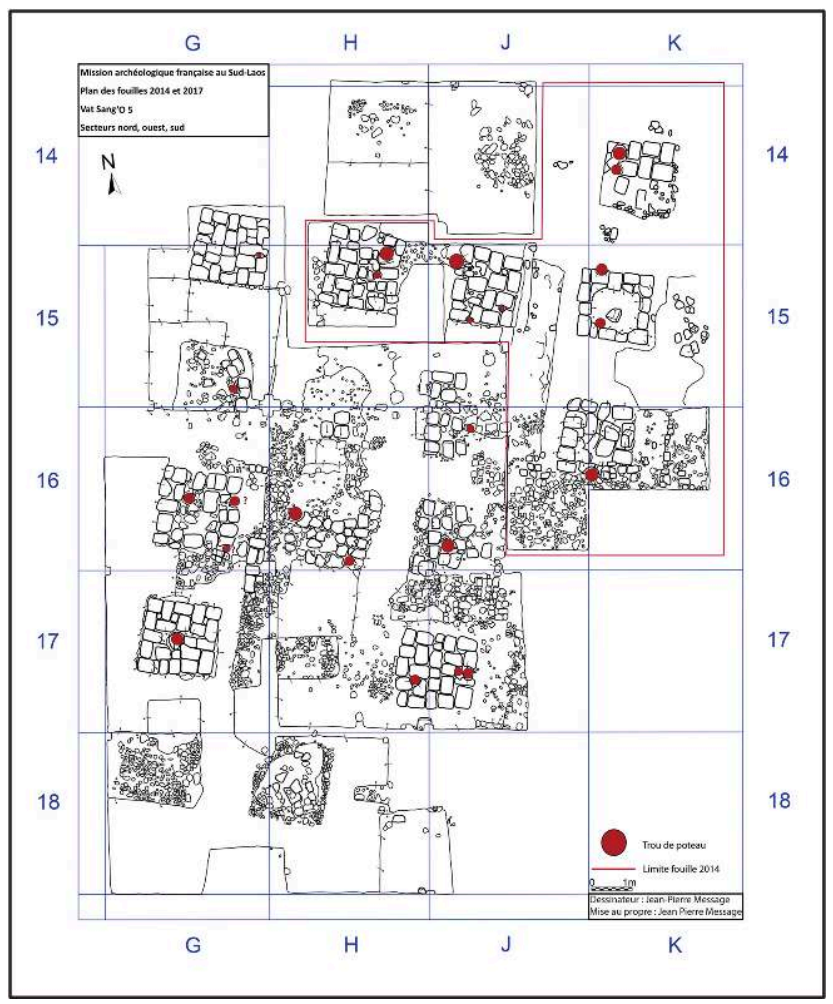

Dessin J.-P. Message, mise au net, D. Bazin ; MAFSL.

Seule la banquette ouest a été fouillée durant la campagne 2017. Le sondage en profondeur pratiqué en $\mathrm{G} 15$ a permis de révéler sa base. Celle-ci est située à $50 \mathrm{~cm}$ au-dessus de la base des fondations des deux structures G 14 et $\mathrm{G} 15$. Elle repose sur le substrat sablo-argileux qui constitue la levée de terre. Une tranchée a été nécessaire pour l'installer. Son fond était plan puisque sa base est horizontale. La composition de cette banquette n'est pas homogène : entre le carré $\mathrm{H} 16$ et jusqu'au carré $G 17$, où elle se termine, la latérite broyée (sans élément anthropique visible) est remplacée progressivement, verticalement et horizontalement, par des galets. La face supérieure des deux banquettes affleure la surface actuelle, les plaçant ainsi au même niveau que la partie supérieure des structures de latérite. La banquette orientale, quant à elle, s'arrête net verticalement dans le carré J 15 (fouilles 2014).

Ces deux banquettes n'étaient pas reliées à des banquettes perpendiculaires qui auraient ainsi formé un rectangle fermé. Ceci a été confirmé lors des fouilles conduites en 2018. En l'état, elles circonscrivent une zone de 12 mètres de long pour 8 mètres de large, ce qui correspond aux dimensions habituelles d'un sanctuaire préangkorien (du moins à $\mathrm{Vat} \mathrm{Phu}$ ).

En admettant qu'il s'agit là encore de fondations de structures disparues, seuls quatre blocs de latérite alignés posés sur les galets ( $(\mathrm{16} / \mathrm{G} 17)$ en témoignent. Elles sont indépendantes des structures carrées, dont elles sont espacées de quelques centimètres à peine. Doit-on alors supposer qu'elles supportaient d'autres constructions en matériaux périssables? Ces banquettes suscitent pour le moment plus d'interrogations que de réponses. Elles isolent l'espace médian et c'est justement dans cette zone que les structures de latérite mises au jour sont moins bien construites, plus «légères » en 
quelque sorte. C'est également là ( $\mathrm{H} 15, \mathrm{H} 16, \mathrm{~J} 15, \mathrm{~J} 16)$ que le matériel céramique est concentré.

En $\mathrm{H} 16$, une poche d'environ $0,60 \mathrm{~m} \times 1 \mathrm{~m}$, peu profonde ( $15 \mathrm{~cm}$ environ), aux limites floues, est bien visible grâce à la coloration rougeâtre de son remplissage de terre argileuse (coloration due à des fragments de briques décomposées). Elle a livré de multiples fragments qui recollent, permettant la restitution de nombreuses formes de céramiques.

Il semble donc que l'espace domestique du lieu était situé dans cette aire, étayant l'hypothèse d'un habitat à cet endroit-là.

Photos 35 et 36. Vues de la poche riche en céramiques en H 16, avant sa fouille, 2017.

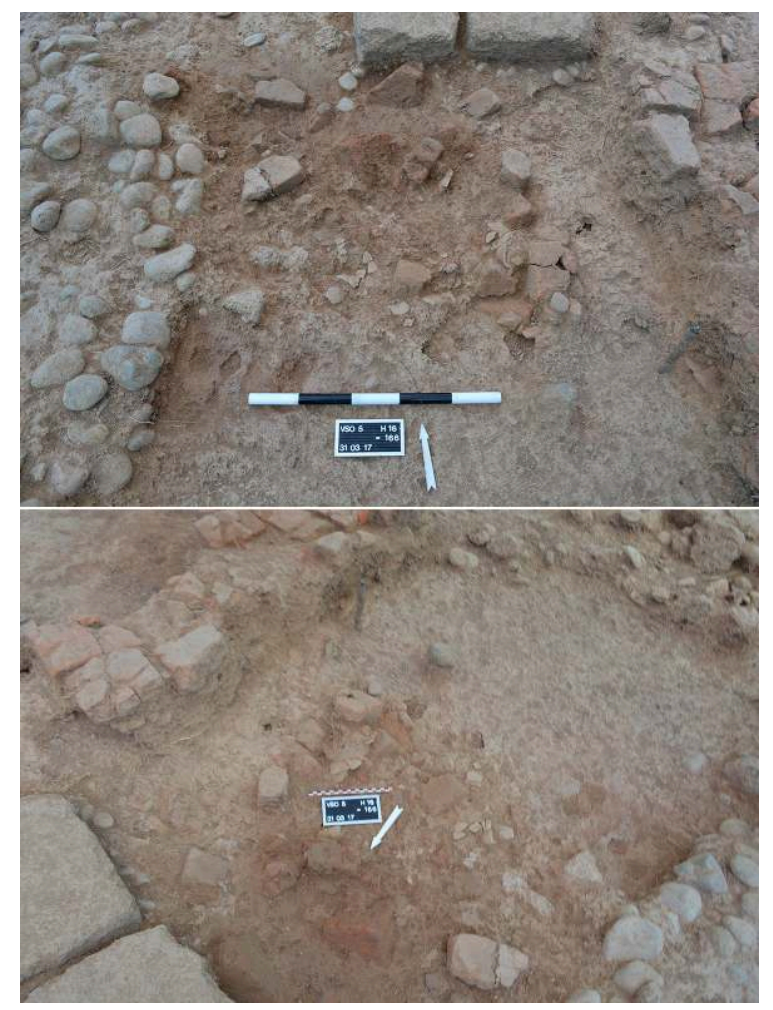

C. Hawixbrock.

61 Nous suggérons que les structures présentes au centre ont été rajoutées postérieurement aux autres structures, à un moment où, peut-être, les banquettes en latérite n'avaient plus d'usage. Ces banquettes pourraient avoir servi de supports à des éléments permettant de surélever l'espace médian pour former une composition à degrés mais les preuves manquent encore.

On pourrait éventuellement penser à une aire de crémation mais outre le fait qu'aucun fragment d'ossement n'a été retrouvé - et qu'il n'y a aucune trace de foyers - la surface délimitée est soit trop vaste pour une unique incinération, soit plutôt étroite pour des incinérations multiples. On peut opposer à cela que les ossements sont recueillis et que les moussons successives effacent les traces des foyers mais cette hypothèse ne s'accorde guère avec la présence des structures carrées externes dont l'utilité ne s'explique pas dans ce cas, de même que celle des poteaux tels qu'ils sont placés. En 
outre, lorsque la latérite est soumise au feu, sa couleur brune évolue vers le rouge, ce qui n'est pas le cas ici.

63 La quantité de céramiques retrouvée sur le site, en particulier dans la partie médiane du dispositif (carrés $\mathrm{H} 16$ et $\mathrm{J}$ 16), invite à écarter cette hypothèse.

Des rejets de pillages visibles en surface isolaient déjà cet espace et nous nous attendions avant de fouiller à mettre au jour une structure centrale entourée des structures carrées périphériques. Une fosse a bien été creusée là par des pilleurs et de la terre végétale noire est venue combler leur fosse de pillage (carré H 17). Un sondage réalisé au centre de cette fosse n'a révélé que des niveaux où le rejet de galets bouleversés se densifie dans le fond, mêlés à quelques fragments de briques, sans que les vestiges d'une quelconque structure soient mis au jour.

L'arrêt de fouille a été décidé alors que la couche de galets devenait importante et des carottages pratiqués avec une tarière n'ont pas donné d'informations complémentaires, la tarière ne mettant au jour que la terre qui compose la levée. On peut se demander pourquoi les pilleurs ont décidé de creuser à cet endroit précis, à moins qu'ils n'aient découvert quelque objet précieux les incitant à penser qu'il n'était pas isolé. Les pilleurs semblent pourtant avoir abandonné leur creusement assez rapidement.

Photos 37 et 38 . Vues du pavement erratique de briques de l'état d'occupation supérieur (carrés H 16, J 17), 2017 et 2014.

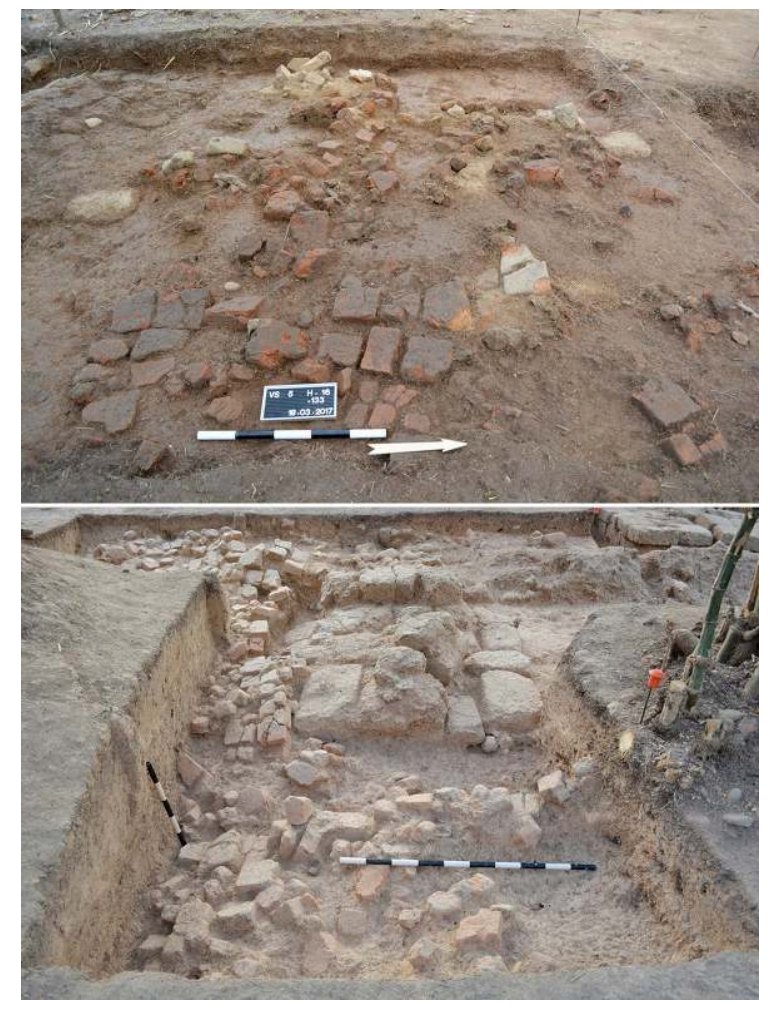

C. Hawixbrock et M. Santoni. 
Photos 39 à 42. Vues générales des fouilles, 2017.

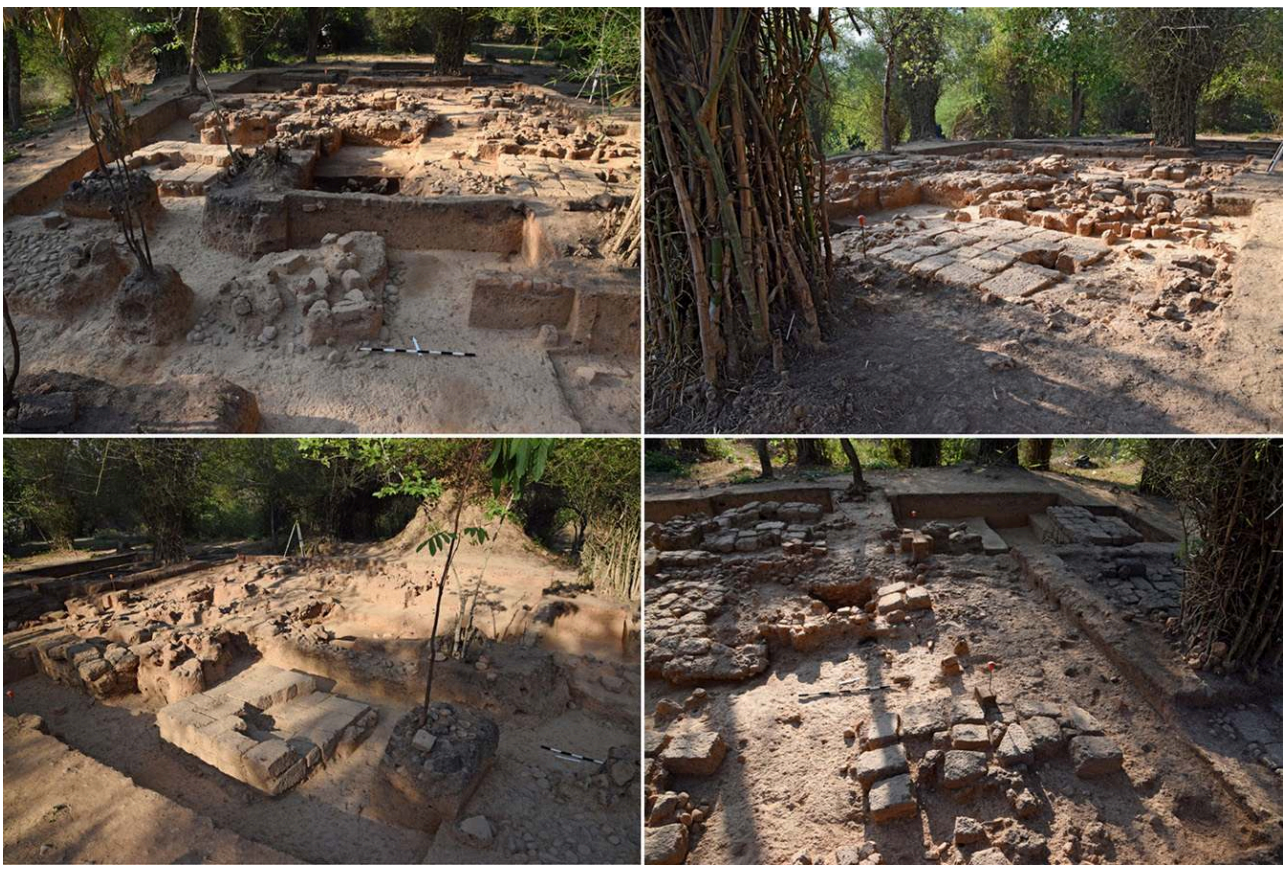

C. Hawixbrock

\section{Les campagnes de fouilles 2018 et 2020}

Ces deux campagnes ont eu pour objectifs de :

- Compléter le plan de ce bâtiment par des sondages et tranchées réalisés sur les côtés nord, est et ouest du bâtiment et de déterminer si possible son accès principal.

- Vérifier la cohérence des éléments d'organisation du bâtiment révélés partiellement en 2017, en particulier l'existence des banquettes en latérite qui signalent manifestement un espace central (à vocation domestique ?) à l'intérieur du bâtiment.

- D'effectuer un nettoyage minutieux de l'ensemble de la levée afin de mettre en évidence la microtopographie de la zone débouchant sur la possibilité d'une sectorisation de l'espace, secteurs qui feront l'objet de futures fouilles.

- De vérifier la présence d'autres aménagements dans le prolongement sud de la levée. 
Fig. 10. Topographie de la levée de Vat Sang'O 5 avec l'emplacement des fouilles 2014 (en rouge), 2017 (en bleu) et 2018 (en vert), 2020.

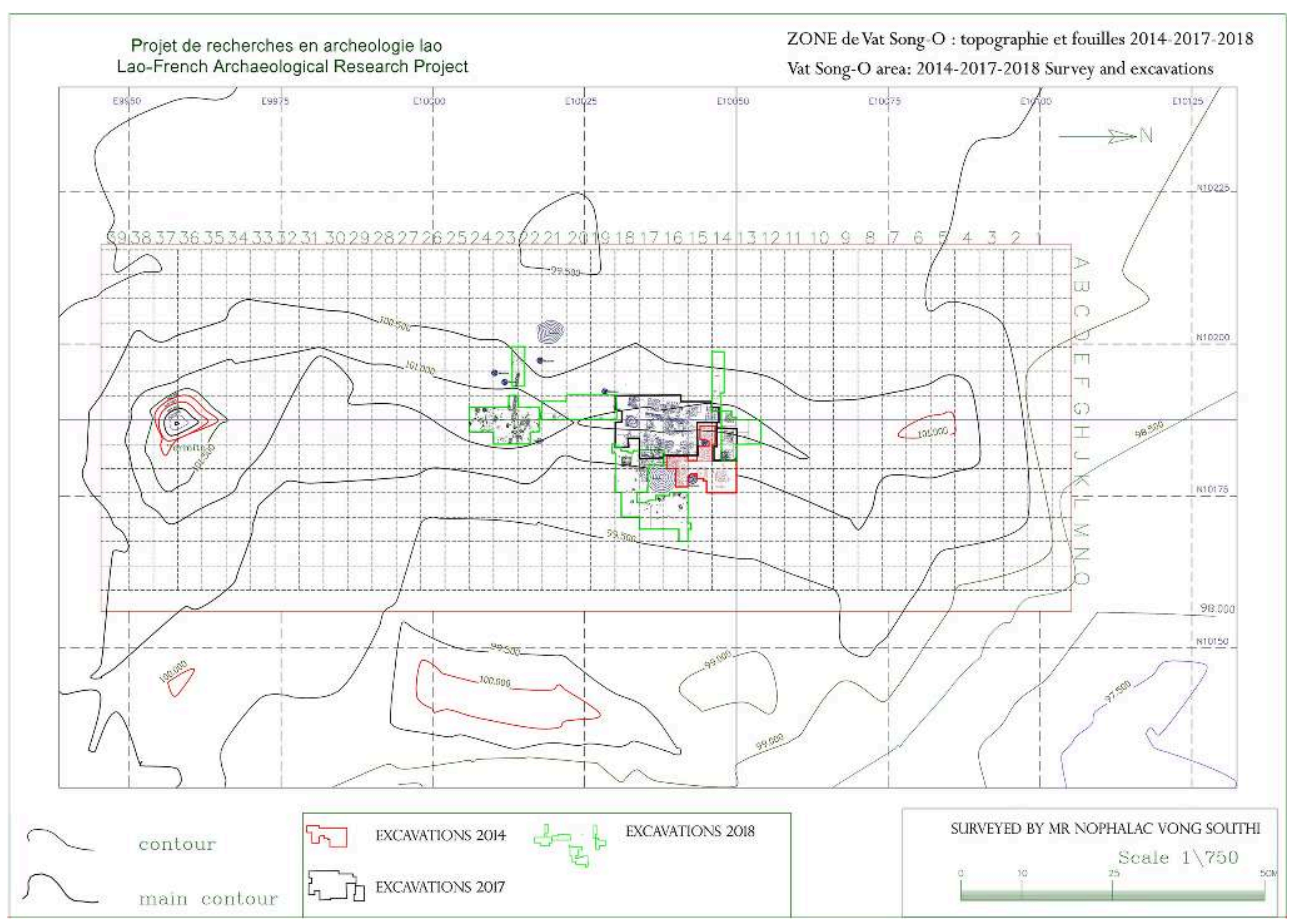

MAFSL.

Fig. 11. Plan d'ensemble des zones fouillées en 2014, 2017 et 2018, 2019.

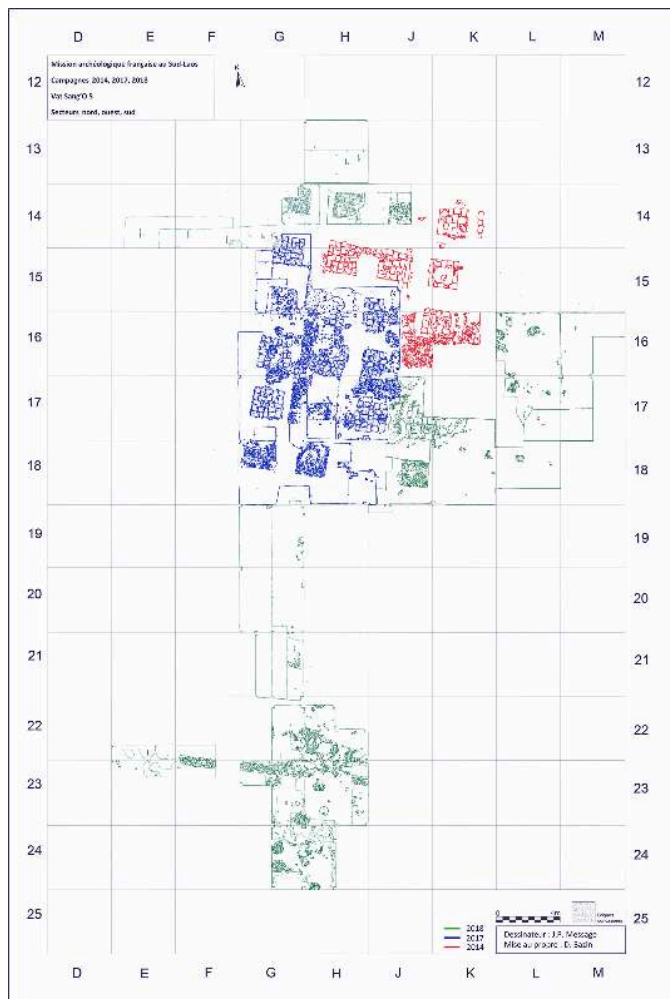

MAFSL. 


\section{Le bâtiment « de haut rang »} effectués ne permettaient pas d'y confirmer la présence de structures semblables à celles décrites ci-dessus. D'une manière générale, les deux extrémités nord et sud du bâtiment sont plus endommagées. Trois sondages ont été réalisés et partiellement réouverts dans les carrés $\mathrm{G} / \mathrm{H} / \mathrm{J} 14$. Les fondations caractéristiques des piles de latérite, composées de sable damé et de galets ont pu être mises au jour sous les amas de blocs de latérite désorganisés découverts lors de la campagne précédente ${ }^{35}$. Elles confirment l'alignement nord des piles du bâtiment. Un second sondage a été ouvert en $\mathrm{G} / \mathrm{H} 13$, afin de vérifier l'existence éventuelle d'une autre rangée de piles en latérite. Il s'est révélé négatif. Très peu de matériel céramique et quelques charbons y ont été mis au jour. Des vérifications à la tarière ont révélé un sol stérile sur plusieurs couches $(80 \mathrm{~cm}$ de profondeur).

Photos 43 à 45. Vues des structures G 14 (à gauche), H 14 (à droite) et J 14 (en bas), 2018.

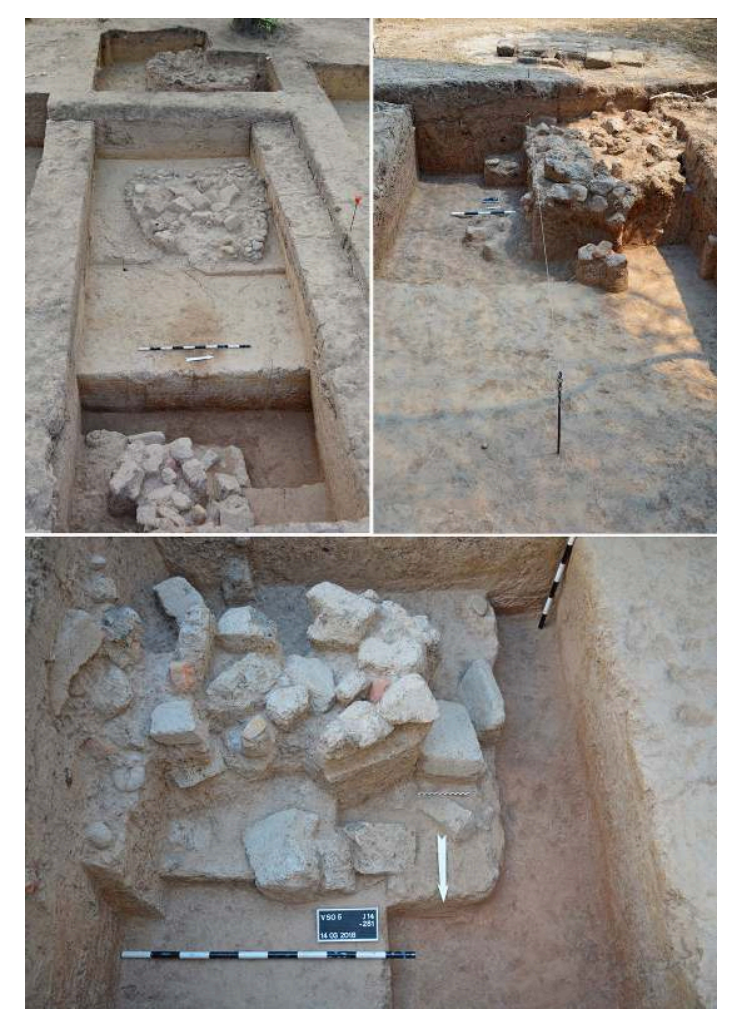

C. Hawixbrock.

Une tranchée a été ouverte sur le côté ouest, dans le prolongement de la limite de fouille de la campagne précédente, entre le carré $\mathrm{G} 15$ et la base de la levée, en $\mathrm{F}$ et $\mathrm{E} 15$. Elle a permis de dégager l'angle nord-ouest de la pile G 14 découverte en 2017. Le haut col quasi-complet d'un vase à pâte fine a été retrouvé à la base des blocs de latérite qui forment le corps de la pile. Cette observation permet de confirmer les constatations effectuées en 2017 montrant que le niveau d'occupation se situe bien à la base des blocs de latérite et que les fondations en galets n'étaient pas visibles mais enterrées. 
Le reste de la tranchée n'a pas livré d'information complémentaire en ce qui concerne le plan du bâtiment. Aucune trace d'un mur de clôture n'a été identifiée. Le matériel céramique est rare. Les couches fouillées correspondent à l'édification de la levée. Des vérifications par carottages confirment la stérilité des couches inférieures.

Photos 46 à 48 . Vues de la tranchée ouest et de la pile $\mathrm{G} 14$ avec la céramique trouvée à sa base, 2018.

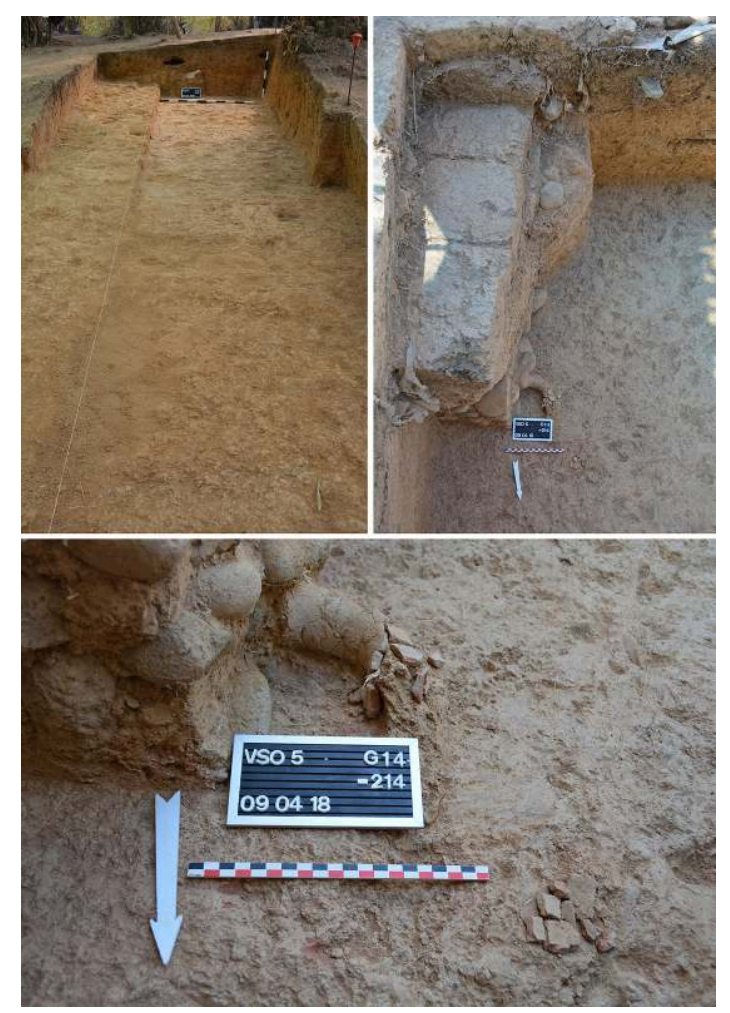

C. Hawixbrock.

71 Du côté est, le carré J 17 a été réouvert afin de vérifier l'existence d'une banquette de latérite associée à celle mise au jour en 2017 dans les carrés H/G 15 à 18 . Les dégagements effectués ont effectivement permis de confirmer l'existence de cette seconde banquette, composée, comme la première, de latérite rapportée non taillée et de galets de rivière, notamment en surface. L'existence d'un espace intérieur, qui a pu être isolé du reste du bâtiment par des éléments en matériaux périssables, se trouve ainsi mis en évidence. Un trou de poteau a par ailleurs été dégagé sur la banquette de latérite, dans le carré J 17.

Ces deux banquettes parallèles ne sont toutefois pas prolongées par des banquettes perpendiculaires. Il n'y a donc pas de rectangle fermé comme l'ont aussi montré les dégagements pratiqués en $\mathrm{G} / \mathrm{H} 14$ (réouverture d'une partie de carré fouillé en 2017). 
Fig. 12. Secteur J/M 16-18. Dessin J.-P. Message, mise au net, D. Bazin. 2018.

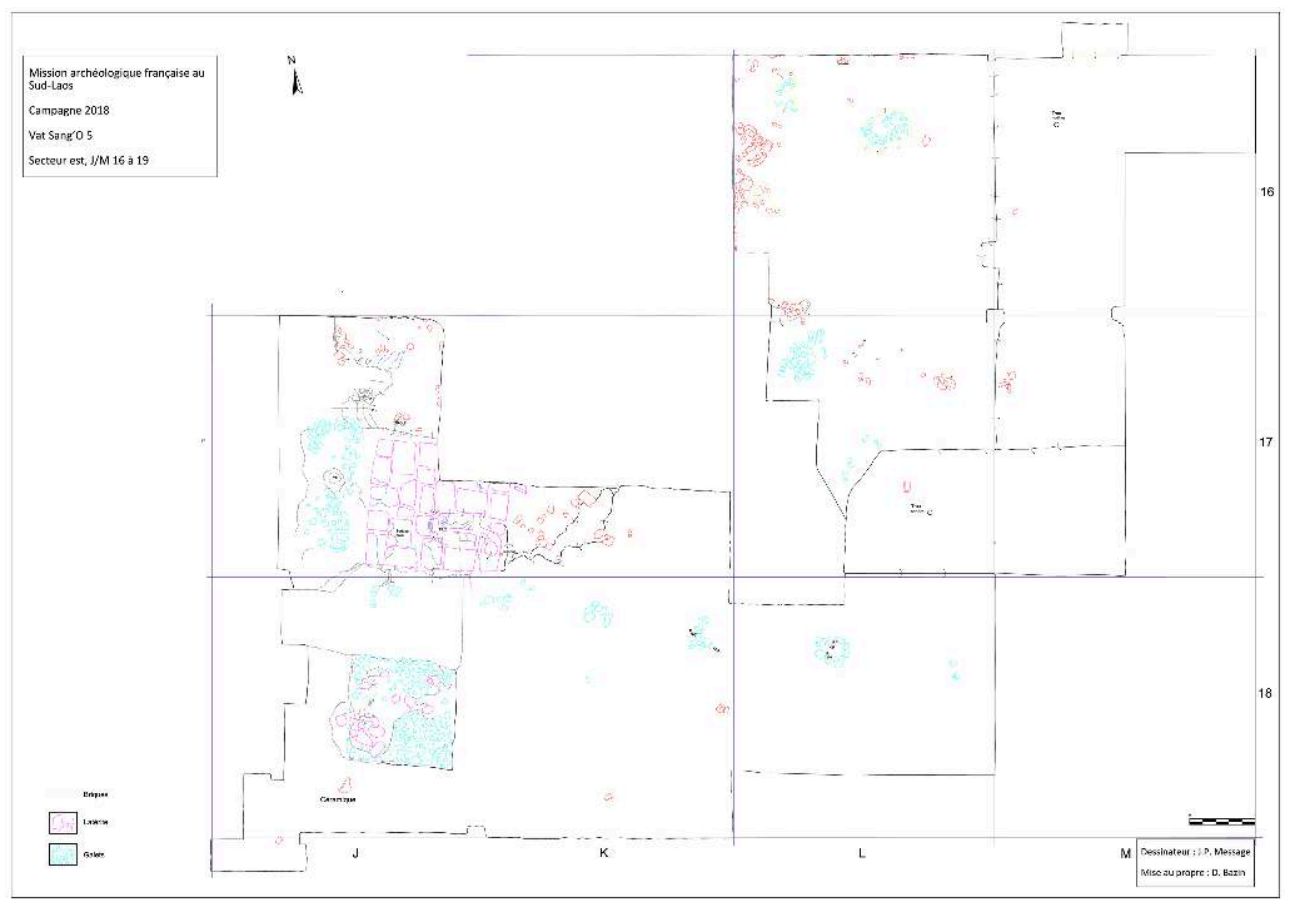

MAFSL.

Photo 49. Au premier plan, vue du niveau d'occupation supérieur avec pavement de briques masquant la pile de latérite située en $\mathrm{J} 16$. À droite sur le cliché, la banquette de latérite est (orientée nord/sud), couverte de galets (visibles au second plan), 2018.

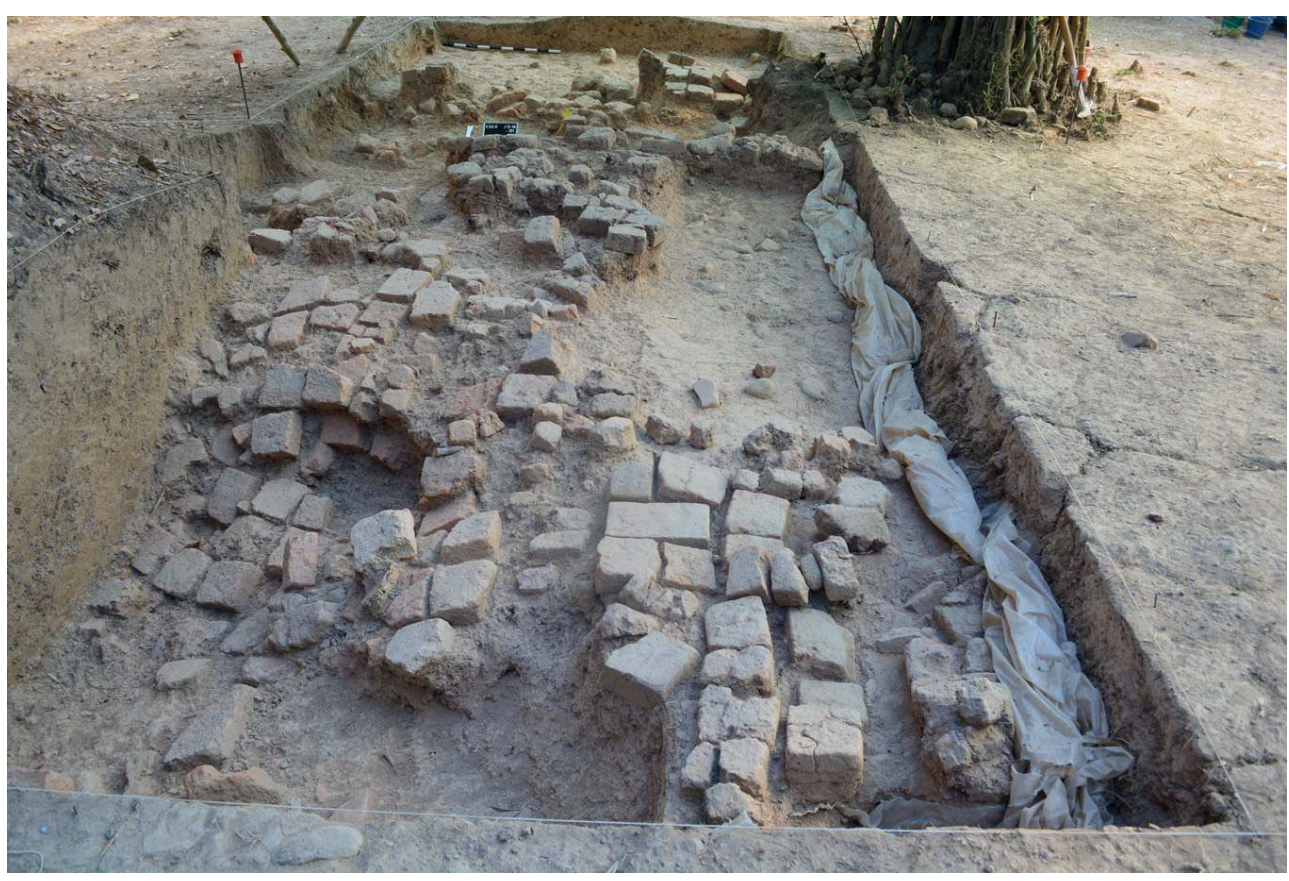

C. Hawixbrock.

L'extension de la fouille vers l'est a permis de mettre au jour la pile J 17, en bon état de conservation (malgré des blocs manquants qui pourraient signaler un poteau) ainsi que 
les vestiges de la pile J 18, dont seules les fondations sont conservées. Cette dernière complète et ferme l'angle sud-est du bâtiment, confirmant là encore son plan général. situe en règle générale dans la largeur.

Photos 50 et 51 . Vues vers le nord des piles $\mathrm{J} 17, \mathrm{~J} 18$ et de l'alignement vers l'est des bases de poteaux, 2018.

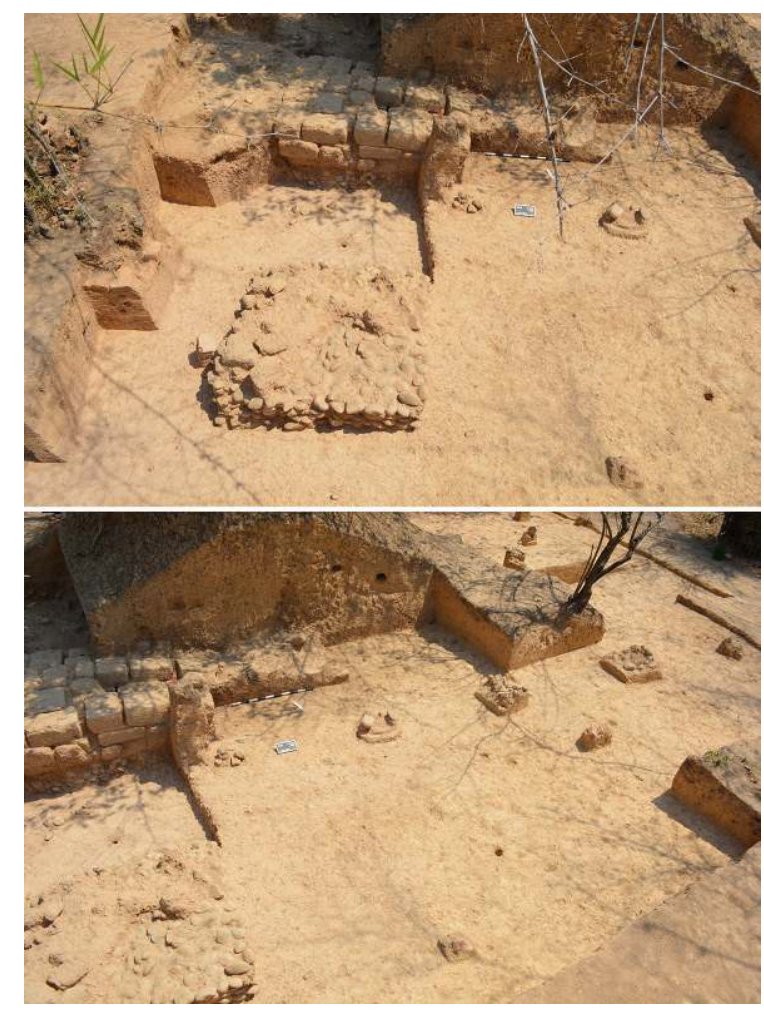

C. Hawixbrock 
Fig. 13. Relevé des carrés $\mathrm{E}$ à H, 22 à 24, 2018.

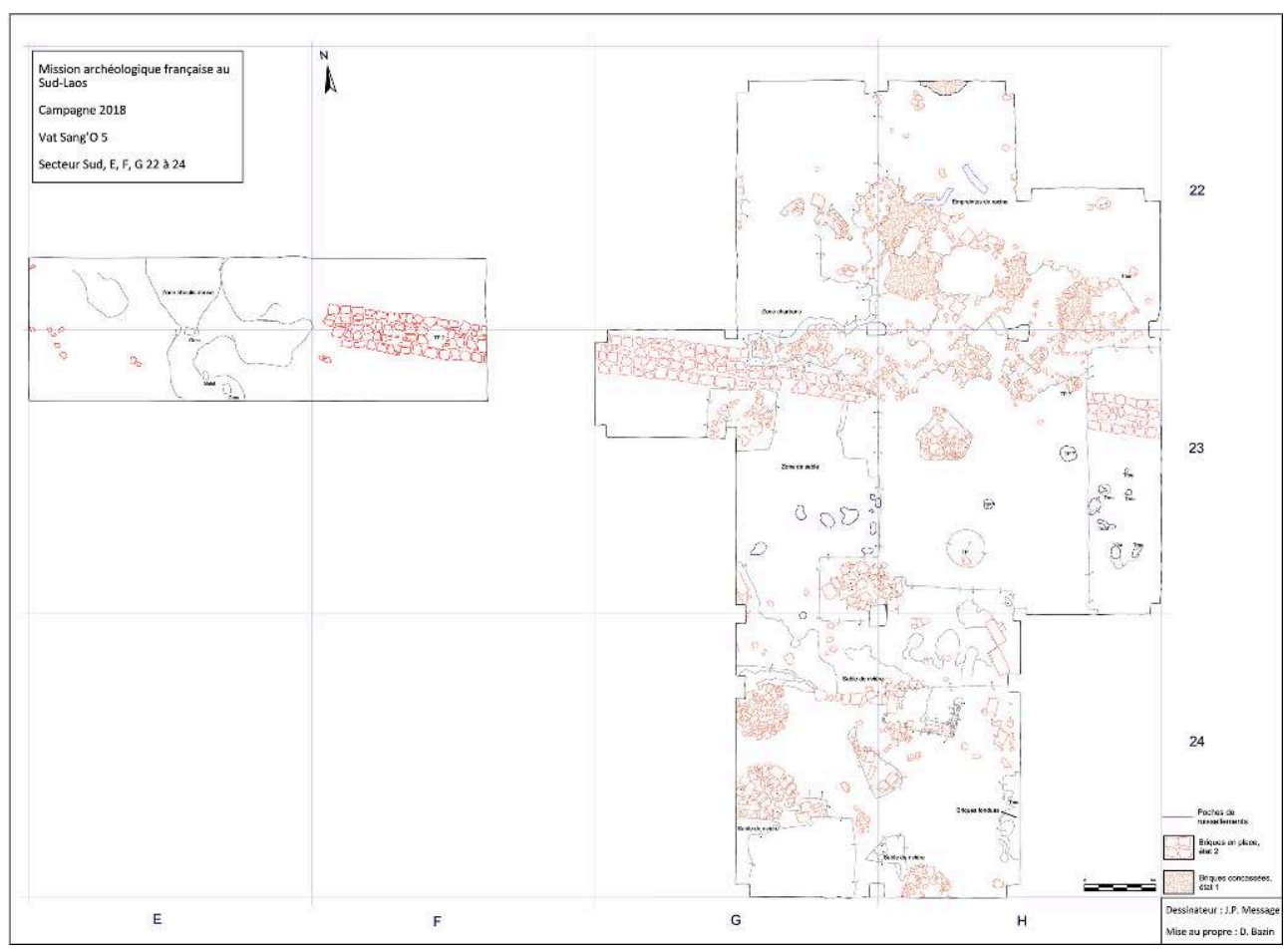

Dessin J.-P. Message, mise au net, D. Bazin ; MAFSL.

Du côté sud, une tranchée d'une largeur comprise entre deux et quatre mètres, a été ouverte dans un premier temps du carré $\mathrm{G} 19$ au carré G 21, selon un axe nord/sud. Malgré la surface accidentée du sol actuel, qui pouvait laisser supposer l'existence de structures construites, elle n'a révélé aucun aménagement sur les niveaux de sol correspondant à celui du bâtiment. Si du matériel céramique est présent dans ces niveaux, il se raréfie en profondeur dans la levée de terre. L'absence de mobilier a conduit à interrompre la fouille de cette tranchée à une profondeur de un mètre.

79 Cette tranchée met néanmoins en évidence la technique d'aménagement de la levée par paliers horizontaux successifs, qui ont été utilisés et aménagés de façon erratique, comme le montrent les quelques briques retrouvées à un mètre de profondeur en $\mathrm{G} 19$ et $G 21$; celles situées dans le carré $G 21$ étant posées sur une mince bande de sable pur formant ce qui semble avoir été un passage provisoire, orienté nord-nord-est/sud-sudest.

L'absence quasi-totale de matériel et de structures bâties en G 19-21 nous a conduit à identifier cet espace comme une cour isolant le bâtiment nord des secteurs de la levée situés plus au sud. 
Photos 52 à 54 . Vues de la tranchée G 19-21 (vers le sud, le nord), 2018.

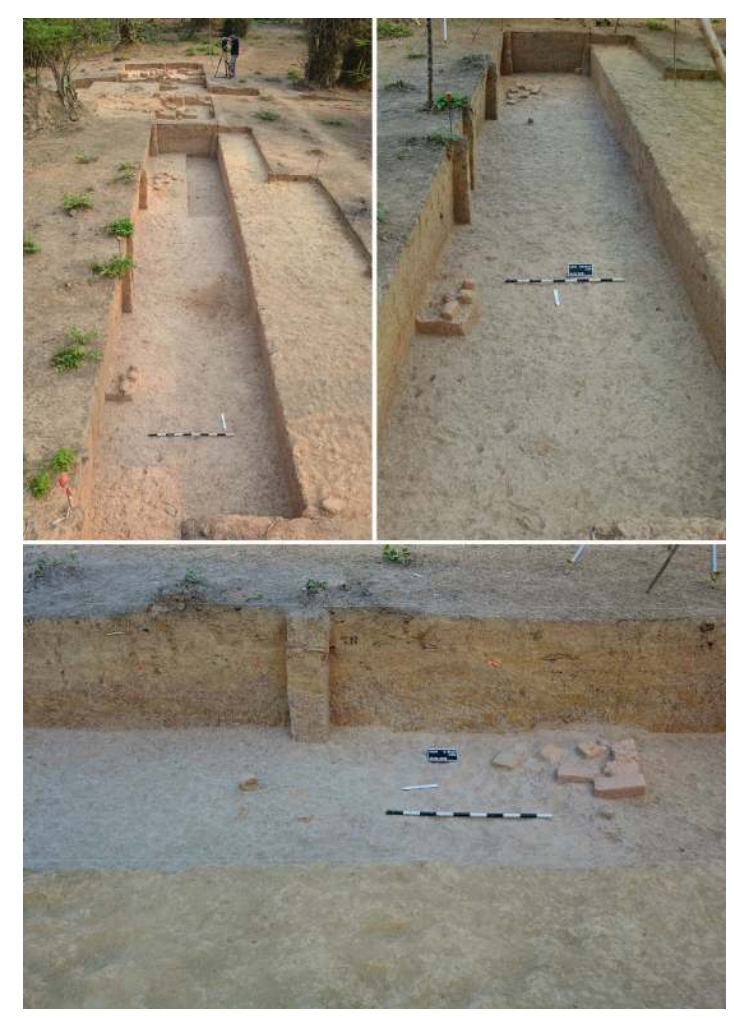

C. Hawixbrock.

81 La tranchée a été poursuivie jusqu'en G 24, puis étendue aux carrés H 22 à 24, avec une extension du côté ouest, en E/F 22-23, en fonction des structures rencontrées.

Un premier niveau d'occupation, situé juste sous la surface du sol de circulation actuel, apparaît dans les carrés G/H 22-23 sur un niveau comparable à celui du pavement discontinu de briques qui recouvre partiellement les piles en latérite du bâtiment. Il s'agit de préparations de sols formées de briques finement concassées disposées les unes contre les autres. Elles dessinent des zones discontinues aux contours irréguliers, reliées ou non entre elles. Cette observation confirme qu'il y a bien un minimum de deux états d'occupation à Vat Sang'O 5. Cette même technique de préparation de sols avait été observée à Vat Sang'O 2, du côté est. Ce niveau recouvrait un état plus ancien (identifié à la tarière).

Ce sondage a révélé de possibles trous de poteaux. L'un d'eux, peu profond mais de grande taille (diam., env. $50 \mathrm{~cm}$ ), est isolé dans le carré $\mathrm{H} 23$. Les autres, de petite taille et profonds d'une quinzaine de centimètres, contenaient des charbons, contrairement au précédent, stérile.

84 Tous ces éléments signalent un habitat ou des ateliers. 
Photo 55. Vue prise par drone de la zone d'habitat domestique (niveaux d'occupation 1 et 2) dans les carrés G/H 22-24. Nord vers la gauche. 2018.

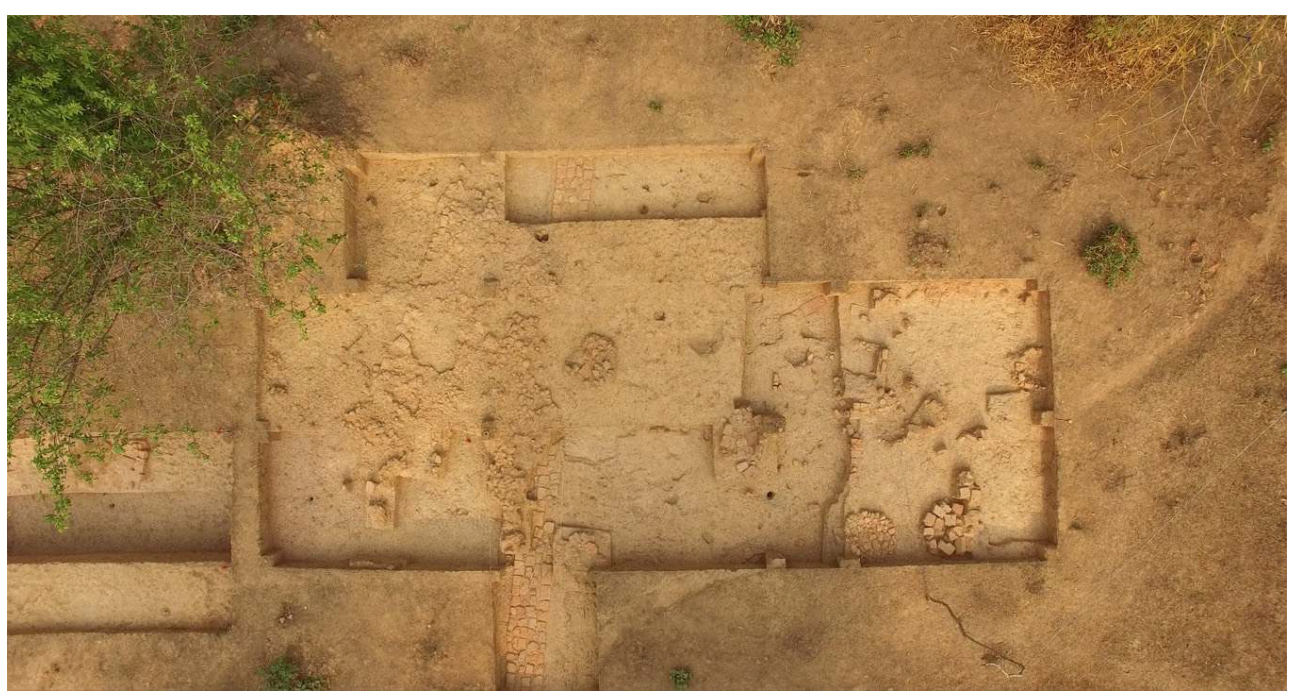

Peter Livermore.

Photo 56 . Vue des préparations de sol du niveau d'occupation supérieur $\left(n^{\circ} 1\right)$ dans les carrés $G /$ H 22-23. 2018.

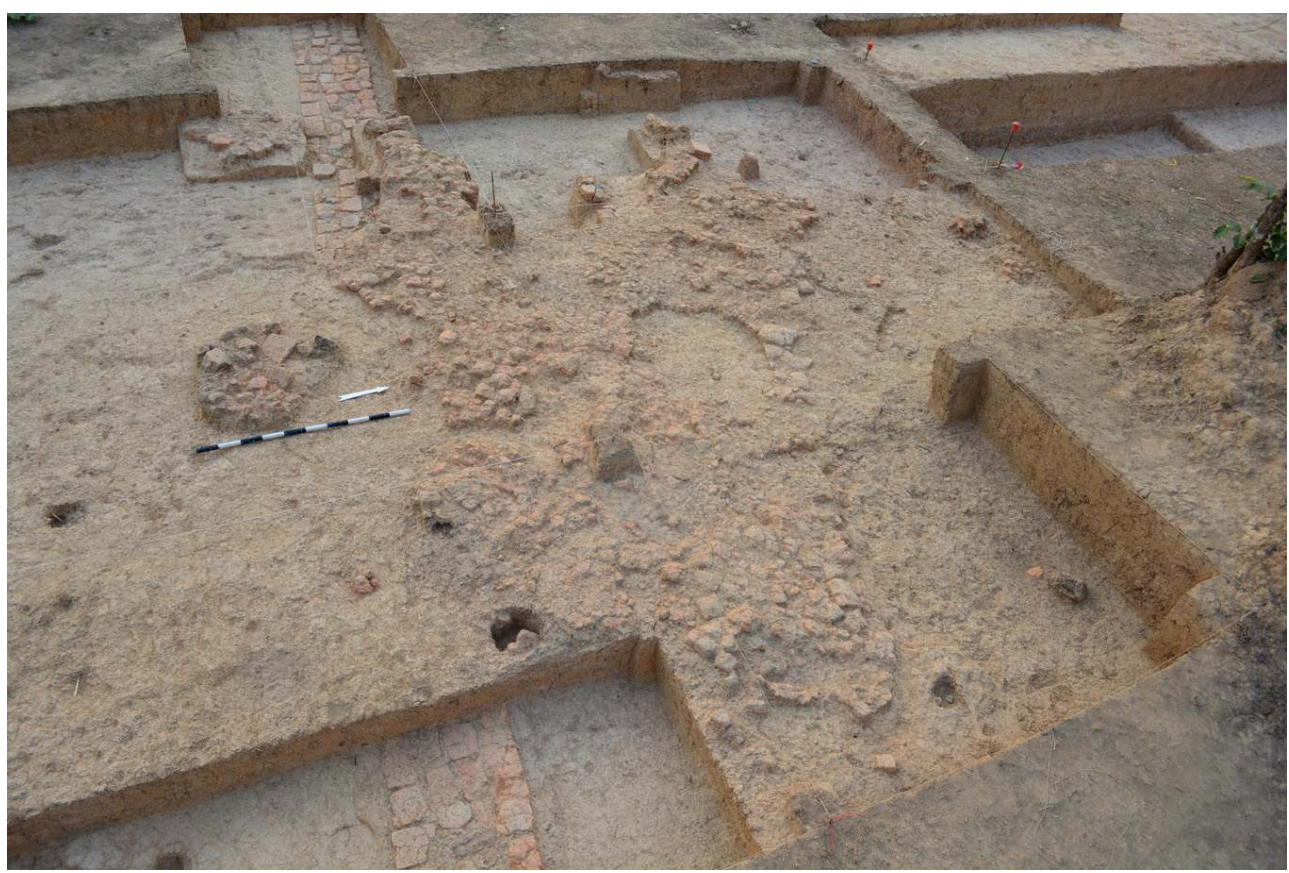

C. Hawixbrock.

Ce pavement étant discontinu, des sondages ont été pratiqués dans tous les endroits possibles à l'intérieur des carrés $\mathrm{G} / \mathrm{H}$ 22-23. Un second niveau d'occupation apparaît à $25 \mathrm{~cm}$ sous le premier. On rencontre d'abord en F/G/H 22-23 une «bande » formée d'un unique lit de quatre rangées de briques qui vient couper la levée au sud de la tranchée G 19-21 selon un axe est/ouest. Cet alignement de briques est bordé, seulement du côté sud, par une fine couche de sable damé ( $1 \mathrm{~cm}$ environ). Au nord, on rencontre la terre argileuse habituelle. 
Parfaitement centré dans la largeur de la bande de briques, un seul trou de poteau, situé en F 23, pourrait indiquer la base d'une palissade (photo 58). Cependant les fouilles pratiquées en 2020 dans le prolongement est de cet alignement (J, K, L 23) n'ont pas révélé d'autres trous de poteaux. Cette bande de briques, trop étroite pour avoir servi de passage, se poursuit quasiment jusqu'à la base actuelle de la levée de terre du côté est, avec un possible retour à angle droit vers le sud (photo 59) ${ }^{36}$.

Photos 57 à 59. L'alignement de briques vu sous divers angles dans les sondages $\mathrm{G} 23, \mathrm{~F} 23$ et $\mathrm{J} / \mathrm{K} /$ L 23. 2018 et 2020.
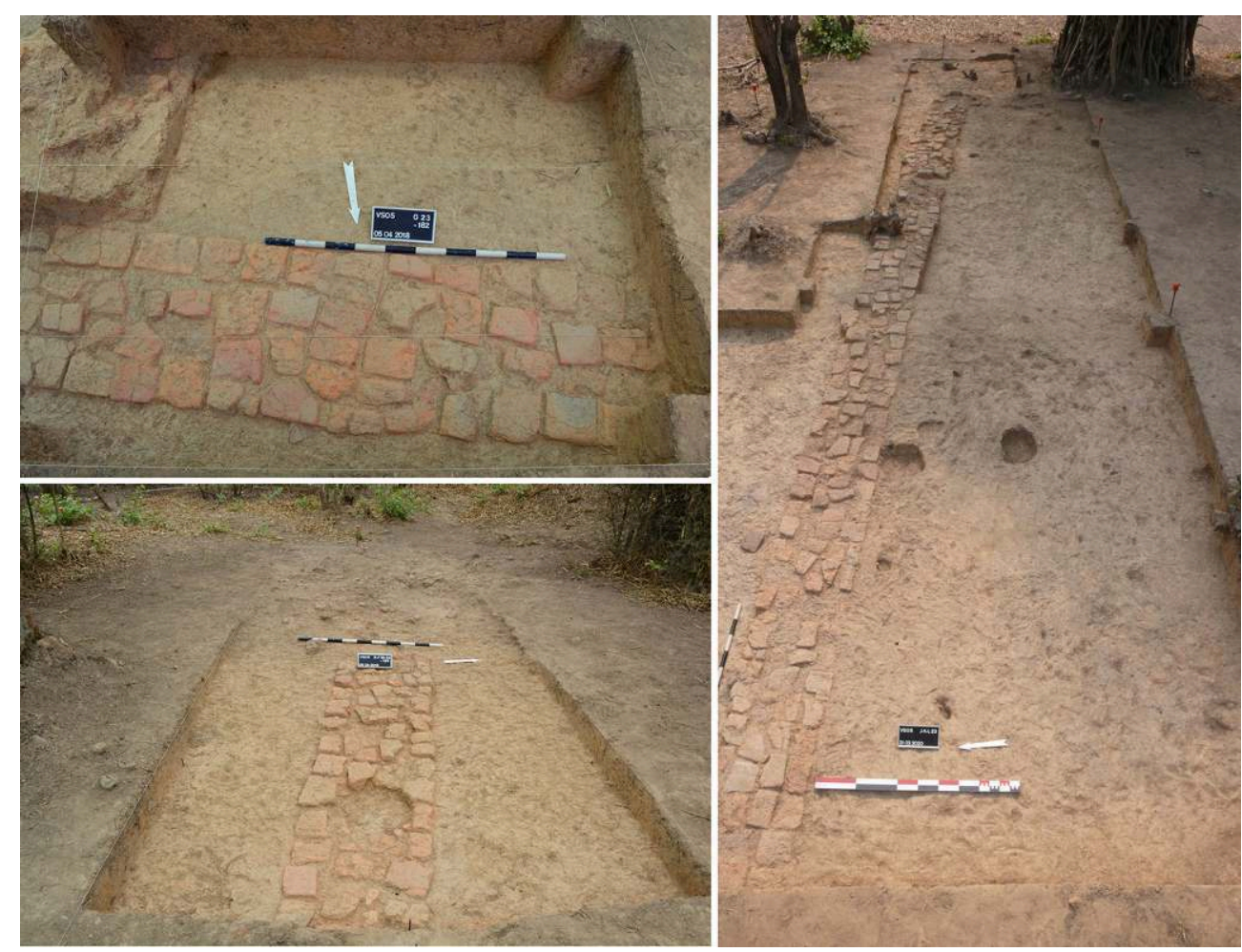

C. Hawixbrock.

87 Sur le même niveau, un aménagement de sol formé, là encore, de sable rapporté parfaitement damé, montre de nombreuses traces possibles de ruissellement et d'eau stagnante (?). Plusieurs petits trous de poteaux (?) contenant des charbons; des plateformes de briques en réemploi de forme circulaire; des structures formées de sable de rivière, de galets et de briques signalent une organisation complexe de toute la zone dont la fonction reste à expliquer. Cet état d'occupation $\mathrm{n}^{\circ} 2$ se situe sur les mêmes niveaux de circulation que le bâtiment nord. 
Photos 60 à 62 . Vues de la zone d'habitat domestique dans les carrés G/H 23-24, niveau d'occupation inférieur $\left(\mathrm{n}^{\circ} 2\right) .2018$.

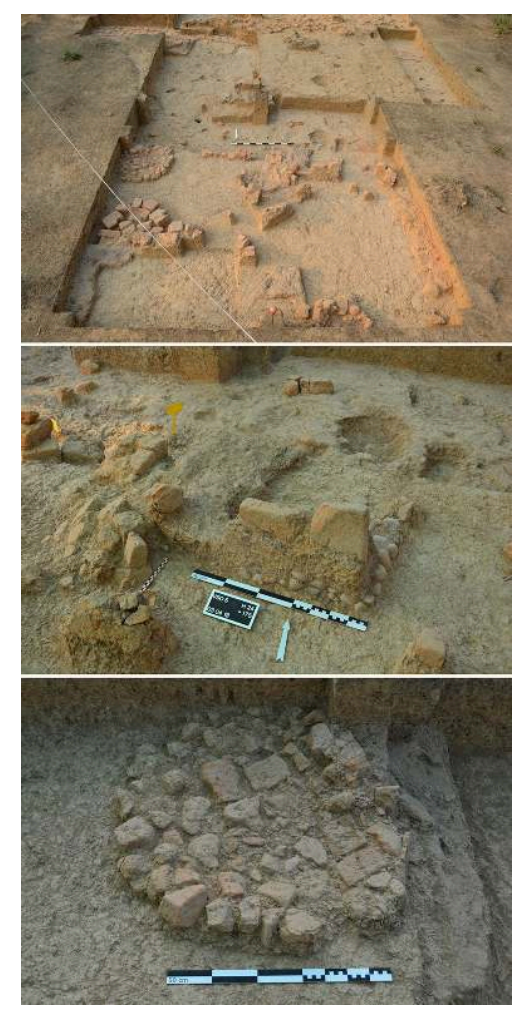

C. Hawixbrock.

\section{Le matériel collecté jusqu'en 2017}

\section{Le matériel métallique}

88 Mis à part une minuscule feuille d'or en G16 $(4 \times 2,5 \mathrm{~mm})$, quatre fragments de métal (fer ?) ont été mis au jour en 2017 en G 17, J 14, et deux en H 16. Celui qui provient du carré J 14 pourrait être une lame complète de petit couteau ${ }^{37}$, dont le manche porte un décor de motifs difficiles à identifier en raison du mauvais état du matériau, peut-être une succession de crosses à bouton central. 
Photos 63 et 64 . Vues de quelques ustensiles en fer et d'une probable lame complète de couteau (J 14) mis au jour en 2017. 2019.

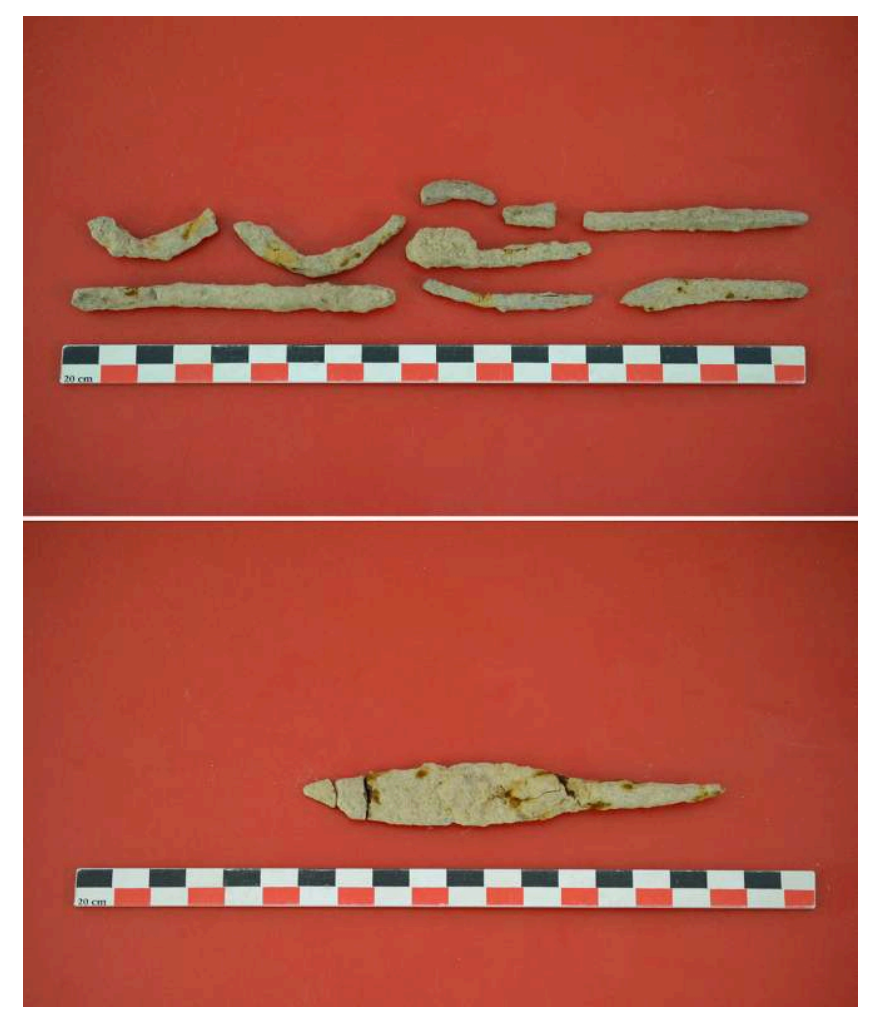

C. Hawixbrock.

89 En 2014, seuls deux fragments de coulures de bronze avaient été découverts en K 15, pratiquement en surface. 


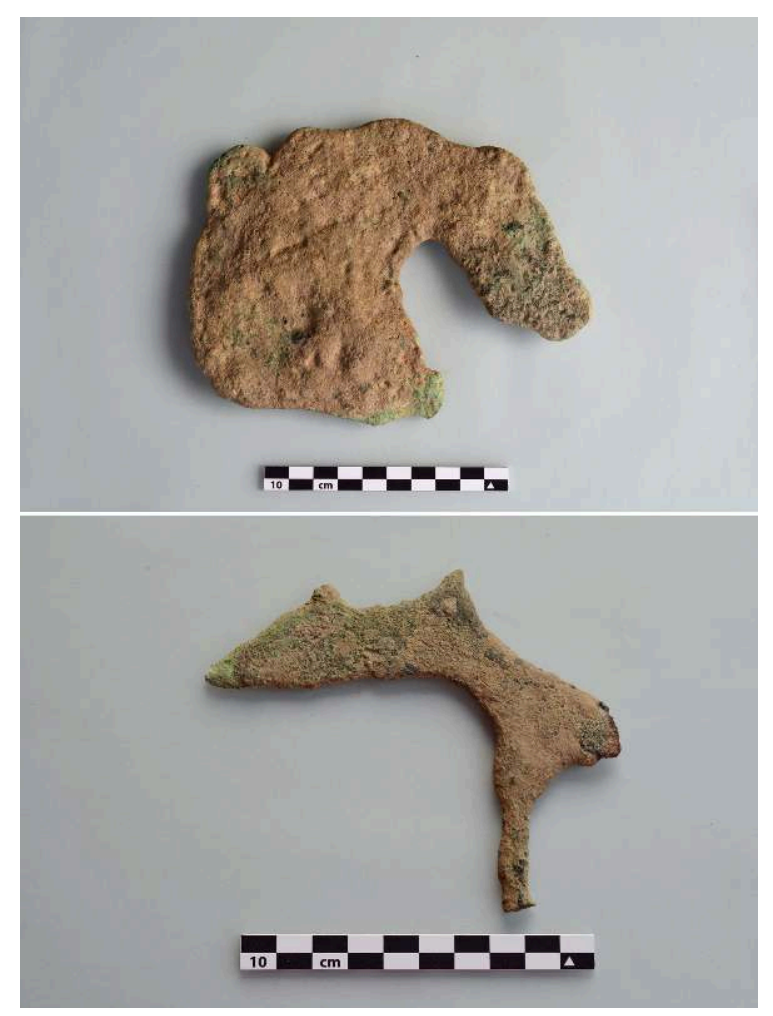

M. Santoni.

\section{Le matériel en pierre}

Deux petites pierres semi-précieuses (cristaux de roche) ont été retrouvées, l'une en $\mathrm{J} 14$, entre les blocs de la structure en latérite, et la seconde en $\mathrm{H} 15$, proche de la surface. Il convient de signaler ici que de nombreuses autres pierres semi-précieuses ont été découvertes lors des fouilles de Vat Sang'O 2 (2013), dont certaines de grande taille (voir infra pour le matériel collecté en 2018 et 2020).

91 Un petit objet en pierre (grès gris fin de qualité), brisé en trois fragments, malheureusement incomplet, a été mis au jour en $\mathrm{H}$ 16. Il est sculpté sur une face de trois cercles partiellement conservés de différents diamètres, de faible profondeur $(2 \mathrm{~mm})$, à fond plat (le plus petit, peu visible, est situé à cheval à la limite conservée de la cassure du fragment principal). La face opposée est lisse. Une partie du bord à angle droit est conservé, son arête supérieure est taillée à $45^{\circ}$. Il pourrait s'agir d'un moule. 
Photos 67 et 68 . Moule (?) en grès sculpté de trois cercles en creux. 2017.

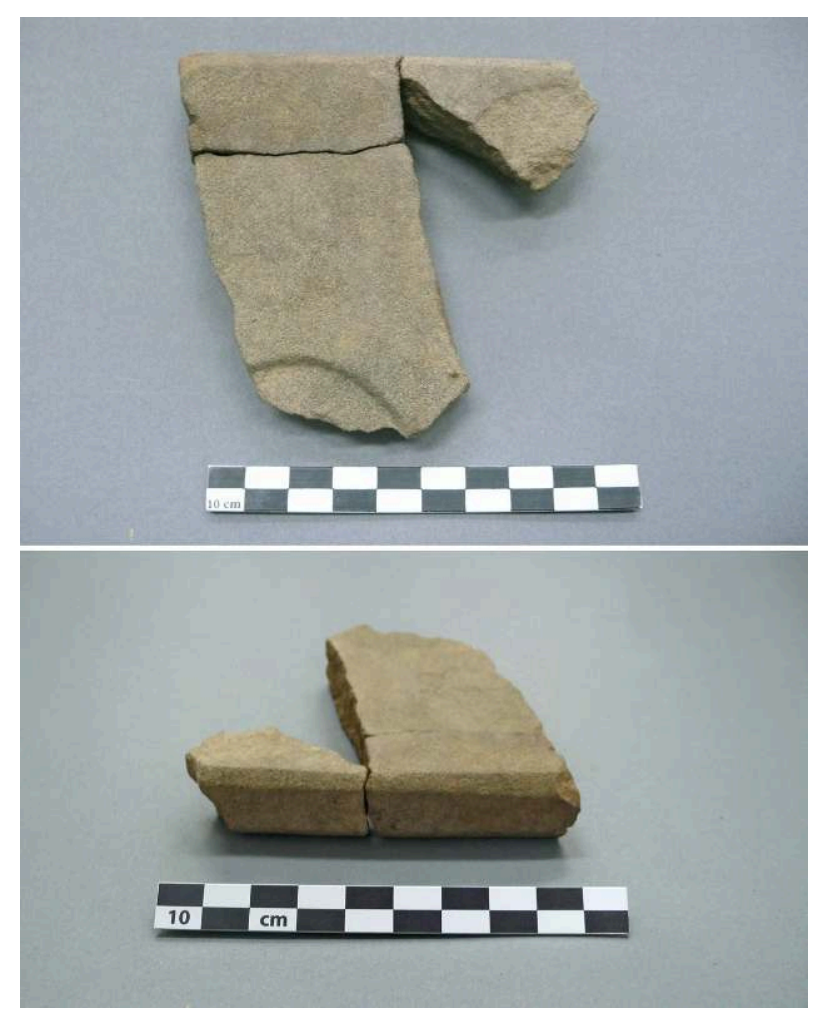

C. Hawixbrock.

92 Un second fragment de pierre (diorite ?) trouvé au même endroit en $\mathrm{H}$ 16, possède d'un côté un bord taillé en biseau bien affûté légèrement convexe tandis que les angles du bord opposé sont coupés. Ce racloir (?) porte des marques en surface probablement liées à son utilisation.

93 Tous deux étaient proches de la surface. Ce carré, situé dans la partie centrale ouest du bâtiment a livré du matériel diversifié sur plusieurs niveaux (fusaïole, deux fragments de fer). C'est également dans ce carré que se trouve la poche contenant de nombreux tessons de céramiques (voir infra). 


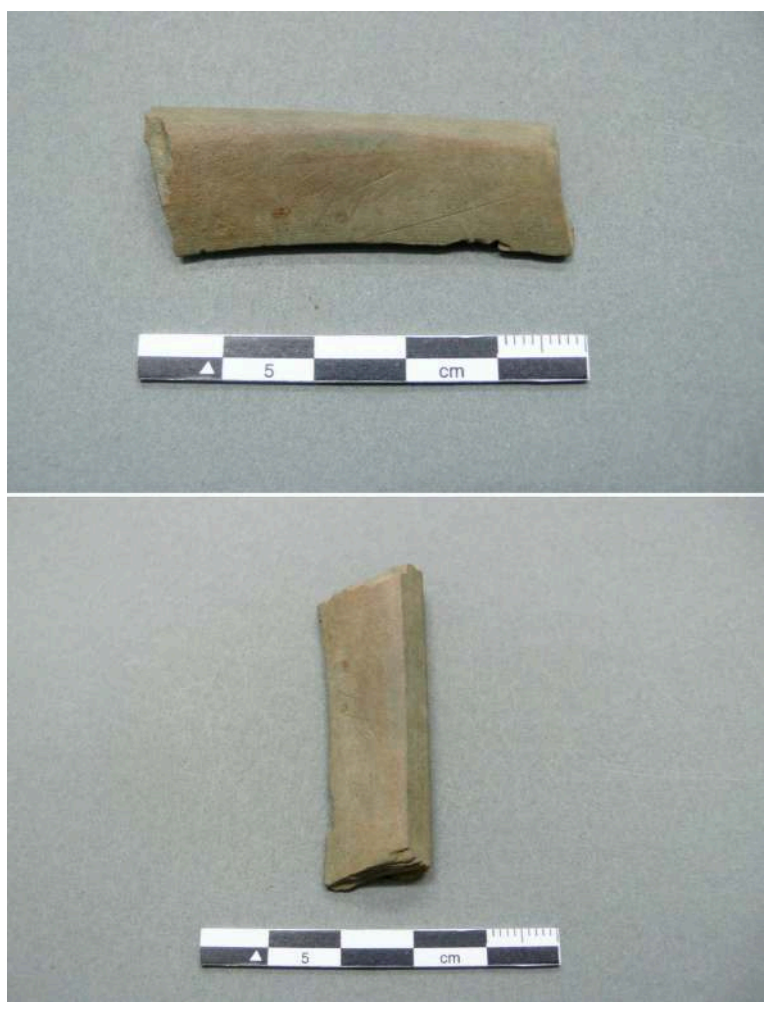

C. Hawixbrock.

\section{La céramique} des cols de vases hauts aux bords éversés ( $\mathrm{H} 16)$, des bords de vases annelés typiques de la céramique soignée préangkorienne (J 14, H 16), des fragments de panses avec 
éléments de préhension fixés à la barbotine ont été collectés. Ils permettront de compléter les formes déjà répertoriées lors des fouilles précédentes de la MAFSL.

Les fragments décorés incluent un pied de coupe - à moins qu'il ne s'agisse d'un goulot de bouteille - épais, orné d'incisions parallèles horizontales au profil arrondi en relief (H 16, cf. photo 90). D'autres tessons d'épaules de vases sont soulignés de double ou triples stries parallèles.

Quelques fragments épais en pâte rouge grossière appartenant à une même pièce (grosse jarre ?) ont partiellement conservé leur engobe : de couleur rouge, épais d'un millimètre, il semble avoir reçu un décor (H 16). Plusieurs petits tessons à pâte ocre ou noirâtre présentent des motifs cordés typiques de la céramique de tradition locale préet protohistorique qui a perduré (en G 15, H 14, H 16).

101 Les fragments d'un petit creuset proviennent du carré G 15, mis au jour à la base de la structure G 14 (photos 91 et 92).

102 Deux fusaïoles (H 15, H 16) complètent cet ensemble particulièrement riche. L'une d'elles (H 15) est ornée de trois stries parallèles sur son pourtour.

103 L'ensemble de ce mobilier concourt à renforcer l'hypothèse de la présence d'une aire d'habitat à Vat Sang'O 5, la céramique étant généralement retrouvée en moindre quantité lors de fouilles de monuments religieux à Vat Phu, sauf sur le site de Houay Sa Houa 2.

104 Cette céramique est comparable à celle du site de Vat Sang'O 2 et rappelle celle de Houay Sa Houa 2 (seconde moitié du $\mathrm{VI}^{\mathrm{e}}$ siècle), ainsi que celle rencontrée dans les couches les plus profondes du temple de Nong Moung situé dans l'angle sud-ouest de la Ville Ancienne, fouillé en 2011.

105 Les formes et les pâtes sont similaires à celles identifiées ailleurs dans la Ville Ancienne. La plupart sont mal cuites, très fragiles et poreuses. Elles perdent systématiquement leur surface externe et interne, souvent de couleur orangée, parfois couvertes d'un engobe rouge. Des pâtes blanchâtres avec dégraissant de latérite, encore plus fragiles, sont pourtant utilisées pour des vases aux cols élevés, aux parois très fines. L'épaisseur des tessons se situe surtout autour de 2 à 4 millimètres mais on rencontre également des tessons très minces, de l'ordre du millimètre. Les grosses jarres peuvent quant à elles dépasser un centimètre d'épaisseur. 
Photos 71 à 79. Tessons de céramiques mis au jour en 2017.

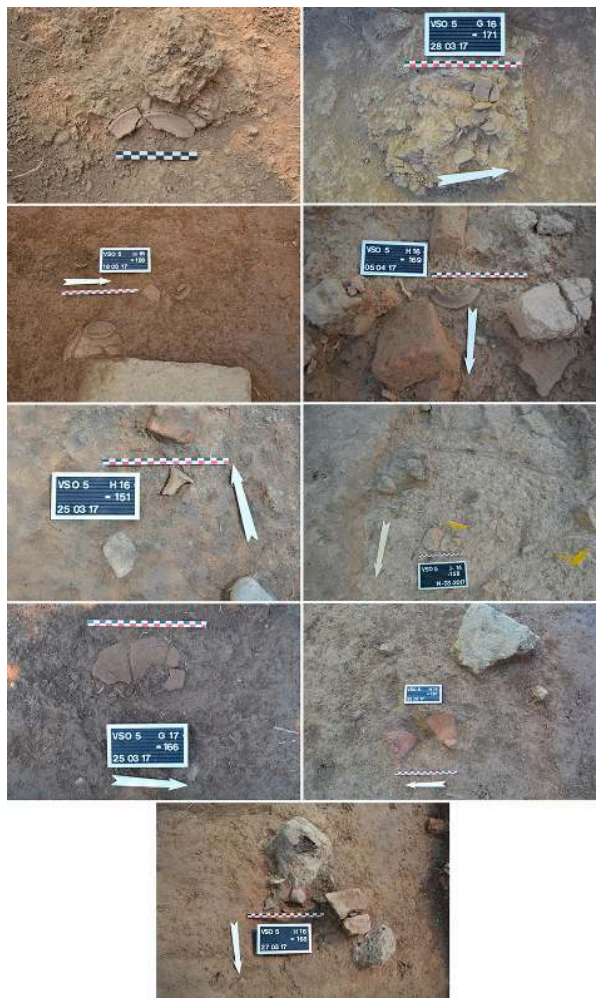

C. Hawixbrock.

Photos 80 et 81. Bouton de préhension de couvercle annulaire, vues des deux faces. 2014.

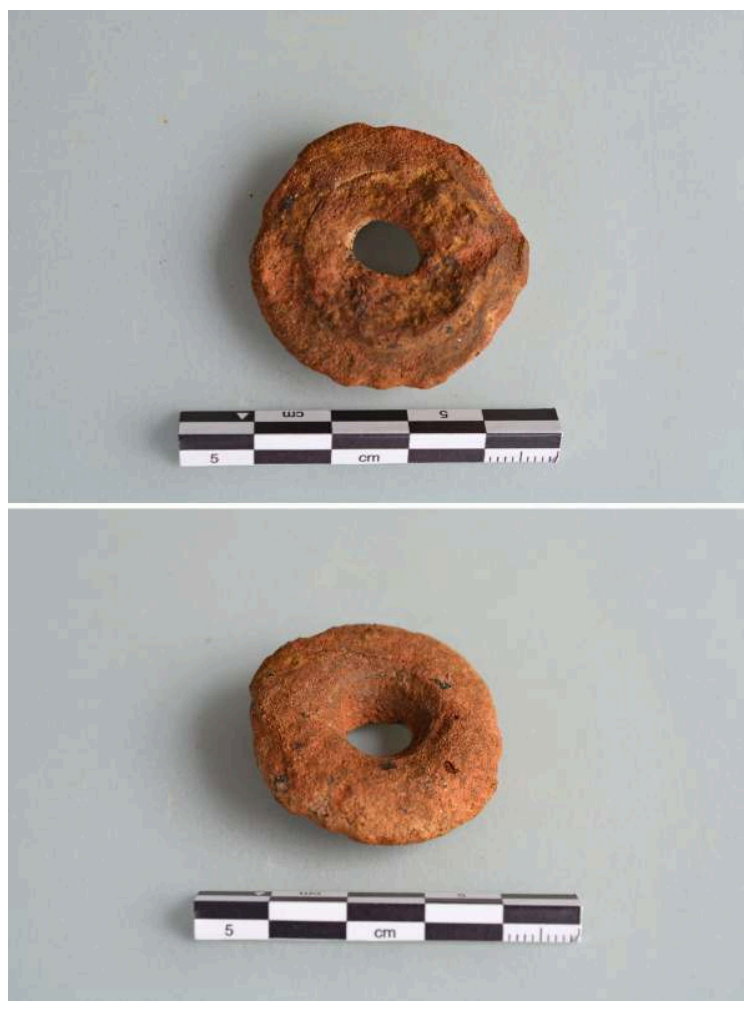

M. Santoni. 
Photos 82 à 84 . Boutons de préhension de couvercles; becs de kendis (vase à eau) ; bords de cols de vases. 2017.

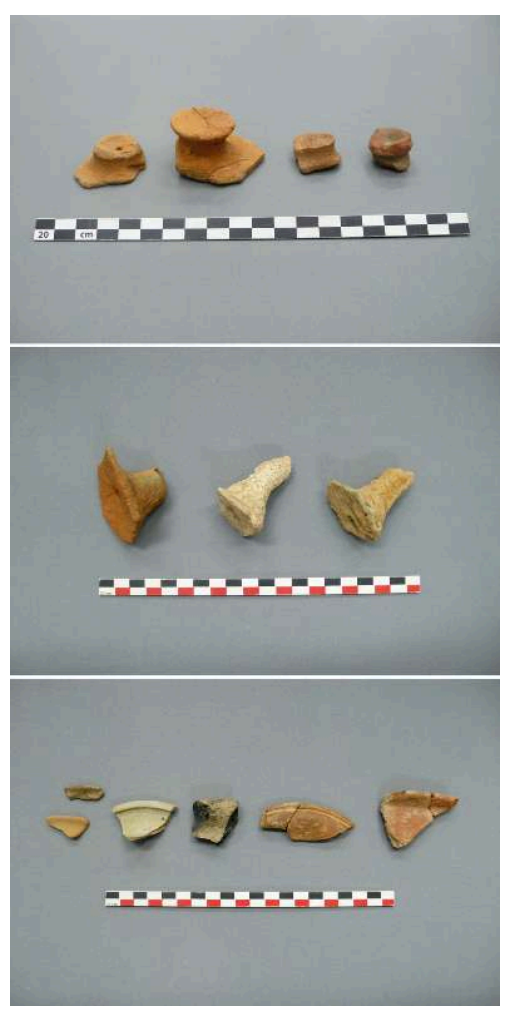

C. Hawixbrock. 
Photos 85 à 87 . Col de vase, deux fonds à base annulaire. 2017.

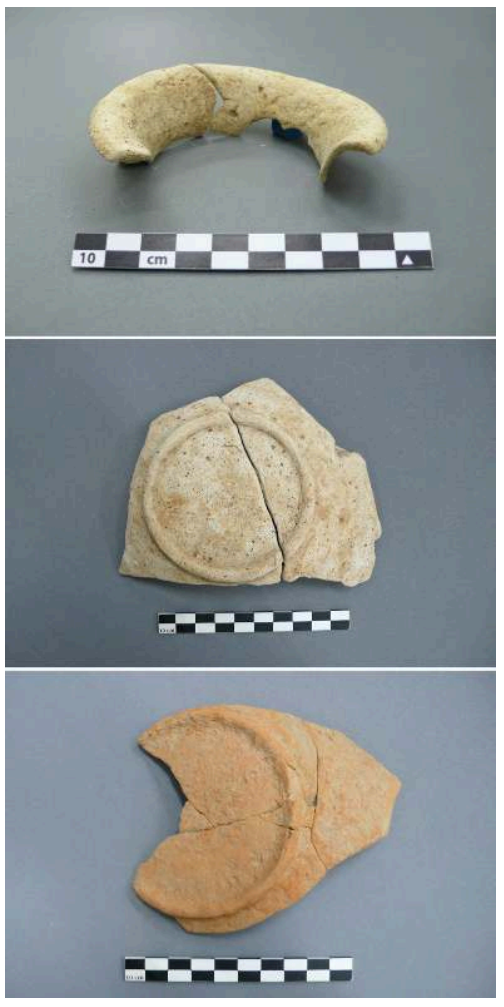

C. Hawixbrock.

Photos 88 à 90. Fusaïoles, céramique « cordée », céramique ornée. 2017.

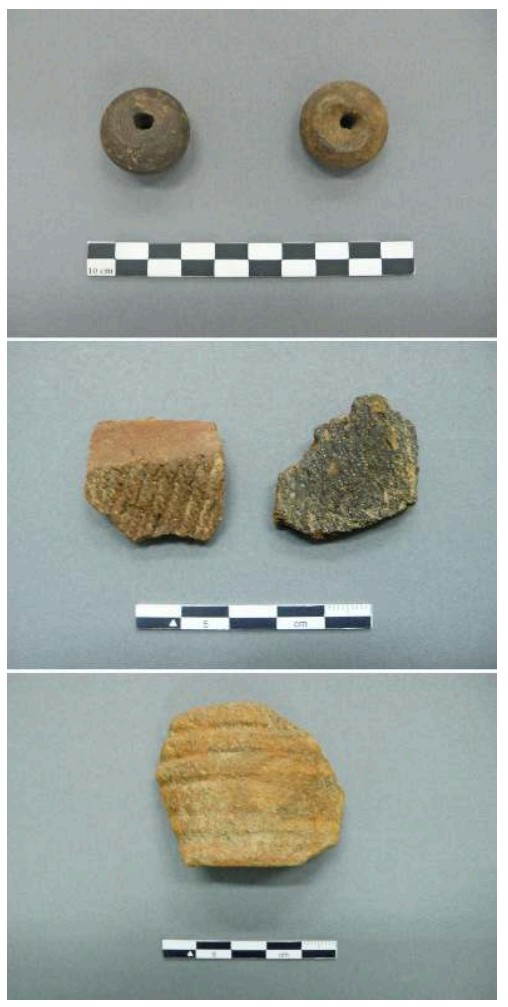

C. Hawixbrock. 
Photos 91 et 92. Creuset (faces interne et externe). 2017.

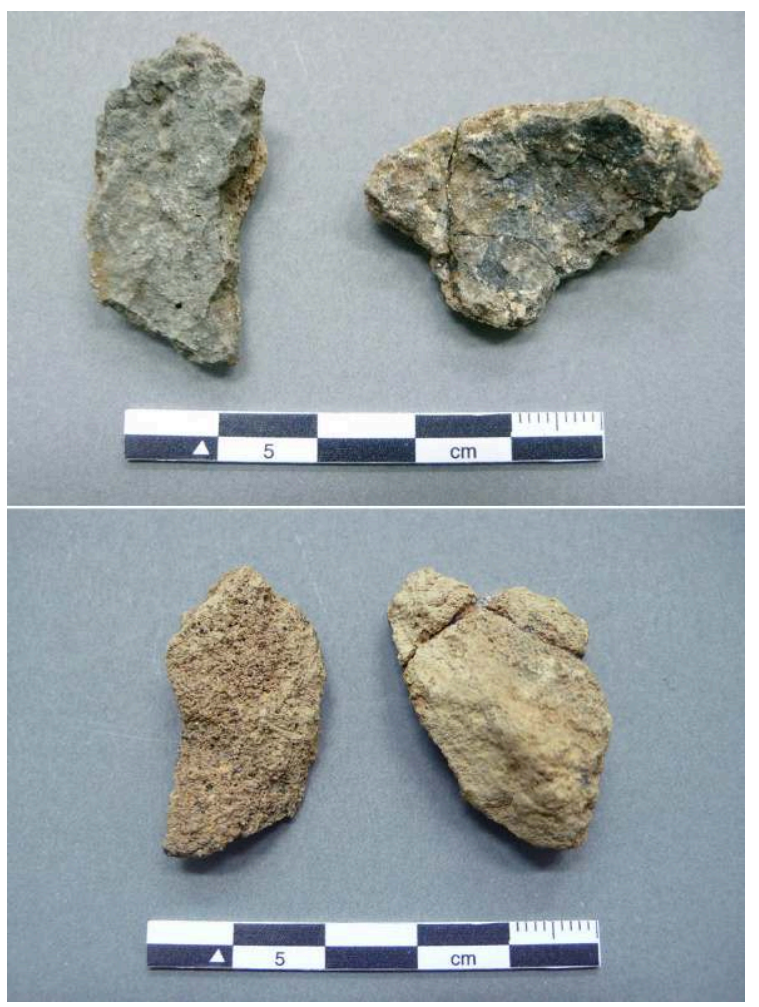

C. Hawixbrock.

\section{Le matériel collecté en 2018}

\section{Le matériel « précieux » et métallique}

256 pierres semi-précieuses ont été mises au jour en 2018 (seules deux avaient été collectées en 2017). 25 d'entre elles étaient réparties sur la quasi-totalité de la surface fouillée en 2018 sauf en J 18-19 où 231 pierres ont été collectées. La plupart sont des trouvailles isolées dont le nombre varie d'une à cinq dans les carrés $\mathrm{G}$ à $\mathrm{M}, 13$ à 24 . Aucune ne provient du côté ouest (E/F 14 et E/F 22-23). Quelques-unes ont été trouvées en surface.

Une poche de 0,80 × 0,60 m, profonde d'environ $30 \mathrm{~cm}$, située à l'angle sud-ouest du carré J 18 et à l'angle nord-ouest du carré J 19, a livré 231 pierres semi-précieuses brutes. Cette poche apparaît au niveau de la base du lit inférieur des blocs de latérite de la pile J 18, qui correspond au sol de circulation du bâtiment. Par ailleurs, aucune limite de fosse d'enfouissement n'a été décelée.

Les dimensions des pierres (cristal de roche transparent, améthyste, quartz rosé, cristaux opaques) varient de quelques millimètres à quelques centimètres. Quelques rares tessons de céramique ont été collectés à proximité. Ces pierres ne semblent donc pas s'être répandues au sol à la suite du bris d'une jarre.

109 Leur présence à cet endroit particulier, leur quantité, ainsi que leur fonction restent à expliquer ${ }^{38}$. 
Photo 93. Une partie des pierres semi-précieuses découvertes en 2018 en J 18-19. 2019.

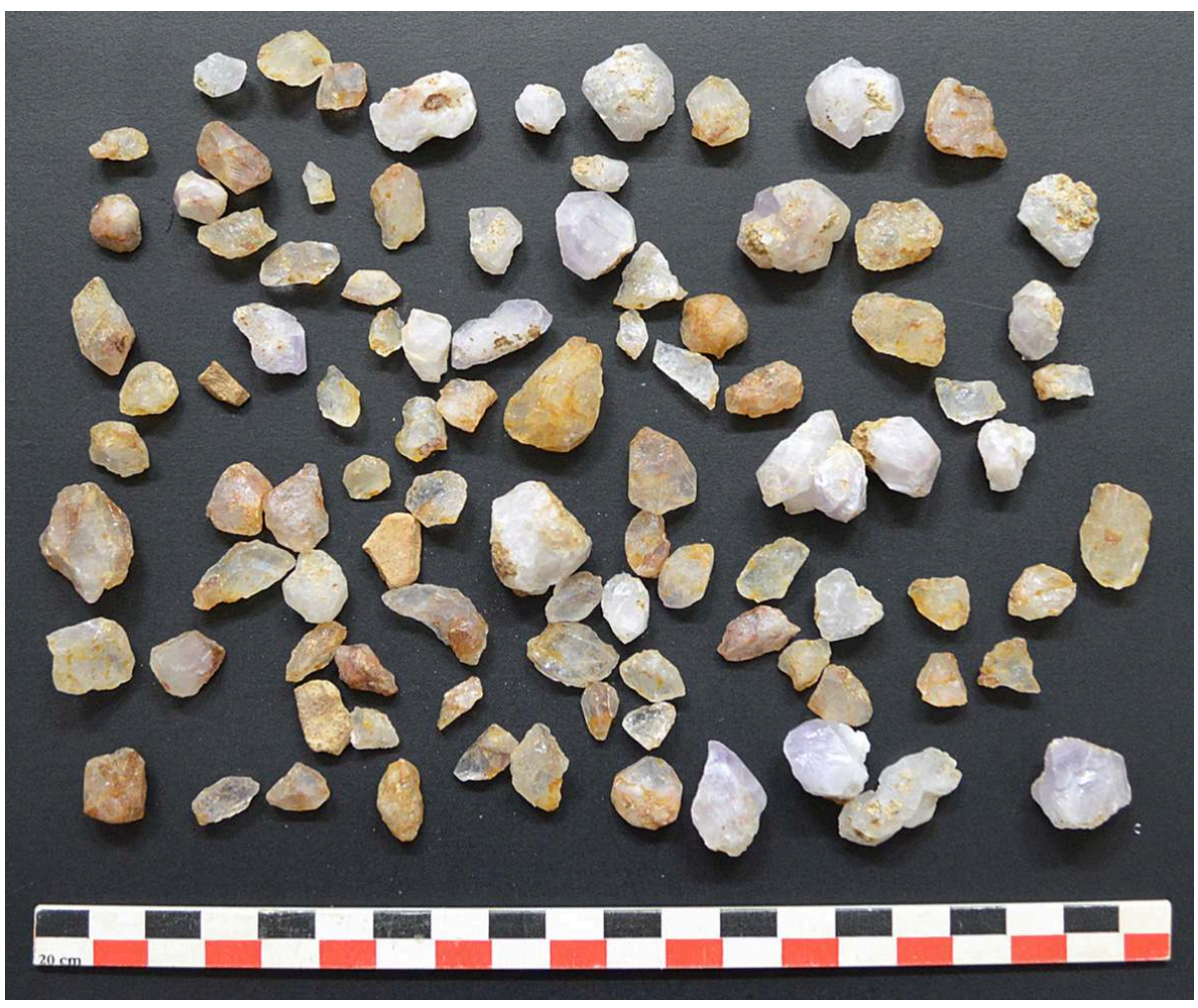

C. Hawixbrock.

110 Un objet en terre cuite de grande taille, incomplet et brisé, relativement épais (plus de $2 \mathrm{~cm}$ à certains endroits), a été retrouvé isolé du côté sud du carré $\mathrm{J} 18$, dans le remplissage de la levée de terre, à une cinquantaine de centimètres au sud de la face verticale sud des fondations de la structure en latérite $\mathrm{J} 18$, et à une vingtaine de centimètres en profondeur de la partie supérieure de la fondation en galets de ladite structure, sur un niveau où l'on rencontre encore du matériel épars (tessons, briques), de $\mathrm{J} 17$ à $\mathrm{J} 19$. Il est à noter que la pile $\mathrm{J} 18$, très endommagée, presque entièrement démontée jusqu'à ses fondations, a vraisemblablement été pillée, bouleversant peut-être les données stratigraphiques.

111 La pâte de couleur orange semble recouverte d'un engobe et/ou de traces de peinture ocre-rouge et noire sur sa face principale (à déterminer). La base, qui s'évase d'un côté « en éventail », comporte trois protubérances parallèles en relief arrondi qu'il reste à identifier. Il pourrait s'agir d'une enseigne décorative ayant orné l'entrée principale du bâtiment. 
Photos 94 et 95 . Vue de l'objet en céramique mis au jour dans le carré $\mathrm{J} 18$ (en place et après nettoyage et remontage). 2018 et 2019.

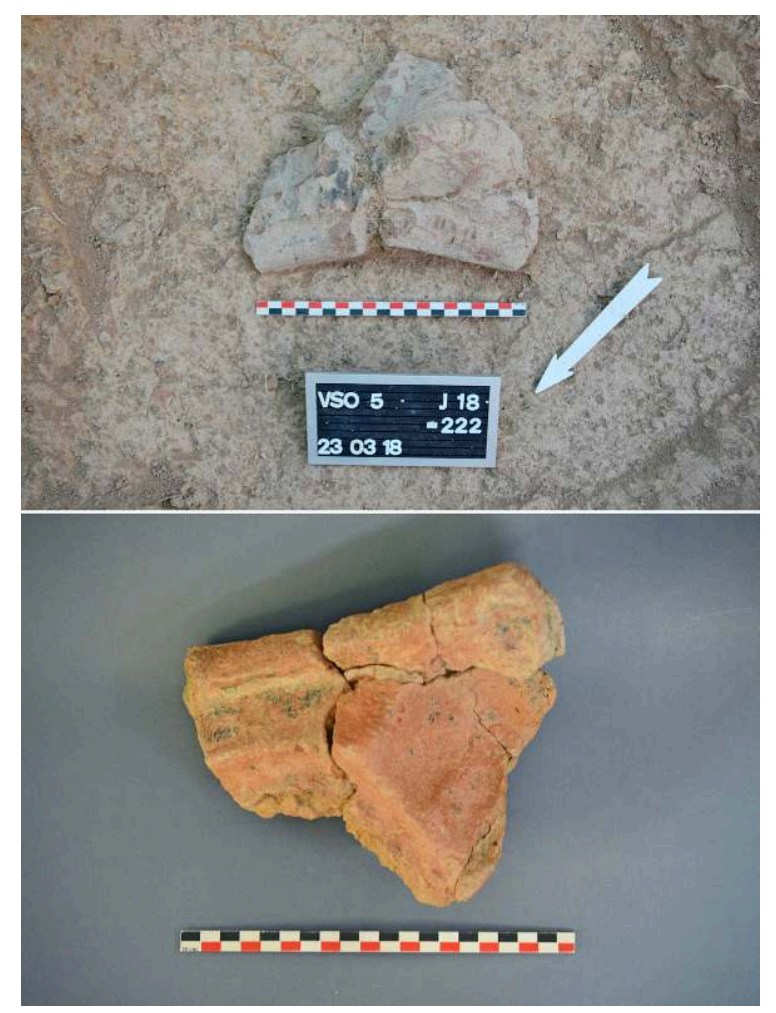

C. Hawixbrock.

Une amulette moderne en pierre (saponite ?) a été retrouvée, toujours en J 18, mais en surface cette fois. Haute de un centimètre et gravée de signes propitiatoires, probablement d'origine thaï, elle représente un Kacchayana, une figure populaire du bouddhisme.

113 Le matériel métallique provient essentiellement du niveau d'occupation supérieur situé sous la couche de surface. Il comprend de très nombreux fragments de bronze brisés en petits morceaux. En dehors de ceux qui sont méconnaissables, un col de nāga à trois têtes, un fragment de buste, trois doigts aux phalanges tendues avec l'ongle indiqué, des décors en tresse, une oreille de statuette de Bouddha avec des fragments en spirales de sa chevelure, ont été mis au jour sur toute la zone G, H, 22-24. Les doigts tendus indiquent plutôt un Bouddha qu'une divinité brahmanique, ces dernières ayant plus généralement les phalanges repliées sur leurs attributs. 
Photos 96 à 99. Objets en bronze mis au jour en 2018.

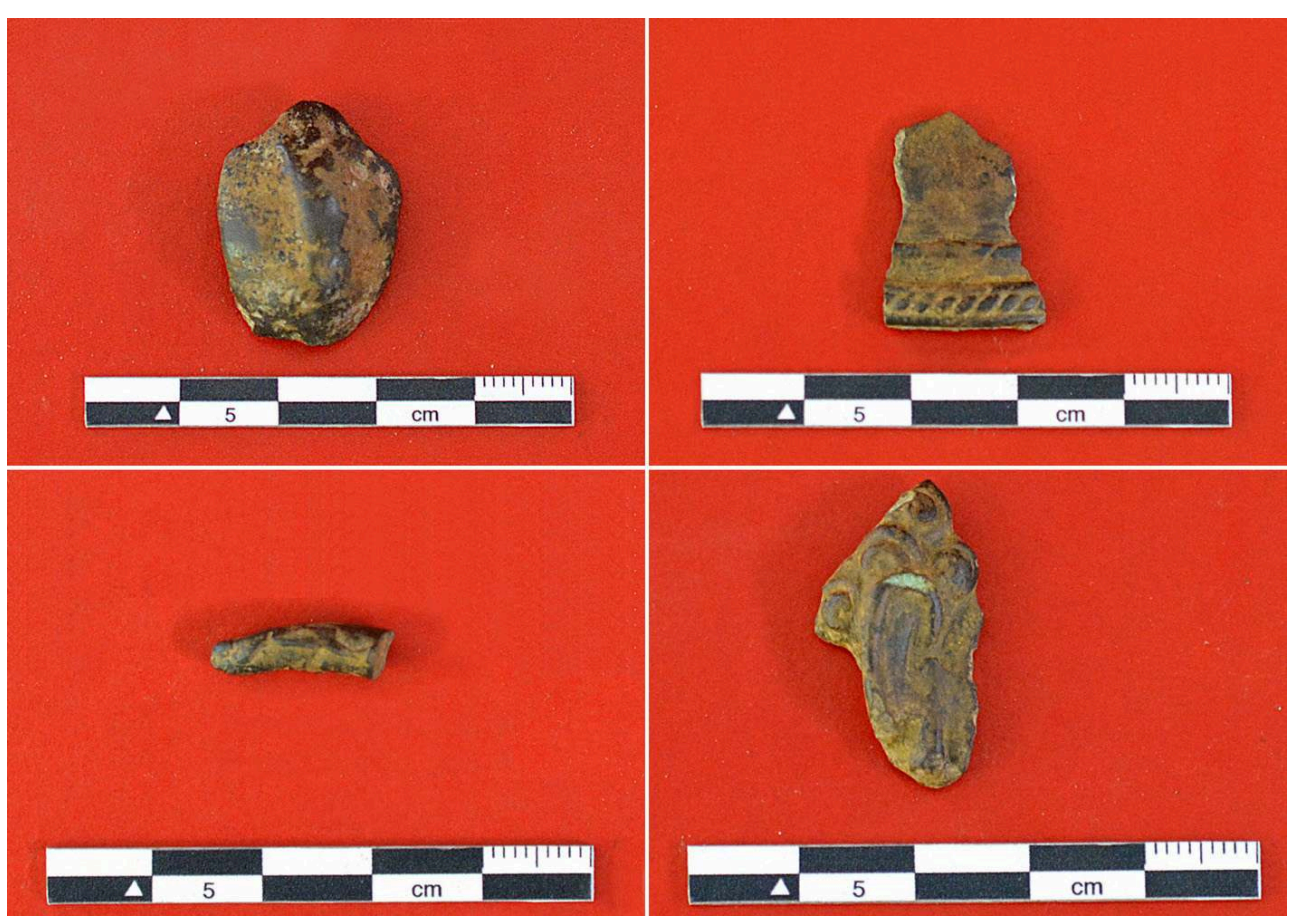

De gauche à droite et de haut en bas : tête de nāga, élément de costume (?) orné de tresses, doigt, oreille appartenant probablement à une statuette de Bouddha. 2019.

c. Hawixbrock.

\section{La céramique}

Le matériel céramique appartient essentiellement à la période préangkorienne et correspond à celui collecté antérieurement à Vat Sang'O 5. Cependant, quelques tessons décorés épais, montrant une pâte très feuilletée par l'ajout de dégraissant minéral, semblent appartenir à la période préhistorique. La présence de tessons du même type sur le côté est du bâtiment, ainsi qu'une perle de verre bleue, pourrait signaler une occupation antérieure, dont les couches auraient été perturbées lors de l'édification de la levée. La zone J/M 16 à 18 a livré de la céramique en grande quantité, y compris des pots presque complets ainsi que des tessons de grande taille. Ce mobilier témoigne d'une activité plus importante dans la partie est du bâtiment, autour de son accès principal.

\section{Le matériel collecté en 2020}

L'étude du matériel est en cours. De nombreux autres fragments de bronze ont été découverts lors des fouilles 2020 réalisées sur les couches supérieures de la levée, dans sa partie médiane (en F, G, 26-27). Leur présence sur ces niveaux et leur large dispersion reste à expliquer. Ils comprennent une statuette de Bouddha, une main de Bouddha en abhayamudrā de taille supérieure à une deuxième main qui tient la tige d'un bouton de lotus, des doigts tendus. Des spirales ayant pu appartenir à des chevelures de Bouddha confirment qu'il s'agit bien d'images bouddhiques. Un élément comportant deux spirales opposées l'une à l'autre pourrait provenir d'un bijou. 
116 Cette campagne 2020 a également permis de collecter plusieurs menues feuilles d'or, une pastille en demi-sphère creuse, une bandelette d'or repliée, des ustensiles en fer, un bracelet en fer, ainsi qu'une vingtaine de pierres semi-précieuses réparties sur les couches supérieures de nombreux carrés et en surface.

117 Dans l'ensemble des carrés fouillés, la céramique est très fragmentée et peu nombreuse sauf dans un sondage réalisé dans la partie sud-est du carré $G 27$ où plusieurs tessons de jarres de cuisson en relation avec des foyers ont été mis au jour.

\section{Les charbons}

Les campagnes 2017, 2018 et 2020 ont permis de collecter 997 échantillons de charbons, depuis la surface (charbons contemporains) jusqu'aux niveaux inférieurs atteints, à environ 1,50 m de profondeur. 55\% d'entre eux ont été découverts en 2020. La plupart (80\%) sont répartis entre les carrés J 14 et F 26, c'est-à-dire dans la moitié est de la levée.

\section{Conclusions provisoires}

119 En l'état actuel des recherches sur Vat Sang'O 5, nos conclusions provisoires amènent à suggérer que ce site, qui révèle un type de structures et le plan d'ensemble d'un espace bâti totalement inédits pour la période préangkorienne, abriterait un habitat. Ce fait est confirmé par la présence en grand nombre de céramiques, de foyers et de fosses charbonneuses. Il pourrait avoir été occupé par des officiants des temples avec le matériel nécessaire aux cultes. Cependant, l'absence d'égrugeoirs en pierre par exemple, fréquemment utilisés pour broyer diverses substances nécessaires aux cultes et aux médications, est étonnante.

Contrairement aux palais royaux identifiés à Banteay au Phnom Kulen et à Prei Monti sur le site de Roluos (Cambodge) ${ }^{39}$ à la fin de la période préangkorienne, respectivement situés au sud-sud-ouest et au nord-nord-ouest des temples d'État pyramidaux qui y sont associés, la levée de Vat Sang'O 5 est située à l'ouest des temples. La disposition régulière de ces probables piles de poteaux en latérite permet de restituer le plan d'un unique bâtiment rectangulaire de grande taille (long., $20 \mathrm{~m}$; larg., $16 \mathrm{~m}$ ), sur pilotis, implanté dans la longueur de la levée. La latérite est peu employée par les Khmers anciens à la période préangkorienne, au moins dans la région de Vat Phu, alors que les Mons en ont fait leur matériau de prédilection. L'agencement particulier des blocs en latérite des piles conduit à le dater de la période préangkorienne la plus ancienne, soit aux alentours des $\mathrm{V}^{\mathrm{e}}-\mathrm{VI}^{\mathrm{e}}$ siècles ${ }^{40}$. Le plan de ce bâtiment a été confirmé lors de la campagne de fouilles 2018. Celle-ci a permis de déterminer son accès principal, qui se développe du côté est dans la longueur du bâtiment, en terrasse ou en escalier, orienté vers le Mékong et le sanctuaire de Vat Sang'O 2, situé dans le même axe, à une quinzaine de mètres plus à l'est. L'absence totale de structures de $\mathrm{G}$ à $\mathrm{H} 19$ à 21 permet d'envisager l'existence d'une cour, isolant ce bâtiment au moins du côté sud, des aménagements domestiques mis au jour dès G et H 22-23. Aucun mur de clôture n'a été mis en évidence, tout au moins sur les côtés nord, ouest et est.

Si cette hypothèse est confirmée, nous serions en présence de l'habitat à destination palatiale le plus ancien identifié et fouillé à ce jour pour la période concernée. Est-ce 
justement pour ne pas utiliser les matériaux réservés aux demeures des dieux (le grès, la brique) que la latérite a été choisie comme matériau pour les piles de la structure sur pilotis ? La question mérite d'être posée.

L'installation de ce bâtiment à l'extrémité nord d'une levée de 150 mètres de long, interrogeait quant à la destination dévolue aux autres parties de la levée. Son organisation spatiale, précisée en 2018, montre qu'elle est subdivisée en secteurs. Une aire à usage domestique, ou bien de travail, ou bien un habitat plus modeste, jouxte la " cour » sud du bâtiment dans la partie médiane de la levée. Une éventuelle palissade installée sur une base en briques, orientée dans le sens est/ouest de la levée, séparait, sans certitude, ces deux espaces.

La fouille 2020 de la zone centrale de la levée, poursuivie dans le prolongement vers le sud des fouilles 2018, a permis de mettre au jour de nouvelles structures inédites, toujours à usage domestique, dont l'étude est en cours. L'extrémité sud de la levée fera l'objet des campagnes à venir. Ce troisième secteur pourrait avoir abrité des activités religieuses. D'après nos observations de surface, il semble être enclos par un muret, une hypothèse à confirmer.

L'abondance du matériel collecté (céramique et charbons) et sa richesse (pierres semiprécieuses, or, bronze, fer) confirme le rang de cet habitat, qui, compte tenu de sa taille et du soin apporté à sa construction, des espaces domestiques et religieux qui l'accompagnent, pourrait être le palais d'une ville antérieure à la Ville Ancienne correspondant à ce que nous avons nommé le « complexe de Vat Sang'O ».

\section{BIBLIOGRAPHIE}

BARTH, 1902

Auguste Barth, «Stèle de Vat Phou, près de Bassac ", Bulletin de l'École française d'Extrême-

Orient II-3, 1902, p. 235-240.

CHEVANCE 2014

Jean-Baptiste Chevance, « Banteay, palais royal de Mahendraparvata », Aséanie 33, juin 2014,

p. 279-330.

CÆEDÈs, 1953

George Cœdès, Inscriptions du Cambodge, vol. v, Paris, Adrien Maisonneuve, 1953, p. 12-13.

CÆEDÈs, 1956

George Cœdès, « Nouvelles données sur les origines du royaume khmer. La stèle de Vat Luong

Kau, près de Vat P'hu ", Bulletin de l'École française d'Extrême-Orient XLVIII-1, 1956, p. 209-220.

CCEDÈs, 1964

George Cœdès, Les États hindouisés d'Indochine et d'Indonésie, Paris, De Boccard, 1964.

GOODALL, 2017

Dominic Goodall, « Sanskrit Text and Translation of K. 1320, a tenth-century edict of the Khmer 
king Isanavarman II about the annual taxes to be paid by Lingapura (Vat Phu) », 2017, en ligne www.vatphou-champassak.com.

GOODALL, JACQUES 2014

Dominic Goodall, Claude Jacques, « Stèle inscrite d'Isanavarman II à Vat Phu : K. 1320 », Aséanie 33, 2014, p. 395-454.

HAWIXBROCK 2012

Christine Hawixbrock, « La stèle inscrite K. 1320. Note sur une nouvelle découverte archéologique à Vat Phu », Aséanie 30, 2012, p. 103-119.

HAWIXBROCK 2019

Christine Hawixbrock, « Vat Phou : le temple de la Montagne », Archéologia, hors-série n 27, 2019, p. 25-55.

HAWIXBROCK, SANTONI, SOUKSAVATDY 2017

Christine Hawixbrock, Marielle Santoni, Viengkèo Souksavatdy, « The French archaeological mission and Vat Phou: Research on an exceptional historic site in Laos », 2017, en ligne www.vatphou-champassak.com.

JACQUES 1962

Claude Jacques, « Note sur l'inscription de la stèle de Vat Luong Kau », Journal Asiatique 2, 1962, p. 249-256.

JACQUES 1979

Claude Jacques, « Fu-nan, Zhen-la: the reality concealed by these Chinese views of Indochina », in Ralph B. Smith, William Watson (éd.), Early South-East Asia: Essays in Archaeology, History and Historical Geography, Londres, Oxford University Press, 1979, p. 371-379.

LORRILLARD 2012

Michel Lorrillard, Autour de Vat Phu. De l'exploration à la recherche (1866-1957) [Textes réunis et présentés par Michel Lorrillard, Vientiane], Paris, EFEO/Département du site du Patrimoine mondial de Vat Phu, 2012.

MARCHAL 1957

Henri Marchal, Le temple de Vat Phou - province de Champassak, Saïgon, Éd. du Département des Cultes du Gouvernement royal du Laos, 1957 (Réédition en 1985).

PARMENTIER 1954

Henri Parmentier, L'art du Laos, Paris, PEFEO XXXV, 2 vol., 1954 (réédition en 1988).

POTTIER 2014

Christophe Pottier, « Nouvelles données sur les premières cités angkoriennes », in Azedine Beschaouch, Franciscus Verellen et Michel Zink (éd.), Deux décennies de coopération archéologique franco-cambodgienne à Angkor, Actes de la journée d'études organisée à la mémoire de Pascal Royère (1965-2014), par l'Académie des Inscriptions et Belles-Lettres, sous le haut patronage de Sa Majesté Norodom Sihamoni, Roi du Cambodge le 9 mai 2014, Paris, Académie des Inscriptions et Belles-Lettres, p. 43-80.

SANTONI, HAWIXBROCK 1998

Marielle Santoni, Christine Hawixbrock, « Fouilles et prospections dans la région du Vat Phu (province de Champassak, sud du Laos) », Bulletin de l'École française d'Extrême-Orient 85, 1998, p. 387-405.

SANTONI, HAWIXBROCK 1999

Marielle Santoni, Christine Hawixbrock, « Prospections 1999 au sud de Vat Phou : du Houay 
Khamouane à la frontière cambodgienne ", Bulletin de l'École française d'Extrême-Orient 86, 1999, p. 394-405.

SANTONI, SOUKSAVATDY 1999

Marielle Santoni, Viengkèo Souksavatdy, «Fouilles sur le site de Vat Phu - Champassak », in Francois Bizot (éd.), Laos, restaurer et préserver le patrimoine national, Vientiane, Éd. des Cahiers de France, 1999, p. 167-250.

SANTONI 2008

Marielle Santoni, « La Mission archéologique française et le Vat Phu : Recherches sur un site exceptionnel du patrimoine historique du Laos », in Yves Goudineau, Michel Lorrillard (éd.), Recherches nouvelles sur le Laos, Vientiane, EFEO, Études thématiques 18, 2008, p. 81-112.

TROUVÉ 1934

Georges Trouvé, «Chroniques », in Bulletin de l'École française d'Extrême-Orient XXXIII-1, 1934, p. 551-553.

UNESCO 2002

UNESCO, Vat Phou et les anciens établissements associés du paysage culturel de Champassak (République démocratique populaire lao), rapport $\mathrm{n}^{\circ} 481$, convention du Patrimoine mondial, vingt-cinquième session (11-16 décembre 2001), 2002, Paris. https://whc.unesco.org/fr/list/481.

\section{NOTES}

1. Les travaux du PRAL ont été interrompus à la demande des autorités lao de 2000 à 2009.

2. Le PRAL, puis la mission archéologique, ont été dirigés jusqu'en 2014 par Marielle Santoni (CNRS), en codirection à partir de 1991 avec Viengkèo Souksavatdy (Directeur général adjoint des Patrimoines). Membre du PRAL depuis 1991, puis de la MAFSL depuis ses débuts, Christine Hawixbrock a succédé à Marielle Santoni à la tête de la mission en 2015. Les autres membres permanents sont, depuis la création de la Mission : Jean-Pierre Message (dessinateur et restaurateur d'objets); à partir de 2010, Chanphenh Phommavandy et Thongbang Phengsavat (musée de Vat Phu - Bureau du Patrimoine Mondial de Vat Phu-Champassak (WHSO) en charge de la gestion du site), et, depuis 2015, Jade Thau, doctorante, diplômée de l'École du Louvre (master II).

3. La période préangkorienne couvre les $\mathrm{V}^{\mathrm{e}}-\mathrm{VIII}{ }^{\mathrm{e}}$ siècles $\mathrm{EC}$ tandis que, comme il est couramment admis, la période angkorienne débute au Cambodge en 802 sous le règne de Jayavarman II.

4. Śiva est la divinité majeure du panthéon brahmanique hérité de l'Inde. Lorsque le dieu Śiva trône et médite sur la montagne, il est également le maitre des ascètes. Plusieurs abris sous roche aménagés ont été identifiés comme des ermitages, installés sur les flancs des montagnes autour de Vat Phu dès la période préangkorienne. Certains, tels que Tham Lek, situé au nord du temple principal, sont connus depuis la première moitié du $\mathrm{Xx}^{\mathrm{e}}$ siècle et comportent des inscriptions (voir notamment, TROUVÉ 1934, CÆDÈs 1953). D’autres ont été visités durant les années 1990 lors des prospections du PRAL : Tham Mani et Tham in Siang (santonI, soukSAVATDY 1999). Au sud de Vat Phu, les sites de Khamkhong et Pha Lek ont été repérés dans les années 1970 et visités en 2007 par Bruno Bruguier (EFEO). Ils ont fait l'objet de prospections systématiques par la MAFSL en 2017 et 2018. Leur publication est en cours. 
5. Le préfixe « $\mathrm{K}$ » (pour khmer) et le numéro de l'inscription font référence à l'inventaire des inscriptions khmères. Cf. https://cik.efeo.fr.

6. Cette stèle a été retrouvée in situ dans la Ville Ancienne, à l'embouchure de la rivière Houay Sa Houa qui marque la limite de la Ville côté nord.

7. CCEDÈs 1956.

8. Le nom exact de ce temple n'est pas cité et reste inconnu à ce jour.

9. BARTH 1902.

10. Le site classé couvre $390 \mathrm{~km}^{2}$. Les termes du classement UNESCO sont les suivants : "intégration d'un paysage symbolique d'une grande valeur spirituelle dans son environnement naturel et illustration de l'interprétation hindoue de la relation entre la nature et l'humanité » (UNESCO 2002, p. 48).

Dans la mythologie indienne, le fleuve Gange (Gangā) prend sa source dans le chignon de Śiva. À Vat Phu, les ruisseaux qui s'écoulent du sommet de la montagne se déversent dans le Mékong. Dans le fleuve, le rocher de Khan Mak Houk (cf. fig. 2) est sculpté aux $\mathrm{XI}$-XII ${ }^{\mathrm{e}}$ siècles de scènes de création brahmaniques comparables à celles qui ornent, sur les monts Kulen à Kbeal Spean, la rivière de Siem Reap qui irrigue Angkor. Dans les deux cas, il s'agit de conférer aux eaux une dimension sacrée et de les «transformer " en Gange (SANTONI, HAWIXBROCK 1998).

11. Pour une description du temple de Vat Phu, voir marchal 1957.

12. SANTONI, rapports préliminaires de mission, 1991 à 1995 (non publiés), MEAE.

13. CEDÈs 1956.

14. SANTONI, HAWIXBROCK 1998 et 1999.

15. Les deux inscriptions sont inscrites sur les piédroits en réemploi de l'entrée est du sanctuaire, d'un côté en sanskrit, de l'autre en vieux khmer. Translittérées et traduites par Claude Jacques, elles restent inédites (voir SANTONI, HAWIXBROCK 1998).

16. CEEDÈs 1964 ; JACQUES 1962 et 1979.

17. Voir l'inscription K. 365.

18. SANTONI 2008 ; HAWIXBROCK, SANTONI, SOUKSAVATDY 2017 ; HAWIXBROCK 2019.

19. PARMENTIER 1954.

20. LORRILLARD 2012. Dans son ouvrage, Michel Lorrillard reprend en les commentant, l'ensemble des articles consacrés à Vat Phu par les épigraphistes, historiens, archéologues et architectes entre 1856 et 1957.

21. Angkor est situé à environ $250 \mathrm{~km}$ à vol d'oiseau de Vat Phu.

22. SANTONI, HAWIXBROCK 1998 et 1999.

23. HAWIXBROCK 2012.

24. GOODAL, JACQUES 2014 ; GOODAL 2017.

25. "Études des roches sculptées sur le site de Vat Phu: Analyses, observations et conservation des collections de sculptures». Rapport de mission de l'EFEO pour le Service d'Aménagement et de Gestion de Vat Phu-Champassak (SAGV) effectuée par Christian Fischer (UCLA), C. Hawixbrock et Bertrand Porte (EFEO Phnom Penh) du 23 au 27 juin 2014 [non publié]. 
26. La mise en valeur de ce trésor au musée historique de Savannakhet, ainsi que son étude scientifique par la MAFSL et l'EFEO, seront réalisées dans le cadre du projet CHAMPA à partir de 2022.

27. La culture cam s'est développée dans la partie méridionale du Vietnam actuel, du II $^{\mathrm{e}}$ au XIX ${ }^{\mathrm{e}}$ siècles.

28. La culture de Dvāravatī, à propos de laquelle il subsiste beaucoup d'interrogations, s'est développée dans le centre de la Thaïlande actuelle entre les $\mathrm{VI}^{\mathrm{e}}$ et XIV ${ }^{\mathrm{e}}$ siècles.

29. Site fouillé par la MAFSL en 2013.

30. Des sondages destinés à mettre en évidence la base ancienne de cette levée et sa hauteur initiale sont prévus lors la prochaine campagne de fouilles.

31. La latérite est un sol tropical présentant de nombreuses cavités et pores, qui contient une très grande quantité de fer sous forme d'ocres rouges et jaunâtres. Extrait meuble, ce matériau peut être taillé avant de durcir rapidement à l'air libre.

32. Aucune étude d'ensemble n'ayant été menée à ce jour sur la céramique de Vat Phu à la période préangkorienne, nous préférons conserver ici le terme générique de " céramique ». Il s'agit cependant toujours d'une production locale.

33. Fouilles PRAL 1993, 1995 et 1996. Fouilles EFEO 2020. Il s'agit du seul monument religieux fouillé sur lequel une grande quantité de céramiques a été collectée.

34. Inscriptions K. 1173 et K. 1174 datant de la fin du $\mathrm{VI}^{\mathrm{e}}$ siècle, translittérées et traduites par Claude Jacques (EPHE), mais non éditées.

35. Ils pourraient provenir du démontage de la pile nord-est, largement pillée, située en $\mathrm{K} 14$.

36. Les fouilles 2020 en E, F, G 26-27, ont révélé deux autres bandes de briques parallèles similaires, espacées de 1,60 m. Là encore, une mince couche de sable rapporté damé, partiellement conservée, couvre l'espace situé entre les deux bandes de briques de même qu'au sud de cet aménagement. Celui-ci pourrait, cette fois, être interprété comme une allée traversant la levée d'est en ouest.

37. Daniel Perret, communication personnelle.

38. Des pierres semi-précieuses brutes auraient été retrouvées lors des fouilles du palais royal d'Angkor Thom dans le secteur nord-ouest du Phumeanakas. Trouvées dans des couches perturbées par des chercheurs de trésors, ces objets n'ont été ni conservés ni référencés et en mai 2020, des pierres semblables ont été mises au jour en assez grand nombre à proximité du site de Srah Srang de Kandal par une équipe archéologique cambodgienne, en relation avec une tortue en grès ayant fonction de dépôt de fondation (Cf. https://www.southeastasianarchaeology.com/2020/05/08/ large-turtle-statue-discovered-at-kandal-srah-srang/ 2020). Il existe bien d'autres occurrences de ces pierres, généralement associées à des dépôts.

39. Voir POTTIER 2014 et CHEVANCE 2014.

40. La céramique n'évoluant quasiment pas à Vat Phu durant la période préangkorienne ( $\mathrm{v}^{\mathrm{e}}$-VIII ${ }^{\mathrm{e}}$ siècles), les analyses de charbons en cours devraient permettre d'affiner cette datation provisoire. 


\section{INDEX}

chronologie https://ark.frantiq.fr/ark:/26678/crtenp58SdbiQ

lieux https://ark.frantiq.fr/ark:/26678/pcrtn6lDSdV0Ep, https://ark.frantiq.fr/ark:/26678/

pcrtko0ptDx5gy

sujets 26678/pcrt9PJh9aTXv4, https://ark.frantiq.fr/ark:/26678/crtiUEzUHzs1A, https://

ark.frantiq.fr/ark:/26678/pcrtbptj4SOA1W, https://ark.frantiq.fr/ark:/26678/pcrtISZAuzsISK,

https://ark.frantiq.fr/ark:/26678/pcrtEznNgQ3h63

Année de l'opération : 2014, 2017, 2018, 2020

Thèmes : EFEO 